Prepared for the U.S. Department of Energy

Under Contract DE-AC05-76RL01830

\title{
Bench-Scale Filtration Testing in Support of the Pretreatment Engineering Platform (PEP)
}

JM Billing

RC Daniel
DE Kurath

RA Peterson

September 2009

\section{Pacific Northwest}

NATIONAL LABORATORY

Proudly Operated by Battelle Since 1965 


\section{Bench-Scale Filtration Testing in Support of the Pretreatment Engineering Platform (PEP)}

$\begin{array}{ll}\text { JM Billing } & \text { DE Kurath } \\ \text { RC Daniel } & \text { RA Peterson }\end{array}$

September 2009

Test Specification: 24590-PTF-TSP-RT-07-001 Rev 2

Work Authorization: WA\# 2007-024

Test Plan: TP-WTP-PEP-044, Rev. 0.2

Test Exceptions: $\quad$ 24590-WTP-TEF-RT-09-0001 Rev. 1, 24590-WTP-TEF-RT-09-00002 Rev. 0

R\&T focus area: Pretreatment

Test Scoping Statement(s): NA

Prepared for

the U.S. Department of Energy

Under Contract DE-AC05-76RL01830

Pacific Northwest National Laboratory

Richland, Washington 99352 


\section{COMPLETENESS OF TESTING}

This report describes the results of work and testing specified by Test Specification 24590-PTF-TSP-RT-07-001, Rev 2 "Pretreatment Engineering Platform (PEP) Testing (Phase I)" and Test Plan TP-WTP-PEP-044, Rev. 0.2 "Test Plan for the PEP Parallel Laboratory Testing." The work and any associated testing followed the quality assurance requirements outlined in the Test Specification/Plan. The descriptions provided in this test report are an accurate account of both the conduct of the work and the data collected. Test plan results are reported. Also reported are any unusual or anomalous occurrences that are different from expected results. The test results and this report have been reviewed and verified.

\section{Approved:}

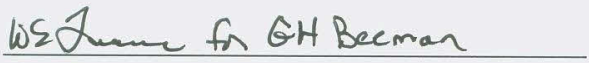

Gordon H. Beeman, Manager WTP R\&T Support Project

\section{9}

Date 


\section{Contents}

Acknowledgments.............................................................................................................. vii

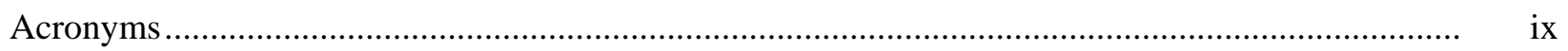

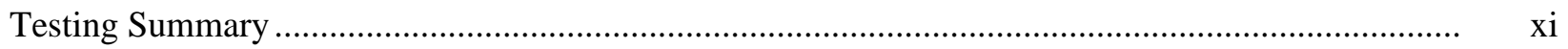

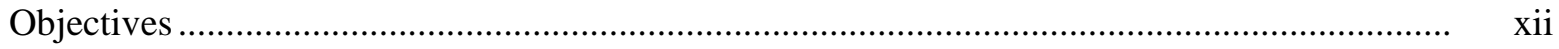

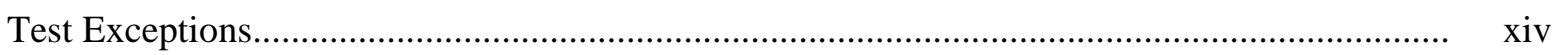

Results and Performance Against Success Criteria ............................................................ x. xv

Quality Requirements .................................................................................................. xvi

R\&T Test Conditions....................................................................................... $\quad$ xvi

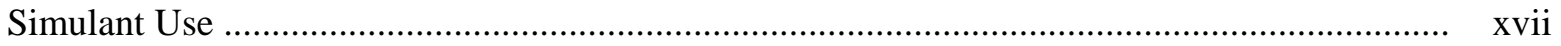

Discrepancies and Follow-on Tests ................................................................................... xviii

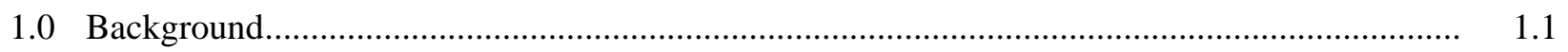

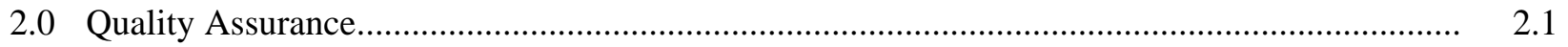

3.0 Process and Equipment Description ...............................................................................

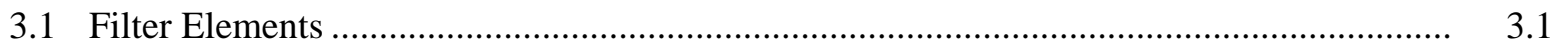

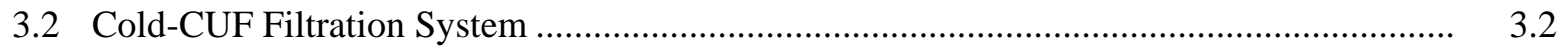

3.3 Measurement and Analysis of Filtration Data............................................................... 3.5

3.3.1 Cold-CUF Instrumentation.............................................................................. 3.6

3.3.2 Measurements of Filtration Performance .............................................................. 3.6

3.3.3 Analysis of CUF DACS Data........................................................................ 3.8

3.3.4 Analysis of Dewatering Curves.................................................................... 3.9

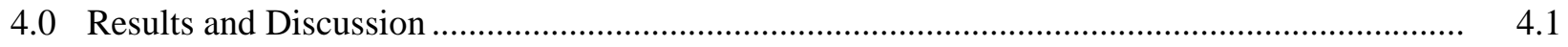

4.1 Low-Solids Filter Conditioning Tests \#1 and \#2 …........................................................ 4.1

4.1.1 Results for Low-Solids Filter Conditioning Tests............................................... 4.1

4.1.2 Discussion for Low-Solids Filter Conditioning Tests ............................................ 4.5

4.2 Low-Solids Dewatering Tests \#1 and \#2 ...................................................................... 4.6

4.2.1 Results for Low-Solids Dewatering Tests......................................................... 4.6

4.2.2 Discussion for Low-Solids Dewatering ............................................................... 4.11

4.3 High-Solids Dewatering Tests \#1 and \#2 ..................................................................... 4.12

4.3.1 Results for High-Solids Dewatering Tests ........................................................ 4.12

4.3.2 Discussion of High-Solids Dewatering Tests....................................................... 4.22

4.4 Post-Caustic-Leach Dewatering and Oxalate Washing Test.............................................. 4.23

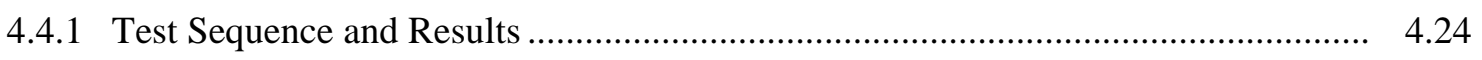

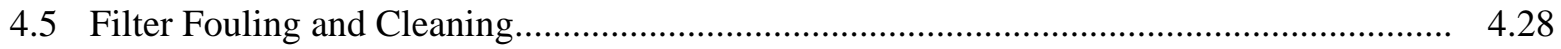

4.5.1 PEP Process Water Fouling and Cleaning Tests ................................................. 4.29

4.5.2 Oxalic Acid Cleaning After Simulant Use ......................................................... 4.32

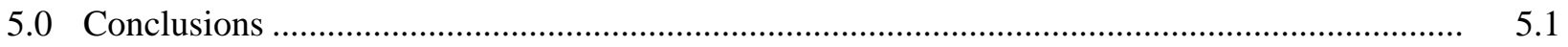

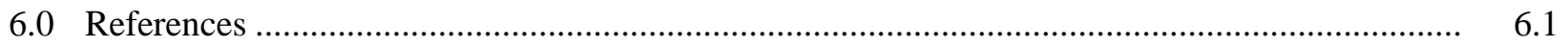




\section{Figures}

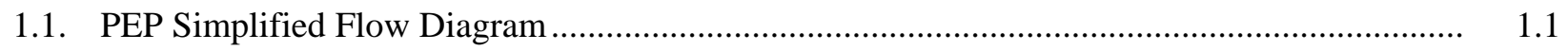

3.1. CUF Filter Element .................................................................................................

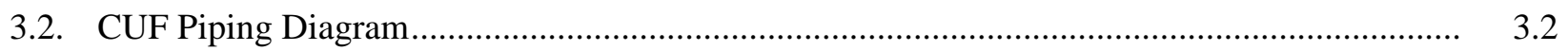

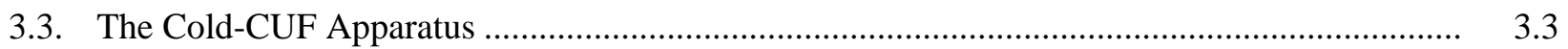

3.4. CUF Filter Assembly Sketch (not to scale) .............................................................................

3.5. The Cell Unit Filter Assembly ........................................................................................

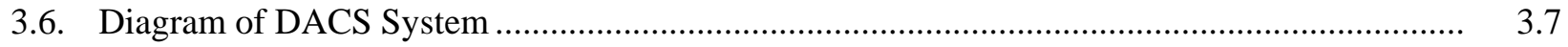

3.7. Typical Filter Flux Behavior as a Function of Solids Concentration ....................................... 3.10

4.1. Process Performance Relative to Target Conditions for TMP ( $40 \pm 5$ psid), AV $(15 \pm 1 \mathrm{ft} / \mathrm{sec})$, and Reservoir Temperature $\left(25 \pm 5^{\circ} \mathrm{C}\right)$ for Low-Solids Filter Conditioning Test \#1......

4.2. Process Performance Relative to Target Conditions for TMP ( $40 \pm 5 \mathrm{psid})$, AV ( $15 \pm 1 \mathrm{ft} / \mathrm{sec})$, and Reservoir Temperature $\left(25 \pm 5^{\circ} \mathrm{C}\right)$ for Low-Solids Filter Conditioning Test \#2 ........

4.3. Comparison of the Corrected Filter Flux between the First and Second Low-Solids Filter Conditioning Tests

4.4. Process Performance Relative to Target Conditions for TMP ( $40 \pm 5$ psid), AV ( $15 \pm 1 \mathrm{ft} / \mathrm{sec})$, Reservoir Temperature $\left(25 \pm 5^{\circ} \mathrm{C}\right)$, and APD $(<2.5 \mathrm{psid} / \mathrm{ft})$ for the Low-Solids Dewatering Test \#1

4.5. Process Performance Relative to Target Conditions for TMP ( $40 \pm 5 \mathrm{psid}), \mathrm{AV}(15 \pm 1 \mathrm{ft} / \mathrm{sec})$, Reservoir Temperature $\left(25 \pm 5^{\circ} \mathrm{C}\right)$, and APD $(<2.5 \mathrm{psid} / \mathrm{ft})$ for the Low-Solids Dewatering Test \#2

4.6. Filter Flux as a Function of UDS Concentration on a Semi-Log Plot for Low-Solids Dewatering Test \#1

4.7. Filter Flux as a Function of UDS Concentration on a Semi-Log Plot for Low-Solids Dewatering Test \#2

4.8. Comparison of Low-Solids Dewatering Test \#2 to Test \#1.

4.9. TMP During Each of the Dewatering Steps of High-Solids Dewatering Test \#1....

4.10. AV During Each of the Dewatering Steps of High-Solids Dewatering Test \#1

4.11. Slurry Reservoir Temperature During Each of the Dewatering Steps in High Solids Dewatering Test \#1

4.12. APD Plotted Against the Natural Log of the Slurry UDS Concentration for High-Solids Dewatering Test \#1 at Various AVs (13, 15, and $17 \mathrm{ft} / \mathrm{sec})$.

4.13. Corrected Permeate Flux Plotted Against wt\% UDS for High-Solids Dewatering Test \#1 at Three $\operatorname{AVs}(13,15$, and $17 \mathrm{ft} / \mathrm{sec})$

4.14. Corrected Permeate Flux Plotted Against the Natural Log of the Slurry UDS Concentration for High-Solids Dewatering Test \#1 at Three AVs (13, 15, and $17 \mathrm{ft} / \mathrm{sec})$

4.15. TMP During Each of the Dewatering Steps of High-Solids Dewatering Test \#2.... 
4.16. AV During Each of the Dewatering Steps of High-Solids Dewatering Test \#2

4.17. Slurry Reservoir Temperature During Each of the Dewatering Steps in High-Solids Dewatering Test \#2

4.18. APD Plotted Against the Natural Log of the Slurry UDS Concentration for High-Solids Dewatering Test \#2 at Various AVs (13, 15, and $17 \mathrm{ft} / \mathrm{sec})$

4.19. Corrected Permeate Flux Plotted Against wt\% UDS for High-Solids Dewatering Test \#2 at Three AVs $(13,15$, and $17 \mathrm{ft} / \mathrm{sec})$

4.20. Corrected Permeate Flux Plotted Against the Natural Log of the Slurry UDS Concentration for High-Solids Dewatering Test \#2 at Various AVs (13, 15, and $17 \mathrm{ft} / \mathrm{sec}$ ).

4.21. Clean Water Flux Before and After Post-Caustic-Leach Dewatering and Oxalate Washing Tests, Showing Minimal Change in Filter Conditioning as a Result of Testing.

4.22. Corrected Filter Flux for the Filtration of the Initial Post-Caustic-Leach Slurry in Recycle Mode Followed by Dewatering of the Slurry

4.23. Corrected Filter Flux for the Two 0.01-M NaOH Wash Dewatering Steps.

4.24. Comparison of the Corrected Filter Flux Between the Initial Post-Caustic-Leach Slurry and the Slurry Reconstituted After Washing with $0.01 \mathrm{M} \mathrm{NaOH}$, Showing Close Agreement in Timeframe Tested.

4.25. Fouling of Cold-CUF During Filtration of PEP Process Water 4.31

4.26. Clean Water Flux Testing of Cold-CUF System Before and After Oxalic Acid Cleaning. 4.31

4.27. Clean Water Flux After Cleaning with 25 ppm Alconox Detergent 4.32 


\section{Tables}

S.1. Test Objectives from TP-WTP-PEP-044 ............................................................................ xiii

S.2. $\quad$ Test Exceptions for Test Plan TP-WTP-PEP-044 .............................................................. xiv

S.3. Results and Performance Against Success Criteria of TP-WTP-PEP-044 ............................. $\quad$ xv

S.4. R\&T Test Conditions .................................................................................................. xvii

3.1. Cold-CUF Filtration System Measurement Instrumentation .................................................. 3.6

4.1. Test Conditions and Operational Parameters for Low-Solids Conditioning Tests.................... 4.2

4.2. Physical Properties of Simulant for Low-Solids Conditioning Tests....................................... 4.2

4.3 Ratio of Permeate Flux Between Low-Solids Conditioning Tests........................................... 4.5

4.4. Test Conditions and Operational Parameters for Low-Solids Dewatering Tests ....................... 4.7

4.5. Physical Properties of Concentrated Simulant Following Low-Solids Dewatering Tests .......... $\quad 4.8$

4.6. Operational Parameters for High-Solids Dewatering Test \#1 ….............................................. 4.13

4.7. Operational Parameters for High-Solids Dewatering Test \#2 ................................................. 4.13

4.8. Physical Properties of High-Solids Simulant Before Initial Dewatering ................................. 4.14

4.9. Physical Properties of Concentrated High-Solids Simulant Following First Dewatering.......... 4.21

4.10. Comparison of Trends for Increasing AV, High-Solids Dewatering Test \#1 ........................... 4.22

4.12. Comparison of Trends for Increasing AV, High-Solids Dewatering Test \#2 ........................... 4.23

4.13. Process Steps and Simplified Mass Balance of .......................................................................... 4.25

4.14. Concentration of Representative Analytes in Process Permeates During the Post-Caustic Leach Dewatering and Oxalate Washing Tests. 4.26

4.15. Cold-CUF Filter Element Conditioning History and Cleaning Performed .............................. 4.29 


\section{Acknowledgments}

The authors would like to thank Wayne Cosby for his extensive editorial support, Dave MacPherson and Kirsten Meier for Quality Assurance support and reviews, and Renee Russell and Amanda Casella for their careful and thorough technical reviews of this report. In addition to these PNNL staff, this report was also supported by many dedicated staff involved in laboratory experiments, sampling, data acquisition, data processing, data-quality confirmation, technical reviews, and data analysis.

OP Bredt

BT Broocks

WC Buchmiller

CA Burns

SP Pilli
AJ Casella
J Chun
EC Golovich
LK Jagoda
ML Luna

RP Pires

DE Rinehart

CP Rodriguez

MJ Schweiger

These individuals are recognized for supporting Cells Unit Filter testing and analysis by working unpredictable, long, and off-hour shifts. The tests and reports could not have progressed this far without their dependable hard work, advice, direction, and assistance. 



\section{Acronyms}

APD axial pressure drop

APEL Applied Process and Engineering Laboratory

ASME American Society of Mechanical Engineers

AV

axial velocity

BNI Bechtel National Inc.

CS centrifuged solids

CUF Cells Unit Filter

DACS data-acquisition collection system

DI

deionized (water)

DOE U.S. Department of Energy

DS dissolved solids

EFRT External Flowsheet Review Team

GPM gallons per minute

HLW high-level waste

JTG Joint Task Group

LAW low-activity waste

PEP Pretreatment Engineering Platform

PNNL Pacific Northwest National Laboratory

PSD particle-size distribution

psid pounds-per square-inch differential (pressure)

psig pounds per square inch gauge

PTF Pretreatment Facility

QA quality assurance

QAM Quality Assurance Manual

QAP Quality Assurance Plan

QARD Quality Assurance Requirements and Descriptions

RPP River Protection Project

R\&T research and technology

RTD resistance temperature detector

SBMS Standards-Based Management System

SWRI Southwest Research Institute

TMP transmembrane pressure

TS total solids

UDS undissolved solids

VFD variable frequency drive

WTP Hanford Tank Waste Treatment and Immobilization Plant 



\section{Testing Summary}

Pacific Northwest National Laboratory (PNNL) has been tasked by Bechtel National Inc. (BNI) on the River Protection Project-Hanford Tank Waste Treatment and Immobilization Plant (RPP-WTP) project to perform research and development activities to resolve technical issues identified for the Pretreatment Facility (PTF). The Pretreatment Engineering Platform (PEP) was designed, constructed and operated as part of a plan to respond to issue M12, "Undemonstrated Leaching Processes."(a) The PEP is a $1 / 4.5$-scale test platform designed to simulate the WTP pretreatment caustic leaching, oxidative leaching, ultrafiltration solids concentration, and slurry washing processes. The PEP testing program specifies that bench-scale testing is to be performed in support of specific operations, including filtration, caustic leaching, and oxidative leaching.

The work described in this report presents filter flux results using a Hanford tank waste simulant for testing performed in support of PEP operations. The tests were made at the bench-scale on a cold (i.e., designated for nonradioactive simulant test materials) Cells Unit Filter (CUF), or cold-CUF, located in the Applied Process and Engineering Laboratory (APEL). The complete suite of testing performed can be summarized into the following categories:

- Low-Solids Conditioning and Dewatering ${ }^{(\mathrm{b})}$ Tests \#1 and \#2-36-hr low-solids concentration continuous/backpulsed recycle filtration operation followed by slurry dewatering using pre-leach simulant slurry.

- High-Solids Dewatering Tests \#1 and \#2-Dewatering operations to achieve high-solids slurries using leached, washed solids.

- Post-Caustic-Leach Dewatering and Oxalate Washing Test-Investigation of the effect of oxalate super-saturation on permeate flux using slurry from a PEP caustic-leach batch.

- Filter Cleaning and Clean Water Flux Testing-Data obtained from fouling and cleaning the CUF, both routine and non-routine, including:

1. PEP process water fouling and cleaning tests

2. Oxalic acid cleaning after simulant use.

Of these tests, three were intended to provide a basis of comparison to assess scaling effects that exist between PEP engineering-scale filtration operations and CUF bench-scale filtration operations. These tests were:

- Low-Solids Conditioning Test \#1

- Low-Solids Conditioning Test \#2

- High-Solids Dewatering Test \#2.

(a) SM Barnes and R Voke,. 2006. Issue Response Plan for Implementation of External Flowsheet Review Team (EFRT) Recommendations - M12, Undemonstrated Leaching Processes. 24590-WTP-PL-ENG-06-0024, Rev. 0, Bechtel National, Inc., Richland, Washington.

(b) Even though the Low-Solids Dewatering Tests result in a high-solids slurry, they are referred to as "low-solids" because they proceeded directly from the Low-Solids Conditioning Tests using the same pre-leach slurry. "Low-solids" in this report always refers to conditioning or dewatering tests using pre-leach simulant slurries. "High-solids" in this report always refers to dewatering slurries of post-caustic-leached, washed solids. 
The low-solids conditioning and dewatering tests were conducted with an unmodified low-solids simulant slurry feed, whereas the high-solids dewatering tests were conducted with a leached and washed simulant slurry. The results of these bench-scale tests and comparison to PEP results to support development of a scale factor for use in the WTP are presented in WTP-RPT-185 (Daniel et al. 2009b). This report also includes previously unreported bench-scale testing performed in support of PEP operations as specified by TP-WTP-PEP-044, ${ }^{(a)}$ but not used to support the determination of scaling factors. The results are reported herein as information, and no systematic attempt to compare them to analogous testing at PEP has been made.

Key findings and observations include the following:

1. For the low-solids conditioning and dewatering tests, differences in flux between Test \#1 and Test \#2 can be explained by the differences in permeate viscosity.

2. Each of the high-solids dewatering tests was repeated at different axial velocities (AVs) to examine the effect of AV on filtration over the range of solids concentrations provided by dewatering. The results indicate that:

a. Increasing AV leads to a higher UDS concentration at the characteristic transition point in the dewatering curve between membrane-dominated flux resistance to cake-dominated flux resistance.

b. Increasing AV leads to higher filter flux over the course of slurry dewatering, leading to a shorter time from the beginning of the dewatering step to the target concentration of 20 -wt\% UDS.

3. The presence of oxalate fines precipitated from a saturated post-caustic-leach solution was determined not to significantly influence filter flux during post-caustic-leach dewatering. The low filter flux observed for this operation is attributable to high permeate viscosity.

4. Oxalic acid cleaning has been shown to be an effective means of restoring clean water filter flux after simulant use and may be applied to general cleaning of the filter element. Alconox detergent cleaning before or after oxalic acid cleaning may enhance the effectiveness of oxalic acid cleaning.

\section{Objectives}

Table S.1 summarizes the objectives along with a discussion of how the objectives were met. The objectives for the entire PEP testing program are provided with discussion limited to those objectives met by the scope of this report. Objectives not met by the scope of this report are shaded in gray.

Parallel laboratory testing was conducted to:

- Establish scale factors between laboratory process measurements (e.g., leach factors, filter fluxes) and those of the PEP.

- Maximize the comparability of the laboratory and PEP process measurements and simplify the development of the scaling relationships. Slurry samples were collected from the PEP at appropriate points during the testing, transported to a laboratory, and subjected to analogous laboratory testing. Filter flux measurements for slurries with low and high solids concentrations, caustic leaching, and oxidative leaching were each examined in this fashion.

(a) RL Russell. 2008. Test Plan for the PEP Parallel Laboratory Testing. TP-WTP-PEP-044, Rev. 0.2, Pacific Northwest National Laboratory, Richland, Washington. 
Permeate precipitation testing were performed to evaluate the propensity of the Phase 1 simulant permeates to precipitate solids.

Table S.1. Test Objectives from TP-WTP-PEP-044

\begin{tabular}{|c|c|c|c|}
\hline \multicolumn{2}{|c|}{ Test Objective } & \multirow{2}{*}{$\begin{array}{c}\begin{array}{c}\text { Objective } \\
\text { Met? (Y/N) }\end{array} \\
\mathrm{Y}\end{array}$} & \multirow{2}{*}{$\begin{array}{l}\text { Discussion } \\
\text { This objective was addressed in reports } \\
\text { WTP-RPT-185 (Daniel et al. 2009b), } \\
\text { WTP-RPT-186, and WTP-RPT-188. The } \\
\text { bench-scale filtration results are presented in } \\
\text { Section } 4.0 \text { of this report. }\end{array}$} \\
\hline & $\begin{array}{l}\text { Establish scale factors between } \\
\text { laboratory process measurements } \\
\text { (e.g., leach factors, filter fluxes) } \\
\text { and those of the PEP. }\end{array}$ & & \\
\hline & $\begin{array}{l}\text { Maximize the comparability of the } \\
\text { laboratory and PEP process } \\
\text { measurements and simplify the } \\
\text { development of the scaling } \\
\text { relationships. Slurry samples will } \\
\text { be collected from the PEP at } \\
\text { appropriate points during the } \\
\text { testing, transported to a laboratory, } \\
\text { and subjected to analogous } \\
\text { laboratory testing. Filter flux } \\
\text { measurements for slurries with low } \\
\text { and high solids concentrations, } \\
\text { caustic leaching, and oxidative } \\
\text { leaching will each be examined in } \\
\text { this fashion. }\end{array}$ & $\mathrm{Y}$ & $\begin{array}{l}\text { This objective was addressed in reports } \\
\text { WTP-RPT-185 (Daniel et al. 2009b), } \\
\text { WTP-RPT-186, and WTP-RPT-188. The } \\
\text { bench-scale filtration results are presented in } \\
\text { Section } 4.0 \text { of this report. }\end{array}$ \\
\hline 3) & $\begin{array}{l}\text { Permeate precipitation testing will } \\
\text { be performed to evaluate the } \\
\text { propensity of the Phase I simulant } \\
\text { permeates to precipitate solids. }\end{array}$ & NA & $\begin{array}{l}\text { This objective is addressed in Section } 8.0 \text { of } \\
\text { WTP-RPT-200. }{ }^{\text {(a) }} \text { It was found that the majority of } \\
\text { the wash solutions formed precipitates that appeared } \\
\text { to be sodium oxalate and sodium phosphate. }\end{array}$ \\
\hline 4) & $\begin{array}{l}\text { Develop an understanding of the } \\
\text { post-precipitation phenomenon. }\end{array}$ & $\mathrm{Y}$ & $\begin{array}{l}\text { This objective is addressed in Section } 6.0 \text { of } \\
\text { WTP-RPT-200. It was found that the precipitates are } \\
\text { mainly sodium oxalate and sodium phosphate. } \\
\text { Filtration data for caustic-leach dewatering and } \\
\text { washing of precipitates can be found in Section } 4.4 \\
\text { of this report. }\end{array}$ \\
\hline 5) & $\begin{array}{l}\text { Develop empirical information } \\
\text { needed to 1) understand the } \\
\text { operating bounds in concentration } \\
\text { and temperature to avoid } \\
\text { post-filtration precipitation in the } \\
\text { caustic-leach process solutions, } \\
\text { and 2) identify and assess a need } \\
\text { for a change to the flowsheet, if } \\
\text { required, to improve process } \\
\text { operability. }\end{array}$ & NA & $\begin{array}{l}\text { These results will be presented in a report that is yet } \\
\text { to be released. }\end{array}$ \\
\hline
\end{tabular}

(a) RL Russell, RA Peterson, DE Rinehart, WC Buchmiller. 2009. PEP Support Laboratory Leaching and Permeate Stability Tests. WTP-RPT-200, Rev. A, Pacific Northwest National Laboratory, Richland, Washington. 


\section{Test Exceptions}

There were two test exceptions issued for Test Plan TP-WTP-PEP-044. These test exceptions are summarized in Table S.2 along with a brief description of how each exception impacted existing objectives and test plan scope.

Table S.2. Test Exceptions for Test Plan TP-WTP-PEP-044

\begin{tabular}{|l|l||}
\hline List Test Exceptions & Describe Test Exceptions \\
\hline 24590-WTP-TEF-RT-09-0001, Rev. 1 & $\begin{array}{l}\text { This test exception did not affect any testing requirements. It added test } \\
\text { objectives concerned with 1) understanding the operating bounds in } \\
\text { concentration and temperature to avoid post-filtration precipitation in } \\
\text { the caustic-leach process solutions, and 2) identifying and assessing a } \\
\text { need for a change to the flowsheet, if required, to improve process } \\
\text { operability. These added test objectives are captured in objective } 5 \text { in } \\
\text { Table S.1. }\end{array}$ \\
\hline 24590-WTP-TEF-RT-09-0002, Rev. 0 & $\begin{array}{l}\text { This test exception did not affect any testing requirements. It added test } \\
\text { objectives concerned with developing an understanding of the } \\
\text { post-filtration precipitation process. This is objective } 4 \text { in Table S.1. }\end{array}$ \\
\hline
\end{tabular}




\section{Results and Performance Against Success Criteria}

Table S.3. Results and Performance Against Success Criteria of TP-WTP-PEP-044

\begin{tabular}{|c|c|c|}
\hline \multicolumn{2}{|c|}{ List Success Criteria } & \multirow[b]{2}{*}{$\begin{array}{l}\text { Explain How the Tests Did or Did Not } \\
\text { Meet the Success Criteria } \\
\text { The low- and high-solids filtration test results presented } \\
\text { in the report were used to determine scale-up factors as } \\
\text { reported in WTP-RPT-185 (Daniel et al. 2009b). } \\
\text { Results used for generating scale-up factors for caustic } \\
\text { and oxidative leaching are presented in WTP-RPT-200. } \\
\text { The scale-up factors are discussed in reports } \\
\text { WTP-RPT-186 (caustic leaching) and WTP-RPT-188 } \\
\text { (oxidative leaching). }\end{array}$} \\
\hline & $\begin{array}{l}\text { Generate testing results that allow a scale-up factor } \\
\text { from the laboratory testing to the PEP testing to be } \\
\text { generated. }\end{array}$ & \\
\hline 2) & $\begin{array}{l}\text { Determine the mineralogy of the precipitate phase, } \\
\text { precipitate composition, and the solution phase } \\
\text { saturation composition for the composite samples } \\
\text { from demonstration Test A. }\end{array}$ & This criterion is not addressed in this report. \\
\hline 3) & $\begin{array}{l}\text { Determine the rate at which the anions-phosphate, } \\
\text { oxalate, sulfate, silicate, and fluoride-approach } \\
\text { equilibrium solution composition (saturation } \\
\text { concentration) in post-caustic-leach slurry at } 25^{\circ} \mathrm{C} \\
\text { before filtration. }\end{array}$ & This criterion is not addressed in this report. \\
\hline 4) & $\begin{array}{l}\text { Identify precipitates formed at ambient temperature } \\
\text { in the presence of phosphate, oxalate, sulfate, } \\
\text { silicate, and fluoride anions in the } \\
\text { post-caustic-leachate solution. Also, determine } \\
\text { particle-size distribution (PSD), crystal shape and } \\
\text { habit (morphology), quantity, and the settling rate } \\
\text { of precipitates formed. }\end{array}$ & This criterion is not addressed in this report. \\
\hline 5) & $\begin{array}{l}\text { Determine the dilution required to re-dissolve the } \\
\text { post-filtration precipitate through incremental } \\
\text { dilution of the slurry with water at } 25^{\circ} \mathrm{C} \text {. }\end{array}$ & This criterion is not addressed in this report. \\
\hline 6) & $\begin{array}{l}\text { Determine solution super-saturation in the } \\
\text { post-caustic-leach filtrate during the dewatering } \\
\text { period, based on the samples collected at discrete } \\
\text { times during Test B in the PEP. The } \\
\text { super-saturation shall be expressed as both the } \\
\text { centrifuged volume fraction and as weight fraction } \\
\text { of the slurry sample. Also, determine the } \\
\text { temperature at which the precipitate goes into total } \\
\text { solution. }\end{array}$ & This criterion is not addressed in this report. \\
\hline 7) & $\begin{array}{l}\text { Determine the effects of blending during the } \\
\text { post-caustic-leach dewatering and wash periods in } \\
\text { Test B in the PEP. }\end{array}$ & This criterion is not addressed in this report. \\
\hline
\end{tabular}




\section{Quality Requirements}

The PNNL Quality Assurance (QA) Program is based upon the requirements as defined in the U.S. Department of Energy (DOE) Order 414.1C, Quality Assurance and 10 CFR 830, Energy/Nuclear Safety Management, Subpart A-Quality Assurance Requirements (a.k.a. the Quality Rule). PNNL has chosen to implement the following consensus standards in a graded approach:

- ASME NQA-1-2000, Quality Assurance Requirements for Nuclear Facility Applications, Part 1, Requirements for Quality Assurance Programs for Nuclear Facilities.

- ASME NQA-1-2000, Part II, Subpart 2.7, Quality Assurance Requirements for Computer Software for Nuclear Facility Applications.

- ASME NQA-1-2000, Part IV, Subpart 4.2, Graded Approach Application of Quality Assurance Requirements for Research and Development.

The procedures necessary to implement the requirements are documented through PNNL's Standards-Based Management System (SBMS).

PNNL implements the RPP-WTP quality requirements by performing work in accordance with the River Protection Project-Waste Treatment Plant Support Program (RPP-WTP) Quality Assurance Plan (RPP-WTP-QA-001, QAP). Work was performed to the quality requirements of NQA-1-1989 Part I, Basic and Supplementary Requirements, NQA-2a-1990, Part 2.7, and DOE/RW-0333P, Rev 13, Quality Assurance Requirements and Descriptions (QARD) as applicable. These quality requirements are implemented through the River Protection Project-Waste Treatment Plant Support Program (RPP-WTP) Quality Assurance Manual (RPP-WTP-QA-003, QAM). The requirements of DOE/RW-0333P Rev 13, Quality Assurance Requirements and Descriptions (QARD) and 10 CFR 830, Subpart A, were not required for this work.

RPP-WTP addresses internal verification and validation activities by conducting an independent technical review of the final data report in accordance with RPP-WTP's procedure QA-RPP-WTP-604. This review procedure is part of PNNL's RPP-WTP Quality Assurance Manual (RPP-WTP-QA-003). Following this procedure, a technical review would verify that the reported results are traceable, that inferences and conclusions are soundly based, and the reported work satisfies the objectives.

\section{R\&T Test Conditions}

The research and technology $(\mathrm{R} \& \mathrm{~T})$ test conditions, as defined in the Test Specification 24590-PTF-TSP-RT-07-001, Rev. $2^{\text {(a) }}$ associated with the Test Plan TP-WTP-PEP-044 are summarized in Table S.5.

The R\&T test conditions for the entire PEP testing program are provided with discussion limited to the R\&T test conditions covered by the scope of this report. R\&T test conditions not addressed in this report are shaded in gray.

(a) JL Huckaby and JR Markille. 2008. Pretreatment Engineering Platform (PEP) Testing (Phase I). WTP Project Doc. No. 24590-PTF-TSP-RT-07-001, Rev. 2, Bechtel National, Inc., Richland, Washington. 
Table S.4. R\&T Test Conditions

\begin{tabular}{|c|c|}
\hline List R\&T Test Conditions & Were Test Conditions Followed? \\
\hline $\begin{array}{l}\text { 1) Filter flux measurements will be conducted on two } \\
\text { low-solids-concentration simulants and on two } \\
\text { high-solids-concentration simulants to demonstrate the } \\
\text { scale up of cross-flow filtration. }\end{array}$ & $\begin{array}{l}\text { Yes. Two low-solids-concentration and two } \\
\text { high-solids-concentration simulants were } \\
\text { tested. }\end{array}$ \\
\hline $\begin{array}{l}\text { 2) Caustic-leaching tests will be performed with slurry } \\
\text { samples collected from the PEP leaching vessels just } \\
\text { before steam heating is initiated in the PEP to obtain } \\
\text { laboratory oxidative leaching data that can be used as a } \\
\text { baseline to evaluate caustic-leaching performance in } \\
\text { the PEP. }\end{array}$ & $\begin{array}{l}\text { Not applicable to this report. It will be } \\
\text { addressed in WTP-RPT-200. }\end{array}$ \\
\hline $\begin{array}{l}\text { 3) Oxidative leaching tests will be performed with slurry } \\
\text { samples collected from the PEP leaching vessels just } \\
\text { before the permanganate is added in the PEP to obtain } \\
\text { laboratory oxidative leaching data that can be used as a } \\
\text { baseline to evaluate oxidative leaching performance in } \\
\text { the PEP. }\end{array}$ & $\begin{array}{l}\text { Not applicable to this report. It will be } \\
\text { addressed in WTP-RPT-200. }\end{array}$ \\
\hline $\begin{array}{l}\text { 4) Permeate precipitation testing will be conducted using } \\
\text { the post-caustic wash solutions, the permeate near the } \\
\text { end of the initial solids concentration process, and the } \\
\text { permeate near the end of the post-caustic-leach } \\
\text { solids-concentration process to evaluate the propensity } \\
\text { of the simulant permeates to precipitate solids. }\end{array}$ & $\begin{array}{l}\text { Not applicable to this report. It will be } \\
\text { addressed in WTP-RPT-200. }\end{array}$ \\
\hline
\end{tabular}

\section{Simulant Use}

PEP process testing was performed with a nonradioactive aqueous slurry of simulant waste chemicals and solids. The simulant composition and make-up recipe were provided by WTP as documented in Simulant Recommendation for Phase 1 Testing in the Pretreatment Engineering Platform. ${ }^{\text {(a) }}$ Aqueous chemical concentrations were within ranges expected for waste feeds to the PTF except for the hydroxide, oxalate, and phosphate anions. The hydroxide concentration was approximately one standard deviation from the average concentration expected in the feeds to the plant. The oxalate and phosphate components were at their respective solubility limits. The solids components and blend were selected to obtain targeted solids mass loss (aluminum and chromium leaching and oxalate washing) and treatment time. The simulant was not selected to represent any particular Hanford tank waste type.

The simulant was blended from the components listed below. The basis for selecting the individual components and the comparison to actual waste behavior is provided where applicable in the indicated references:

(a) PS Sundar. 2008. Simulant Recommendation for Phase 1 Testing in the Pretreatment Engineering Platform. 24590-PTF-RT-08-006, Rev. 0, Bechtel National, Inc., Richland, Washington. 
- Boehmite (for Al) (Russell et al. 2009a)

- Gibbsite (for Al) $)^{(a)}$

- Chrome oxyhydroxide (CrOOH) slurry (Rapko et al. 2007)

- Sodium oxalate

- Filtration simulant (Russell et al. 2009b)

- Supernate (Russell et al. 2009b).

Because the high-temperature caustic leaching of the Shakedown/Functional Test and Tests A and B dissolved significant amounts of the $\mathrm{CrOOH}$ solids, a separate chromium solids simulant was prepared and added to the PEP process after post-caustic-leach washing (a non-prototypic addition). In Test $\mathrm{D}$, the chromium solids component of the simulant was added to the feed to demonstrate the PTF permanganate addition strategy.

Simulant was procured from NOAH Technologies Corporation (San Antonio, TX). Samples of each simulant batch were characterized to make sure that chemical and physical properties requirements were met. ${ }^{(b)}$ Batches of the simulant were procured as follows:

- A 15-gallon trial batch of the blended simulant for laboratory testing to demonstrate the efficacy of the simulant fabrication procedure.

- A 250-gallon scale-up batch of the blended simulant to demonstrate scale-up of the simulant fabrication procedure to an intermediate scale.

- Batches 0, 1, and 2, each nominally 3500 gallons, of blended simulant for the Shakedown/Functional Tests and Integrated Tests A and B. These batches did not contain the CrOOH component.

- Batch 3, nominally 1200 gallons, for Integrated Test D. This batch contained the CrOOH solids component.

- The CrOOH solids slurry for the Shakedown/Functional Test and Tests A and B was obtained in two separate batches containing nominally 18 and $36 \mathrm{~kg}$ of $\mathrm{Cr}$ as $\mathrm{CrOOH}$.

\section{Discrepancies and Follow-on Tests}

None.

(a) RL Russell, WC Buchmiller, KJ Cantrell, RA Peterson, and DE Rinehart. 2009. Results of Aging Tests of Vendor-Produced Blended Feed Simulant. WTP-RPT-198, Rev. 0, Pacific Northwest National Laboratory, Richland, Washington.

(b) For a complete description of the simulant procurement process, including quality assurance requirements for simulant manufactured by NOAH Technologies Corporation, please see the statement of work in Appendix A of WTP-RPT-204: RD Scheele, GN Brown, DE Kurath. 2009. Manufacture of PEP Simulants - Lessons Learned. WTP-RPT-204, Draft, Pacific Northwest National Laboratory, Richland, Washington. 


\subsection{Background}

Pacific Northwest National Laboratory (PNNL) has been tasked by Bechtel National Inc. (BNI) on the River Protection Project-Hanford Tank Waste Treatment and Immobilization Plant (RPP-WTP) project to perform research and development activities to resolve technical issues identified for the Pretreatment Facility (PTF). The Pretreatment Engineering Platform (PEP) was designed, constructed, and operated as part of a plan to respond to issue M-12, Undemonstrated Leaching Processes. ${ }^{(a)}$ The PEP is a $1 / 4.5$-scale test platform designed to simulate the WTP pretreatment caustic leaching, oxidative leaching, ultrafiltration solids concentration, and slurry washing processes. The PEP testing program specifies that bench-scale testing is to be performed in support of specific operations, including ultrafiltration, caustic leaching, and oxidative leaching. The PEP replicates the WTP leaching and filtration processes using prototypic equipment and control strategies. Though the processes and equipment at PEP are prototypic of WTP PTF operations, the PEP flow diagram does not mimic the WTP PTF flowsheet. A simplified flow diagram of the PEP system is shown in Figure 1.1.

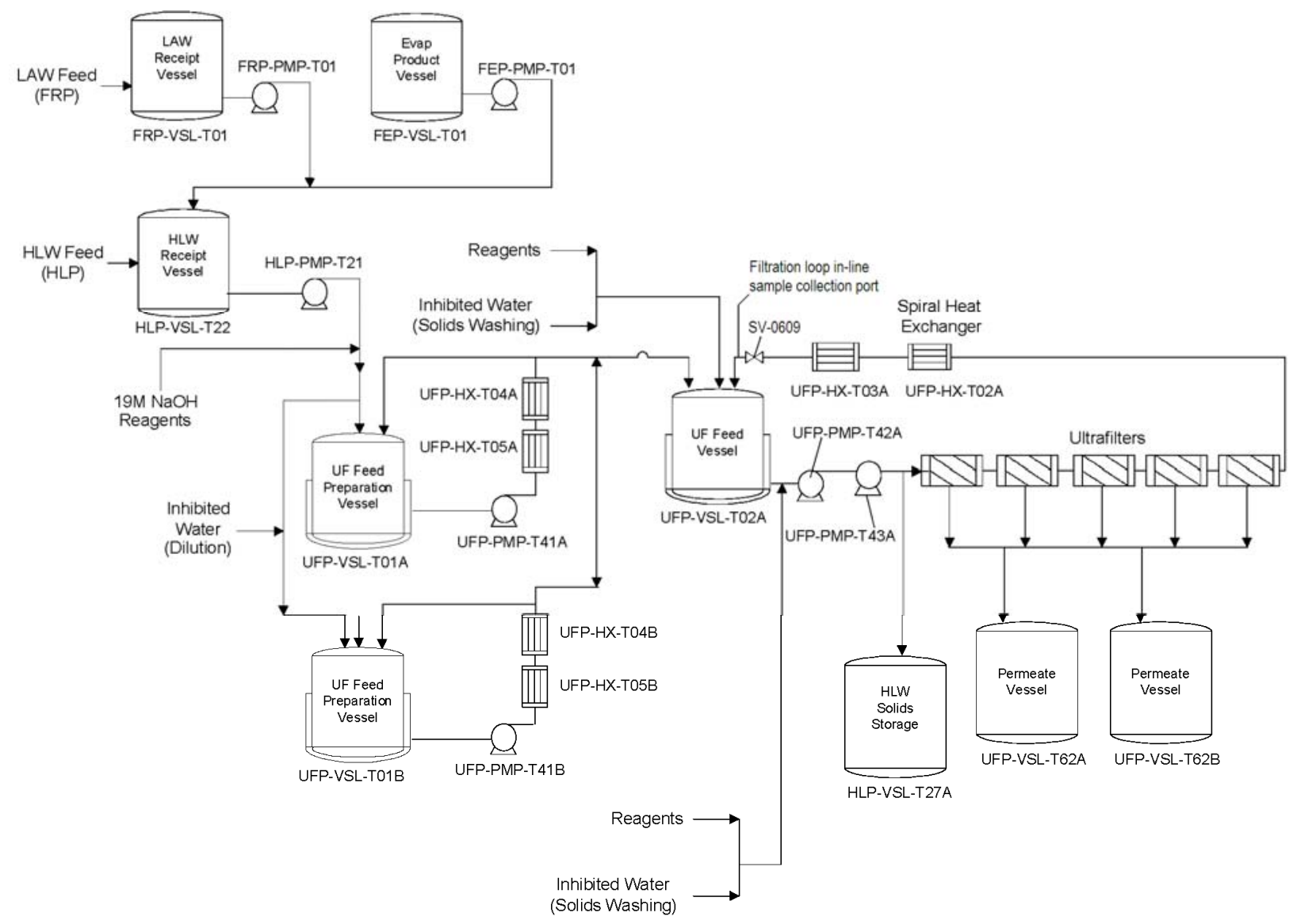

Figure 1.1. PEP Simplified Flow Diagram

(a) SM Barnes and R Voke,. 2006. Issue Response Plan for Implementation of External Flowsheet Review Team (EFRT) Recommendations - M12, Undemonstrated Leaching Processes. 24590-WTP-PL-ENG-06-0024, Rev. 0, Bechtel National, Inc., Richland, Washington. 
The cold Cells Unit Filter (CUF) and PEP test systems are designed to simulate WTP waste pretreatment operations. Pretreatment activities involve separating high-level waste (HLW) from the low-activity waste (LAW) liquid stream by cross-flow filtration in the pretreatment facility (PTF). The waste solids intended for the HLW stream will undergo caustic and oxidative leaching processes to dissolve and wash out materials that would otherwise limit the HLW loading in the immobilized waste glass. The concentrated HLW solids are sequentially caustic leached and oxidative leached during pretreatment. After each leaching step, the HLW solids are concentrated and undergo a wash operation using cross-flow filtration.

The objective of the current report is to present results from bench-scale filtration testing under Test Plan TP-WTP-PEP-044, ${ }^{\text {(a) }}$ using the cold-CUF filtration system located in the Applied Process Engineering Laboratory (APEL). Each test was connected to operations at PEP, either as described in TP-WTP-PEP-044 or to provide operational support for PEP. These tests included:

- Low-Solids Conditioning and Dewatering Tests \#1 and \#2-36-hr low-solids concentration continuous/backpulsed recycle filtration operations followed by slurry dewatering using blended, pre-leach simulant from Shakedown/Functional Testing at PEP.

- High-Solids Dewatering Tests \#1and \#2-Dewatering operations using leached, washed solids generated during Shakedown/Functional Testing at PEP (Test \#1) and Integrated Tests A and B (Test \#2).

- Post-Caustic-Leach Dewatering and Oxalate Washing Test-Investigation of the effect of oxalate super-saturation on permeate flux using slurry from a PEP caustic-leach batch.

- Filter Cleaning and Clean Water Flux Testing-Data obtained from fouling and cleaning the CUF, both routine and non-routine, including:

1. PEP process water fouling and cleaning tests using inhibited water $(0.01 \mathrm{M} \mathrm{NaOH})$ containing blue dye withdrawn during water shakedown testing at PEP.

2. Oxalic acid cleaning between the first and second low-solids conditioning and dewatering tests.

In Section 3, the CUF process equipment, instrumentation, measurements, and calculations for filtration data are presented. In Section 4, the filtration tests and waste simulant slurry properties are described in detail with accompanying results and discussion. The low-solids conditioning and dewatering tests were conducted with an unmodified low-solids simulant slurry feed, whereas the high-solids dewatering tests were conducted using a leached and washed simulant slurry. To maximize the comparability of results, all bench-scale testing was conducted using simulant slurries and process solutions received from PEP that were withdrawn during parallel steps in the PEP testing sequence. Each of the high-solids dewatering tests was repeated at different axial velocities (AVs) to examine the effect of $\mathrm{AV}$ on filtration over the range of solids concentrations provided by dewatering.

(a) RL Russell. 2008. Test Plan for the PEP Parallel Laboratory Testing. TP-WTP-PEP-044, Rev. 0.2, Pacific Northwest National Laboratory, Richland, Washington. 
Results for three of these tests were included as part of the External Flowsheet Review Team (EFRT) filtration report (Daniel et al. 2009b) to assess scaling effects that exist between PEP engineering-scale filtration operations and cold-CUF (bench-scale) filtration operations. These scaling tests are:

- Low-Solids Filter Conditioning Test \#1

- Low-Solids Filter Conditioning Test \#2

- High-Solids Dewatering Test \#2. 



\subsection{Quality Assurance}

The PNNL Quality Assurance (QA) Program is based upon the requirements as defined in the U.S. Department of Energy (DOE) Order 414.1C, Quality Assurance, and 10 CFR 830, Energy/Nuclear Safety Management, Subpart A-Quality Assurance Requirements (a.k.a. the Quality Rule). PNNL has chosen to implement the following consensus standards in a graded approach:

- ASME NQA-1-2000, Quality Assurance Requirements for Nuclear Facility Applications, Part 1, Requirements for Quality Assurance Programs for Nuclear Facilities.

- ASME NQA-1-2000, Part II, Subpart 2.7, Quality Assurance Requirements for Computer Software for Nuclear Facility Applications.

- ASME NQA-1-2000, Part IV, Subpart 4.2, Graded Approach Application of Quality Assurance Requirements for Research and Development.

The procedures necessary to implement the requirements are documented through PNNL's Standards-Based Management System (SBMS).

PNNL implements the RPP-WTP quality requirements by performing work in accordance with the River Protection Project-Waste Treatment Plant Support Program (RPP-WTP) Quality Assurance Plan (RPP-WTP-QA-001, QAP). Work was performed to the quality requirements of NQA-1-1989, Part I, Basic and Supplementary Requirements, NQA-2a-1990, Part 2.7 and DOE/RW-0333P, Rev 13, Quality Assurance Requirements and Descriptions (QARD) as applicable. These quality requirements are implemented through the River Protection Project-Waste Treatment Plant Support Program (RPP-WTP) Quality Assurance Manual (RPP-WTP-QA-003, QAM). The requirements of DOE/RW-0333P Rev 13, Quality Assurance Requirements and Descriptions (QARD) and 10 CFR 830, Subpart A, were not required for this work.

RPP-WTP addresses internal verification and validation activities by conducting an independent technical review of the final data report in accordance with RPP-WTP's procedure QA-RPP-WTP-604. This review procedure is part of PNNL's RPP-WTP Quality Assurance Manual (RPP-WTP-QA-003). Following this procedure, a technical review would verify that the reported results are traceable, that inferences and conclusions are soundly based, and the reported work satisfies the objectives. 



\subsection{Process and Equipment Description}

The cold-CUF test system is designed to perform bench-scale demonstrations of select WTP pretreatment operations. The operations that can be examined on the CUF nominally include waste filtration, filter cleaning, waste solids chemical leaching, and waste solids washing. Unlike the PEP test system, CUF equipment and vessel dimensions were not designed as prototypes of WTP process equipment. In addition, all CUF equipment and instrumentation (as they currently exist) are tied to the filtration process. For example, the CUF leaching vessel also serves as the slurry reservoir for waste filtration operations. A full description of cold-CUF equipment and instrumentation is given in Section 3.2.

To facilitate comparable filtration performance on test scales, the PEP and cold-CUF test systems both employ 1) the same type of filter elements in similar cross-flow ultrafiltration configurations, and 2) a similar slurry mass-to-filter surface-area ratio. Additional information regarding filter elements is provided in Section 3.1.

\subsection{Filter Elements}

The filter elements used in the cold-CUF are porous sintered metal tubes. The filter feed flows through the inside of the filter element axially while the feed permeate passes through the tube walls radially. Filtration occurs when the pressure differential between the inside and outside walls of the filter element (the transmembrane pressure [TMP]) is high enough to drive the slurry permeate through the tubular walls. The axial flow across the filter walls minimizes solids buildup and allows filtration to occur continuously with minimal downtime for back-pulsing to remove the solids buildup.

The filter elements were obtained from the Mott Corporation (Farmington, CT) using the same specifications for the filters being purchased for the WTP-PTF. Filters for CUF and PEP were taken from

the same manufacturer's lot number (see Specification WTP-070110 ${ }^{(\mathrm{a})}$ for more details). The filters are constructed of porous sintered 316 stainless steel with an effective filtration rating of $0.1 \mu \mathrm{m}$. The cold-CUF employs a single 2-ft-long element (dimensions shown in Figure 3.1).

(a) Specification WTP-070110, written by JGH Geeting, for PNNL, Purchase Order 38825, February 2, 2007. 

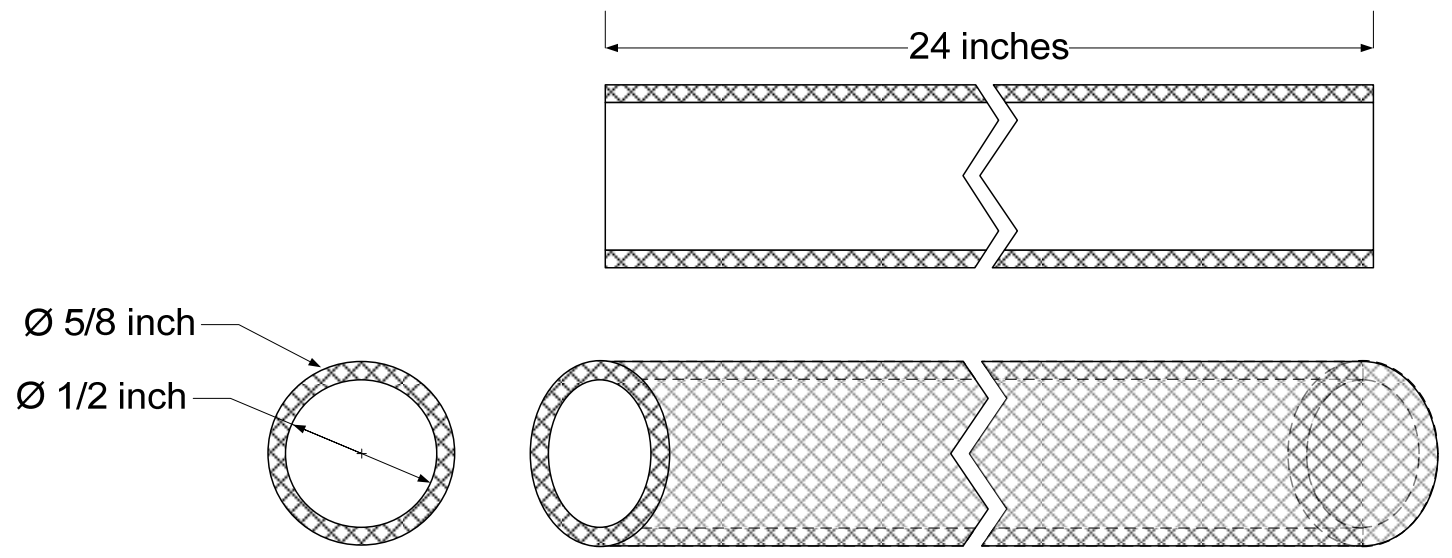

Figure 3.1. CUF Filter Element

\subsection{Cold-CUF Filtration System}

The cold-CUF filtration system is composed of five main components: 1) a slurry reservoir tank; 2) a slurry recirculation loop; 3) a CUF filter assembly; 4) a permeate flow loop; and 5) a permeate backpulse chamber. Figure 3.2 shows a piping diagram of the CUF. Figure 3.3 is a photograph of the assembled testing apparatus. The 3-HP electric motor and positive displacement pump that drives the filtration slurry simulant are shown to the left in this view.

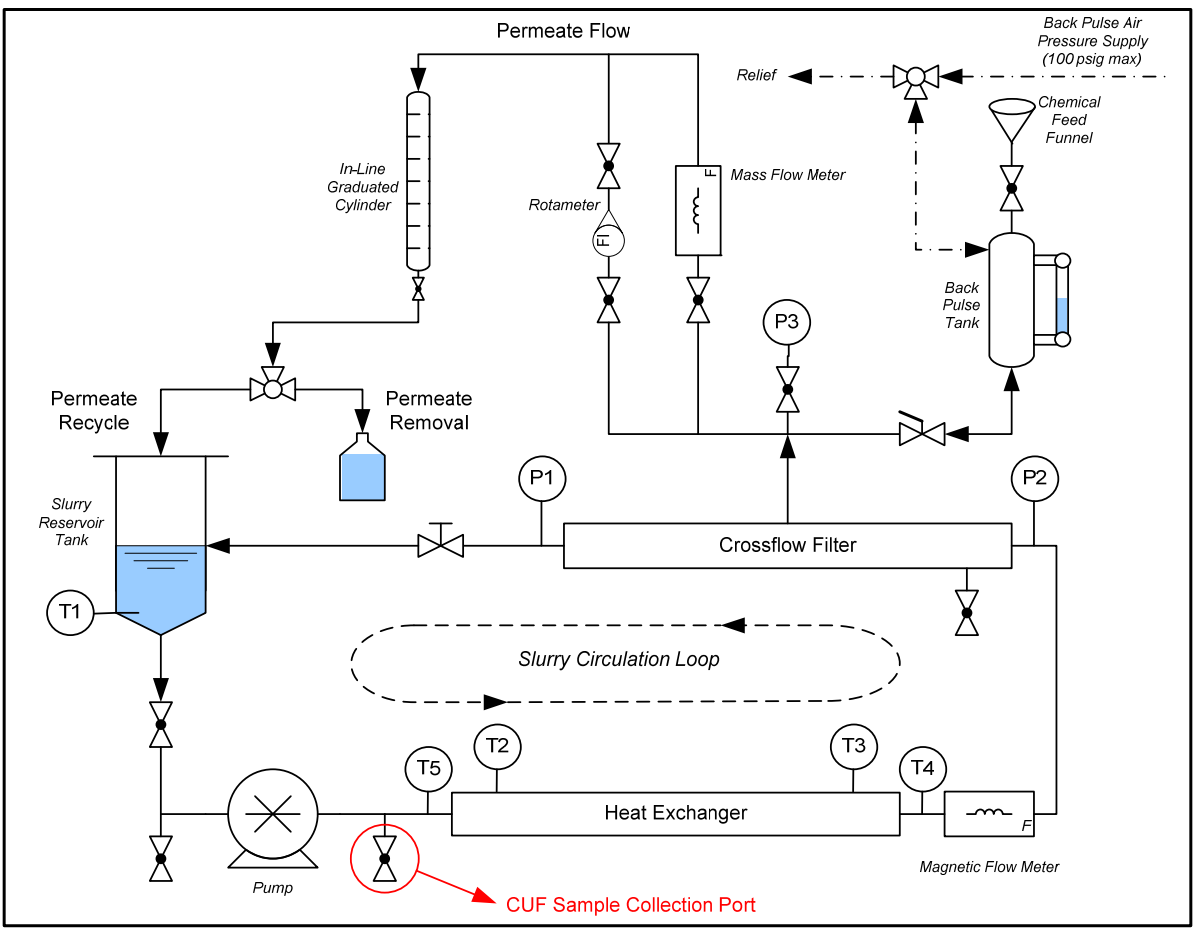

Figure 3.2. CUF Piping Diagram 


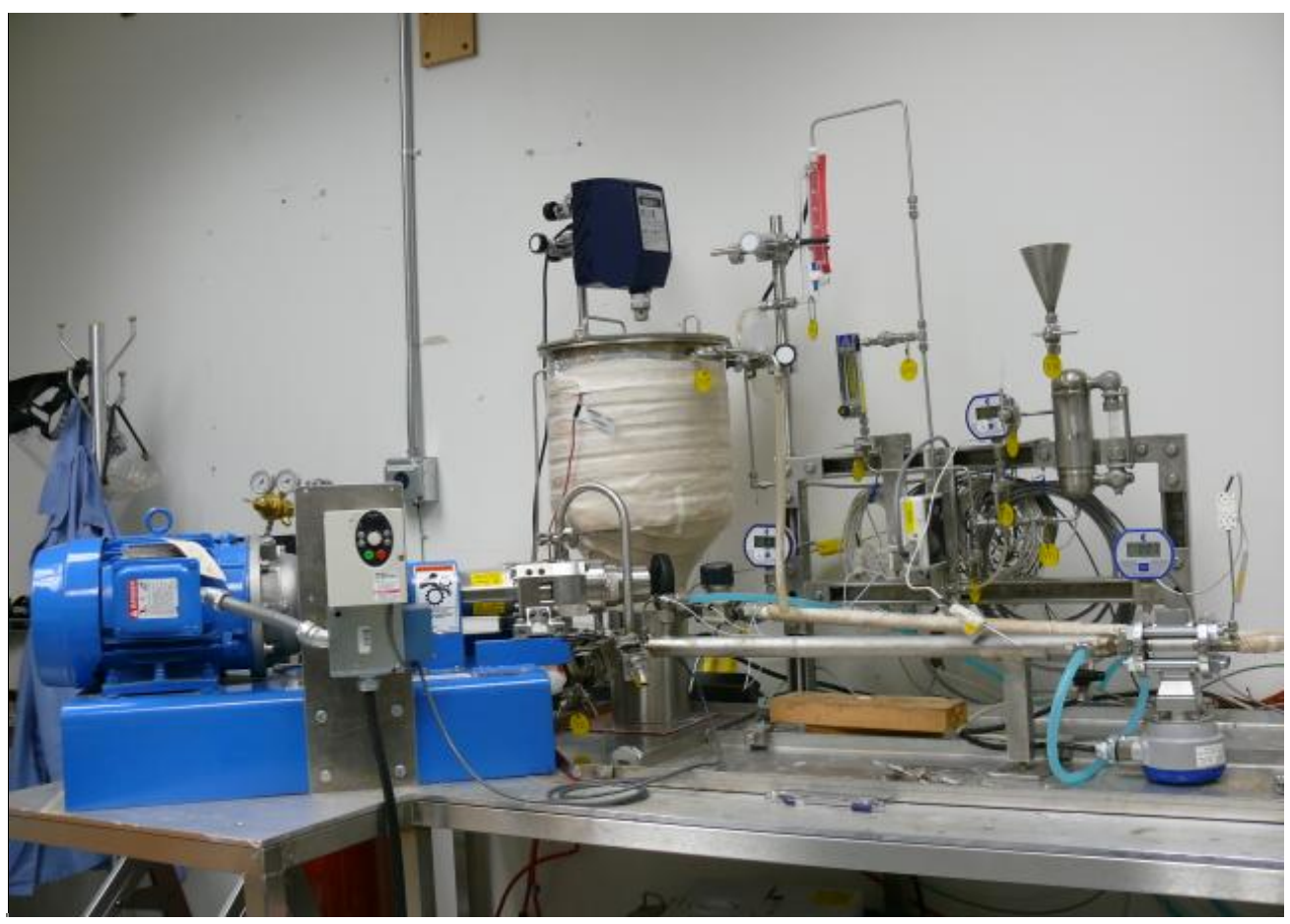

Figure 3.3. The Cold-CUF Apparatus

The slurry reservoir tank is a 25-L tank constructed of 304-L stainless steel. It is composed of two cylindrical sections of 5-in. and 12-in. inner diameter with a conical transition section between them. Figure 3.3 shows the upper and conical parts of the reservoir; the lower cylinder resides behind the pump housing. All sections are appropriately baffled, with four baffles in the 12-in.-diameter section and transition section and three baffles in the 5-in.-diameter section. Agitation in the tank is provided from an overhead mixer using two impellers: 1) 2-in.-diameter, 3-blade marine propeller at the end of the shaft at one tank radius from the bottom; and 2) 3-in.-diameter, pitched, 3-blade turbine positioned 5 inches above the propeller. Both impellers push fluid toward the suction line to the pump. To facilitate draining, the bottom of the vessel is sloped at a $15^{\circ}$ angle. The slurry reservoir thermocouple is installed near the bottom of the tank, extending just below the overhead mixing impeller.

In the slurry recirculation loop, a progressive cavity rotary-lobe pump directs slurry flow from the slurry reservoir through the heat exchanger, magnetic flow sensor, filter element, and back into the slurry reservoir. The bottom of the slurry reservoir is connected to the suction side of the slurry pump, and the discharge of the pump first flows through a single-pass shell-and-tube heat exchanger used to remove excess heat from mechanical energy input and heat generated from frictional flow. Next, the slurry flows through a magnetic flow sensor that monitors the volumetric flow of the slurry inside the slurry recirculation loop. The data from this device are used to calculate the AV inside the filter element.

The flowing slurry then enters the CUF filter assembly. All cold-CUF tests use a single filter element. This element was received from the Mott Corporation installed in a tube-in-tube configuration. In this configuration, the outer tube surrounding the filter element has been added to capture the filtrate. The outer tube has two stainless steel tubes exiting from the filter assembly, one in the center to collect filtrate from the filter, and the other near the inlet of the filter to function as a drain. Pressure gauge ports are installed on the inlet and outlet connections to the assembly to measure the pressure inside the filter 
(P1 and P2 in Figure 3.2). Figure 3.4 and Figure 3.5 show the filter element assembly used in cold-CUF testing.

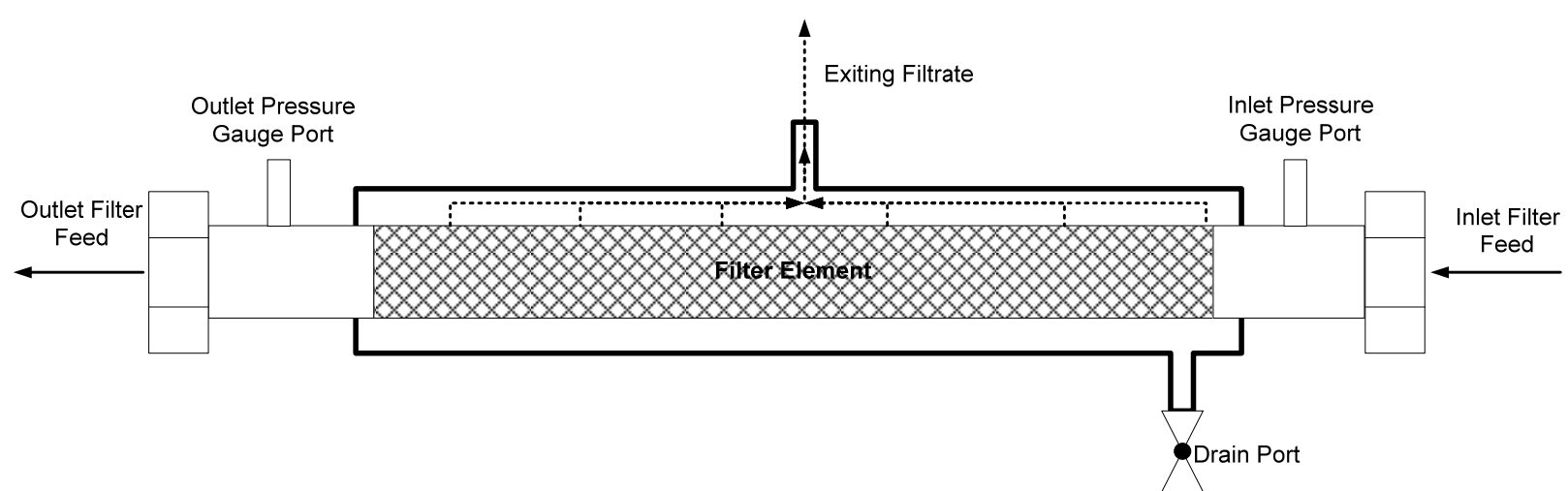

Figure 3.4. CUF Filter Assembly Sketch (not to scale)

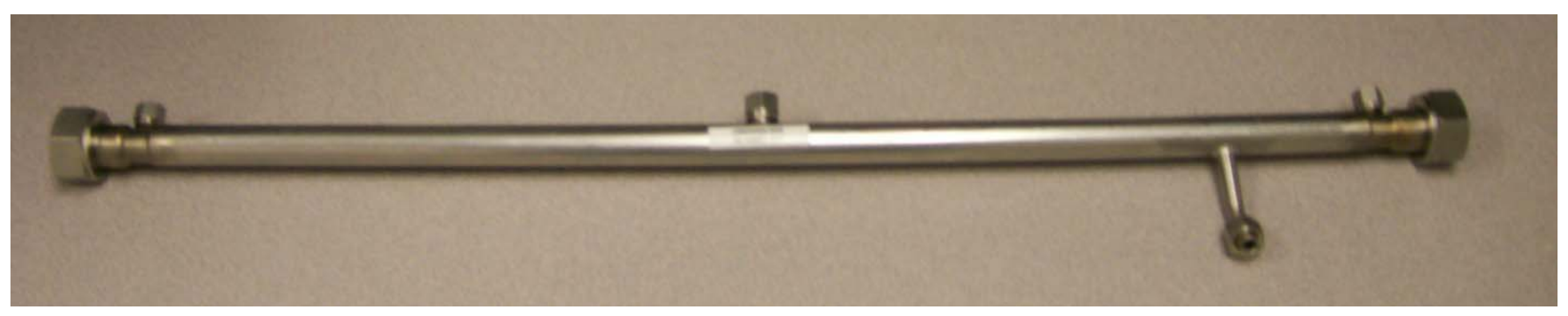

Figure 3.5. The Cell Unit Filter Assembly

Digital pressure gauges are installed on the inlet and outlet port of the filter, displaying the pressure at both locations in pounds-per-square-inch gauge (psig). The data from these devices were used to calculate the average pressure inside the filter and the axial pressure drop (APD) across the element.

A manual pinch valve is located at the filter's discharge. The valve may be used to adjust the pressure inside the filter to drive permeate flow through the filter membrane wall. The downstream side of this valve is connected to the slurry reservoir tank, completing the slurry recirculation loop.

The permeate flow loop starts at the center of the filter assembly where permeate from the outer tube of the filter assembly is directed through a series of measurement devices. A digital pressure gauge at this point measures the pressure on the permeate side of the filter in psig (P3 in Figure 3.2). The TMP across the filter is calculated by subtracting the pressure on the permeate side of the filter from the average of the inlet and outlet tube-side pressures. TMP is reported in pounds-per square-inch differential pressure (psid).

Permeate flow is directed through one of two mass flow meters connected in parallel, one calibrated up to $0.18-\mathrm{L} / \mathrm{min}$ and the other calibrated up to $1.2-\mathrm{L} / \mathrm{min}$. The mass flow meters also measure the density of the permeate flow. An in-line graduated glass cylinder installed after the meters may be used to take manual measurements of the permeate flow rate. Following these measurement devices, the permeate exits through a three-way valve. This valve may be oriented to direct permeate back to the slurry reservoir tank to be mixed with the slurry (known as "recycle mode") or to a sampling hose used to collect permeate into sample containers. 
The permeate backpulse chamber is located to the right of the permeate flow loop and is connected to the filter at the same location of the permeate pressure gauge. The chamber is a stainless steel vessel of approximately $425-\mathrm{mL}$ with a sight-glass to track the permeate volume inside the chamber. The chamber has three entry ports:

- A $1 / 4$-in. line with a two-way valve on the bottom connecting the vessel to the permeate side of the filter.

- $\mathrm{A}^{3} / 8$-in. line with a two-way valve connecting the top of the vessel to a funnel.

- A $1 / 4$-in. line with a three-way valve connecting the top of the vessel to a compressed air line and vent line connected to the top of the slurry reservoir tank.

When opened by the toggle valve, the bottom line is used to direct permeate flow from the chamber to the filter. The funnel on the top of the chamber is used to introduce cleaning and rinse solutions directly to the vessel. The compressed gas line is used to pressurize the fluid in the chamber with compressed gas and to vent the chamber to atmospheric pressure.

To backpulse the filter, the vessel is first vented to atmospheric pressure. Next, the toggle valve is opened to allow permeate to fill the chamber. Once the chamber is half full of permeate (as seen from the sight-glass), the valve is closed. The three-way valve is then positioned to allow compressed gas at 80 psig to fill the chamber and pressurize the fluid. The three-way valve is then positioned to isolate the now pressurized chamber. Next, the slurry pressure inside the filter is decreased below 20 psig. The toggle valve at the bottom of the tank is then opened, allowing the pressurized permeate inside the chamber to flow backwards through the filter element. The toggle valve is closed when the permeate level drops below the visible portion of the sight glass. After the backpulse has been applied to the filter, the three-way valve is positioned to vent the chamber back to atmospheric pressure.

Slurry samples may be taken from the system in two ways, either withdrawn from the slurry reservoir via pipette or collected from a sample valve connected to the slurry recirculation loop (shown between the pump and heat exchanger in Figure 3.2). For these tests, samples were collected from the sample valve unless otherwise noted. Before collection, 30 to 50 -mL of slurry was discharged from the valve and was set aside. It should be noted that the discharge volume was equivalent to 3 to 5 sample leg volumes (assuming hold-up in valve to be $\sim 10-\mathrm{mL}$ ). After the prescribed samples had been collected, the slurry volume set aside was added back to the slurry reservoir.

\subsection{Measurement and Analysis of Filtration Data}

Filtration performance for the cold-CUF is assessed through process instrumentation and measurement as well as by analysis of slurry and permeate samples collected during testing. The system is equipped with an array of test instrumentation to measure process parameters (such as slurry flow) and equipment performance (such as the rate of permeate production). Post-measurement analysis of these data is used to reduce and/or convert test results to a more usable form (e.g., converting a mass permeate production rate to a filter flux). Analytical analysis of slurry samples provides further information on process performance, such as the range of solids concentrations achieved during dewatering operations. In this section, a brief description of the measuring instrumentation for the cold-CUF filtration system is given. Next, the equations used to analyze filtration results are defined. Finally, an overview of the analytical techniques used to characterize slurry and permeate samples is given. 


\subsubsection{Cold-CUF Instrumentation}

Key components for measuring filtration performance on the cold-CUF test system match those for PEP. The cold-CUF test system includes instrumentation for measuring 1) filter AV (or slurry flow rate), 2) filter transmembrane pressure and APD, and 3) rate of permeate production and density. Table 3.1 provides a summary of CUF process instrumentation relevant to the current study.

Table 3.1. Cold-CUF Filtration System Measurement Instrumentation

\begin{tabular}{ll}
\hline Parameter & Units \\
\hline Slurry Reservoir Temperature & ${ }^{\circ} \mathrm{C}$ \\
\hline Permeate Pressure & psig \\
\hline Filter Inlet Pressure & psig \\
\hline Filter Outlet Pressure & psig \\
\hline Filter TMP & psid \\
\hline Volumetric Slurry Flow & $\mathrm{GPM}$ \\
\hline Filter AV & $\mathrm{ft} / \mathrm{s}$ \\
\hline Permeate Flow & $\mathrm{mL} / \mathrm{min}$ \\
\hline Permeate Density & $\mathrm{g} / \mathrm{mL}$ \\
\hline
\end{tabular}

Most of the sensors on the cold-CUF testing apparatus transmit analog data to an external data acquisition collection system (DACS) from the National Instruments Corporation (Austin, TX). This system relays the analog data to a LabVIEW data-collection application. The software application scales the analog data, simultaneously records the data electronically, and displays it on the computer monitor. For each channel, data are collected at a rate of $0.4 \mathrm{~Hz}$ and written to two data files, one containing the raw data updated every 2.5 seconds, and a second file containing 1-minute averages (24 samples) updated every minute. Figure 3.6 shows a diagram of the electronic sensors attached to the DACS. The National Instruments hardware was calibrated according to the requirements of PNNL's RPP-WTP Quality Assurance Manual (RPP-WTP-QA-003), and the LabVIEW software application was validated under the same program.

\subsubsection{Measurements of Filtration Performance}

Filtration testing for the cold-CUF test system involves sampling and analytical testing of waste simulant slurries and permeates. Analyses relevant to filtration performance include measurement of:

- Slurry and supernate rheology (i.e., yield stress, consistency, and/or viscosity).

- Particle-size distribution.

- Slurry total solids (TS), undissolved solids (UDS), dissolved solids (DS), and centrifuged solids (CS) concentrations.

- Slurry, supernate, and permeate densities. 


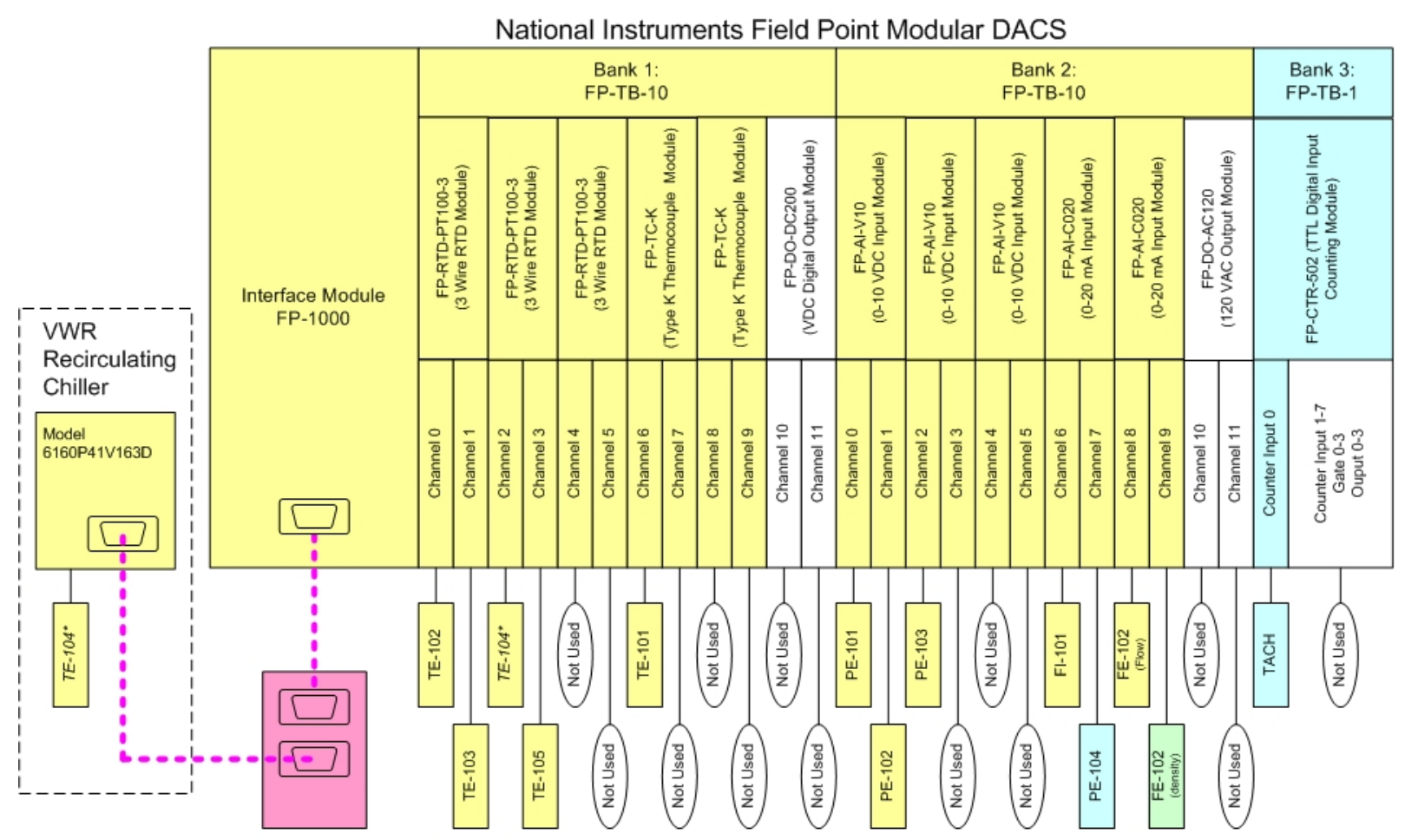

\begin{tabular}{|lll|}
\hline Windows XP PC & $\square$ M\&TE Data & $\begin{array}{l}\text { Indication Only * Note: TE-104 can only be wired to } \\
\text { either the chiller or the Field } \\
\text { Point system - not both. }\end{array}$ \\
\hline RS-232 Communication & $\square$ User Calibration & $\begin{array}{l}\text { Not Used } \\
\text { R }\end{array}$
\end{tabular}

Figure 3.6. Diagram of DACS System

Slurry and supernate rheologies were measured by PNNL with an Anton Parr MCR 301 rheometer with a concentric cylinder geometry operated in a controlled-rate mode. The rheology was characterized through flow-curve tests that measured the stress response of the fluid as a function of applied shear rate. Tests consisted of three segments. During the first segment, the shear rate was ramped from 0 to $1000 \mathrm{~s}^{-1}$ over 5 min. During the second segment, the shear rate was held constant at $1000 \mathrm{~s}^{-1}$ for 1 minute. In the final segment, the shear rate was decreased from $1000 \mathrm{~s}^{-1}$ to 0 over 5 minutes. Measurement data were recorded and subsequently analyzed with the RHEOPLUS/32 V3.21 software. This software allowed the slurry or supernate sample’s yield stress, consistency, and/or viscosity to be determined.

For measurement of slurry solids concentrations (including TS, UDS, DS, and CS) and slurry and supernate densities, samples were shipped to the Southwest Research Institute (SWRI) for analysis. SWRI measured these physical properties using methods based on Guidelines for Performing Chemical, Physical, and Rheological Properties Measurements. ${ }^{\text {(a) }}$ Reviewed analytical reports from SWRI for samples used to generate the results presented in this report are on file with WTP Project Records.

Exceptions to the referenced methods above include the three following performance-based measurements, listed with the anticipated impact on results:

(a) GL Smith and K Prindiville. 2002. Guidelines for Performing Chemical, Physical, and Rheological Properties Measurements. 24590-WTP-GPG-RTD-001, Rev. 0, Bechtel National, Inc., Richland, Washington. 
- Caustic-leach and oxidative-leach samples taken during this testing must be separated more quickly than the standard method using syringes. This testing will use a modified method with a shorter centrifuge time and will apply higher $g$ forces (e.g., $4000 \mathrm{~g}$ vs. $1000 \mathrm{~g}$ ). Impact on results: If the standard method were used, the longer time could very well lead to greater precipitation and inaccurate results. Laboratory testing will be conducted with simulants to confirm that this method of sample handling is adequate.

- Densities of samples smaller than 10-mL can only be established within two significant figures of accuracy. Density measurements for this test plan require greater accuracy. Therefore, a more accurate method employing a pycnometer will be used. Impact on results: The change to a pycnometer will generate more precise results than the standard method. The main impact is expected to be on analysis time. The pycnometer method will be slower.

- The process for determining the wt\% UDS content of the slurries will in some cases be determined with the use of a moisture analyzer. In addition, the method of drying samples will be modified to allow the use of glass fiber filters to aid in drying the samples. Impact on results: Both modifications are intended to decrease the time required to obtain results.

\subsubsection{Analysis of CUF DACS Data}

The cold-CUF test system contains only a single 2-ft filter element. As such, process conditions such as $A V, T M P, A P D$, and $J$ are defined only for the single element. The filter flux is defined as:

$$
J=\frac{Q_{c}}{A}
$$

where $J$ is the filter flux (and is most comparable to $J_{\text {tot }}$ from the PEP calculations), $Q_{c}$ is the temperature-and TMP-corrected volumetric permeate flow rate, and $A$ is the filtration surface area. The filter area is calculated using:

$$
A=\pi D_{\text {inner }} L
$$

where $D_{\text {inner }}$ is the filter element inner diameter (0.5 inches), and $L$ is the filter element length (2 ft). The permeate volumetric flow rate and/or filter flux is corrected for deviations in 1) slurry temperature from the target test temperature (typically $25^{\circ} \mathrm{C}$ ) and 2) TMP from the target TMP (typically 40 psid) using

$$
\begin{gathered}
Q_{t}=Q_{p} \exp \left[2500\left(\frac{1}{T+273}-\frac{1}{298}\right)\right] \\
Q_{c}=\left[\frac{T M P_{t}}{T M P}\right] \cdot Q_{t}
\end{gathered}
$$

Here $Q_{p}$ is the uncorrected permeate volumetric flow rate (provided directly by the CUF DACS). The TMP is calculated using 


$$
T M P=\frac{\left(P_{\text {inlet }}+P_{\text {outlet }}\right)}{2}-P_{\text {permeate }}
$$

where $P_{\text {inlet }}$ is the pressure at the filter inlet, $P_{\text {outlet }}$ is the pressure at the filter outlet, and $P_{\text {permeate }}$ is the pressure at the permeate side of the filter. APD is defined as the pressure difference along the axis of the filter element and is calculated by subtracting $P_{\text {outlet }}$ from $P_{\text {inlet }}$ and dividing by the length of the filter element to give a value in units of $\mathrm{psid} / \mathrm{ft}$.

Equation 3.4 should only be applied in cases where TMP deviation is persistent and not simply a result of process or measurement noise. Therefore, measurements are averaged over 1-minute intervals (24 samples/minute) to damp out random process variation and measurement noise.

The AV inside the filter is calculated by dividing the volumetric slurry flow of the filter by the cross section area of the inside diameter of the filter:

$$
A V=\frac{Q_{s}}{\frac{\pi}{4} D_{\text {inner }}^{2}}
$$

where $Q_{s}$ is the volumetric slurry flow rate in the axial direction.

\subsubsection{Analysis of Dewatering Curves}

Overall filter behavior may be modeled by the Darcy equation, which describes filter flux as:

$$
J=\frac{\Delta P_{m}}{\mu_{\text {permeate }} R}
$$

where $\Delta P_{m}$ is the pressure drop across filter membrane (or TMP), $\mu_{\text {permeate }}$ is the viscosity of the permeate, and $R$ is the overall resistance of the filter membrane to permeation. The overall filter resistance term is a sum of the resistance of the actual filter, the resistance of the filter cake that forms on the surface of the filter, and the resistance due to fouling of the filter.

The dependence of the overall filter resistance on slurry solids concentration is key for assessing the dewatering behavior of the slurry. A typical dependence observed during dewatering operation of Hanford tank waste simulants is shown in Figure 3.7. For dilute slurries and when turbulent flow conditions exist, the filter resistance is usually constant and characterized by the resistance of the porous filter element $\left(R_{m}\right)$ such that,

$$
J \sim \frac{\Delta P_{m}}{\mu_{\text {permeate }} R_{m}}
$$

For filtration in this regime, the TMP and permeate viscosity are the controlling operational parameters. 
At the higher slurry solids concentrations that occur during dewatering operations, the filter cake resistance plays a more significant role in determining filter flux. The filter cake resistance is dependent on system operational properties like AV. The treatment of filtration data against the Darcy equation is complicated by the need to account for the dependence of filter cake resistance on AV and slurry concentration. Ultimately, the slurry can only be dewatered to a maximum UDS concentration limit at a given TMP. This limiting concentration is known as the gel concentration and is typically similar to the slurry's centrifuged solids concentration. As the slurry's solid concentration approaches the gel concentration, the filter flux can be described as

$$
J=k \cdot \ln \left[\frac{C_{s}}{C_{g}}\right]
$$

where $C_{s}$ is the slurry UDS concentration, $C_{g}$ is the slurry gel concentration at a given TMP, and $k$ is a constant for a given TMP and AV (note that $\mathrm{k}$ is a negative value and is typically termed the "mass transfer coefficient”).

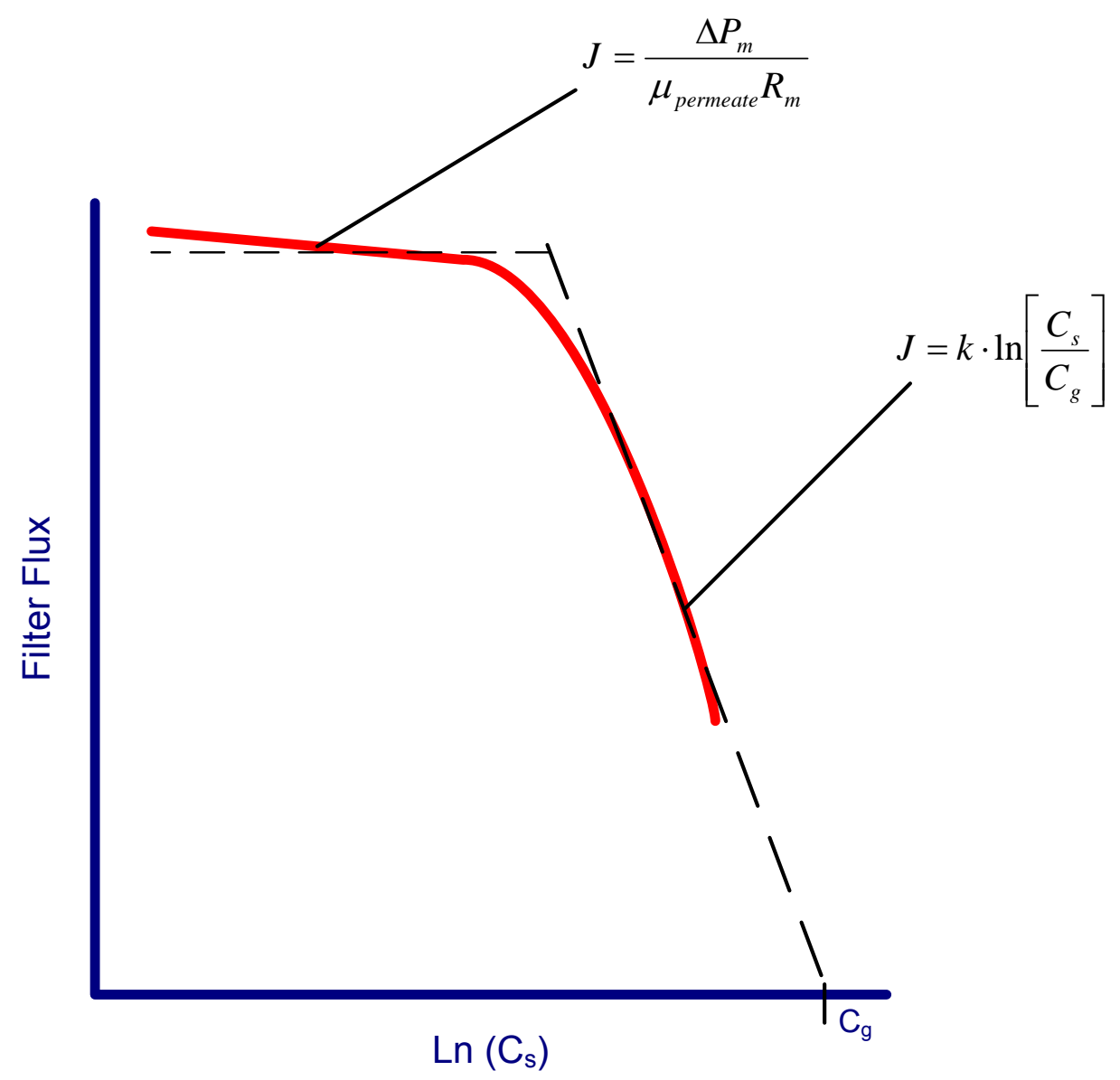

Figure 3.7. Typical Filter Flux Behavior as a Function of Solids Concentration 
Dewatering operations effect a change in the slurry UDS concentrations by removing permeate from the slurry. Unlike continuous recycle filtration, the collected permeate is not returned to the slurry reservoir. Because the cold-CUF measures the rate of permeate production, it is possible given the known starting mass and concentration of circulating slurry to estimate the UDS as a function of time. The circulating slurry is defined as that contained in the slurry reservoir (i.e., mixing tank) and filtration loop. If filtration is assessed at several equally spaced time intervals $(\Delta t)$, then for a given time step $n$, the slurry UDS concentration $\mathrm{x}(\mathrm{n})$ can be determined using:

$$
x(n)=\frac{m_{U D S}}{m_{T}(n)}
$$

Here, $m_{U D S}$ is the mass of UDS, and $m_{T}(n)$ is the total mass of circulating slurry remaining in the filter loop at time interval $n$. Filtration is assumed 1 ) to retain all slurry solids, and 2) proceed with no dissolution of slurry solids such that:

$$
m_{U D S}=x_{o} m_{T, o}
$$

where $\mathrm{x}_{\mathrm{o}}$ and $\mathrm{m}_{\mathrm{T}, \mathrm{o}}$ are the initial UDS concentration and mass of the circulating slurry (and are given process parameters). The mass of circulating slurry at time interval $n$ is given by:

$$
m_{T}(n)=m_{T}(n-1)-G(n) \cdot \Delta t
$$

Here $G(n)$ is the mass flow rate of permeate and is determined by the permeate volumetric flow rate $(Q)$ and measured permeate density $\left(\rho_{p}\right)$ using

$$
G(n)=\rho_{p}(n) \cdot Q(n)
$$

The circulating slurry mass may also be expressed in terms of the original slurry mass using,

$$
m_{T}(n)=m_{T, o}-\Delta t \cdot \sum_{j=1}^{n} G(j)
$$

Thus, the slurry UDS concentration at time interval $n$ may be expressed in terms of the previous permeate mass flow rates:

$$
x(n)=\frac{x_{o} m_{T, o}}{m_{T, o}-\Delta t \cdot \sum_{j=1}^{n} G(j)}
$$





\subsection{Results and Discussion}

In the following sections, the filtration tests and waste simulant slurry properties are described in detail. Bench-scale testing was conducted using simulant slurries and process solutions received from PEP that were withdrawn during parallel steps in the PEP testing sequence. Specific information about the simulant slurry used for each test, such as during which step of which test at PEP the slurry was collected, can be found in the applicable results section (e.g., low-solids conditioning, high-solids dewatering). Each section contains results and discussion for related tests and comparison between tests. The order of presentation is:

1. Low-Solids Filter Conditioning Tests.

2. Low-Solids Dewatering Tests.

3. High-Solids Dewatering Tests.

4. Oxalate Dissolution Testing.

5. Filter Cleaning and Clean Water Flux Testing.

\subsection{Low-Solids Filter Conditioning Tests \#1 and \#2}

Two separate low-solids filter conditioning tests were performed using simulant slurry from PEP in the cold-CUF filtration system in APEL. The 36-hour filter conditioning test included three 12-hour segments: steady-state operation, periodic backpulsing, and steady-state operation. The testing proceeded according to these general steps:

1. Load low-solids PEP simulant slurry into the cold-CUF slurry reservoir.

2. Operate the cold-CUF in recycle mode at target conditions of TMP $=40 \pm 5$ psid and $\mathrm{AV}=15 \pm 1 \mathrm{ft} / \mathrm{sec}$ for 12 hours.

3. Operate the cold-CUF in recycle mode at target conditions of TMP $=40 \pm 5$ psid and $\mathrm{AV}=15 \pm 1 \mathrm{ft} / \mathrm{sec}$ and perform a single backpulse every 30 minutes for 12 hours.

4. Operate the cold-CUF in recycle mode at target conditions of TMP $=40 \pm 5$ psid and $\mathrm{AV}=15 \pm 1 \mathrm{ft} / \mathrm{sec}$ for 12 hours.

Before each filter conditioning test, the cold-CUF was cleaned with oxalic acid, and a clean water flux of $>1.5 \mathrm{GPM} / \mathrm{ft}^{2}$ was measured. The filter conditioning history and cleaning steps may be found in Table 4.14 in Section 4.5. All tests were performed at a target reservoir temperature of $25 \pm 5^{\circ} \mathrm{C}$. Permeate flow values were corrected for temperature to $25^{\circ} \mathrm{C}$ and for TMP to 40 psid and were then converted to flux values. These results are used in the development of scaling factors in WTP-RPT-185 (Daniel et al. 2009b).

\subsubsection{Results for Low-Solids Filter Conditioning Tests}

Upon receipt of each simulant sample from PEP, the simulant was loaded into the cold-CUF, and the conditioning commenced according to the steps above. Both simulant samples for the low-solids conditioning tests came from Shakedown/Functional Testing at PEP and were withdrawn immediately before the 36-hour low-solids conditioning tests after the permeate lines had been filled. The low-solids conditioning test was performed twice during Shakedown/Functional Testing at PEP, once in late 
November 2008 and once in December 2008. Both samples were withdrawn from UFP-VSL-T02A using the Coriolis densitometer middle-low port, although the sample from Test \#1 was initially planned to be taken from the filtration loop in-line sample collection port. Table 4.1 contains a summary of various test conditions, and Table 4.2 contains physical property data for the low-solids simulants used in each test.

Table 4.1. Test Conditions and Operational Parameters for Low-Solids Conditioning Tests

\begin{tabular}{lcc}
\hline Parameter & Test \#1 & Test \#2 \\
\hline Sample ID & S 000FL 008 XX 0250 CUF 4 & S 02AML 008 XX 0868 CUF 4 \\
PEP Test ID & Shakedown/Functional & Shakedown/Functional \\
Mass and volume of slurry added & $5.805 \mathrm{~kg}$ & $5.278 \mathrm{~kg}$ \\
to reservoir & $4.6 \mathrm{~L}$ & $4.1 \mathrm{~L}$ \\
Process start time & $12 / 02 / 2008$ 06:52 PST & $01 / 05 / 2009$ 07:48 PST \\
Process end time & $12 / 03 / 200819: 00 \mathrm{PST}$ & $01 / 06 / 200920: 01 \mathrm{PST}$ \\
Elapsed time (duration) & $36.12 \mathrm{hours}$ & $36.22 \mathrm{hours}$ \\
Transmembrane Pressure & $40.2 \pm 0.8 \mathrm{psid}$ & $40.2 \pm 0.4 \mathrm{psid}$ \\
Axial Velocity & $14.9 \pm 0.1 \mathrm{ft} / \mathrm{sec}$ & $15.0 \pm 0.2 \mathrm{ft} / \mathrm{sec}$ \\
Slurry Reservoir Temperature & $24.6 \pm 0.6^{\circ} \mathrm{C}$ & $25.0 \pm 0.2^{\circ} \mathrm{C}$
\end{tabular}

Table 4.2. Physical Properties of Simulant for Low-Solids Conditioning Tests

\begin{tabular}{lccl}
\hline & Measured Value & \\
Property & Test \#1 & Test \#2 & Units \\
\hline Rheology & & & \\
Bingham Yield Stress & $0.052 \pm 0.005$ & $0.057 \pm 0.005$ & $\mathrm{~Pa}$ \\
Bingham Consistency & $4.32 \pm 0.03$ & $4.81 \pm 0.04$ & $\mathrm{mPa} \cdot \mathrm{s}$ \\
$\quad$ Permeate Viscosity & $2.51 \pm 0.05$ & $2.88 \pm 0.06$ & $\mathrm{mPa} \cdot \mathrm{s}$ \\
Density & & & \\
$\quad$ Slurry Bulk Density & $1.27 \pm 0.02$ & $1.28 \pm 0.02$ & $\mathrm{~kg} / \mathrm{L}$ \\
$\quad$ Permeate Density & $1.20 \pm 0.02$ & $1.22 \pm 0.02$ & $\mathrm{~kg} / \mathrm{L}$ \\
$\quad$ Coriolis Permeate Density & $1.21 \pm 0.00$ & $1.23 \pm 0.00$ & $\mathrm{~kg} / \mathrm{L}$ \\
Solids Concentrations & & & \\
Total Solids & $30.4 \pm 0.5$ & $32.1 \pm 0.5$ & $\mathrm{wt} \%$ \\
$\quad$ Undissolved Solids & $6.9 \pm 0.1$ & $6.9 \pm 0.1$ & $\mathrm{wt} \%$ \\
Dissolved Solids In Permeate & $25.4 \pm 0.4$ & $27.2 \pm 0.4$ & $\mathrm{wt} \%$ \\
Particle Size Distribution & & & \\
$\mathrm{d}_{10}$ & $1.3 \pm 0.1$ & $1.1 \pm 0.1$ & $\mu \mathrm{m}$ \\
$\mathrm{d}_{50}$ & $5.9 \pm 0.1$ & $5.6 \pm 0.1$ & $\mu \mathrm{m}$ \\
$\mathrm{d}_{90}$ & $18.4 \pm 0.1$ & $18.1 \pm 0.1$ & $\mu \mathrm{m}$ \\
\hline
\end{tabular}

Once the initial target conditions of TMP $=40 \pm 5$ psid and AV $=15 \pm 1 \mathrm{ft} / \mathrm{sec}$ were established for these tests, the filtration system required only minor adjustments in operational parameters during the completion of the three test segments. Small adjustments were made to the chiller set-point, the pump variable frequency drive (VFD) potentiometer, and the throttle valve. The system performance with respect to the target conditions for each test is shown in Figure 4.1 and Figure 4.2. The target conditions were maintained within the specified tolerances throughout both tests, with the exception of transient deviations in TMP and AV as a result of performing backpulsing. Such deviations are required by the process and do not reflect any irregular or unexpected behavior. Corrected filter flux over the course of the conditioning tests is shown in Figure 4.3. 
During the backpulsing segment, a single backpulse (70-mL typical volume) was delivered to the filter element over a duration of $\sim 5$ seconds (average reverse flux of $\sim 0.85 \mathrm{GPM} / \mathrm{ft}^{2}$ ). Detailed steps for delivering a backpulse are as follows:

1. At the close of the current 30-minute period, the permeate recycle valve was closed in preparation for backpulsing, marking the end of one period and the beginning of the next.

2. The toggle valve at the base of the backpulse chamber was opened to begin filling the backpulse chamber. After the chamber was filled to the mark at the center of the sight glass, the toggle valve was closed, the chamber was pressurized, and then the toggle valve was opened to deliver the backpulse. The toggle valve was closed when the liquid level reached the bottom of the sight glass.

3. Target filtration conditions were re-established, and then the permeate recycle valve was opened and the cold-CUF operated in recycle mode for the remainder of the 30-minute period.

Upon completion of the final 12-hour steady-state filtration segment of the filter conditioning test, preparations were made for adding additional slurry for the low-solids dewatering tests described in Section 4.2. A brief discussion of the results of the low-solids conditioning tests may be found in Section 4.1.2.

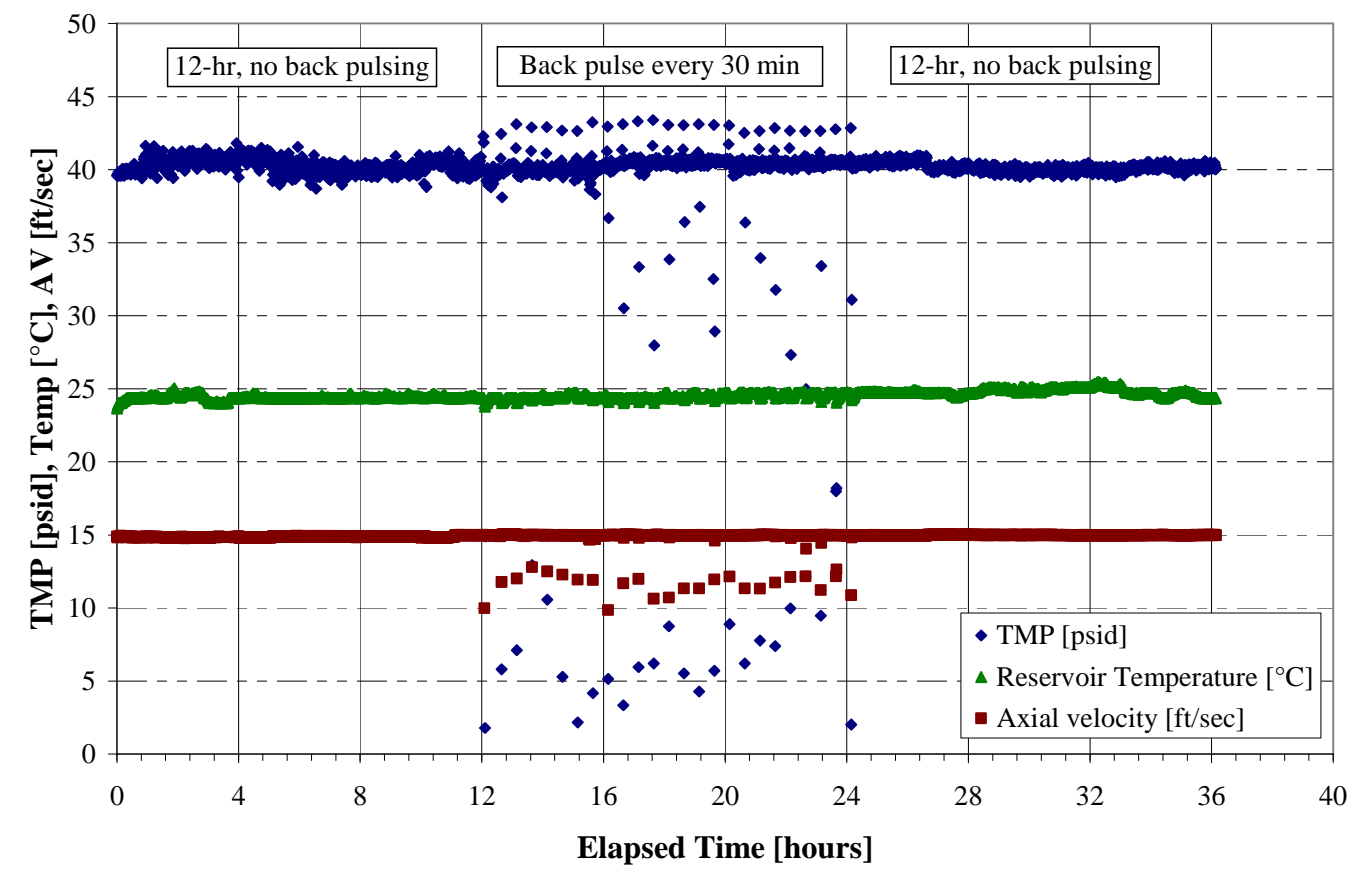

Figure 4.1. Process Performance Relative to Target Conditions for TMP ( $40 \pm 5 \mathrm{psid}), \mathrm{AV}(15 \pm 1 \mathrm{ft} / \mathrm{sec})$, and Reservoir Temperature $\left(25 \pm 5^{\circ} \mathrm{C}\right)$ for Low-Solids Filter Conditioning Test \#1 


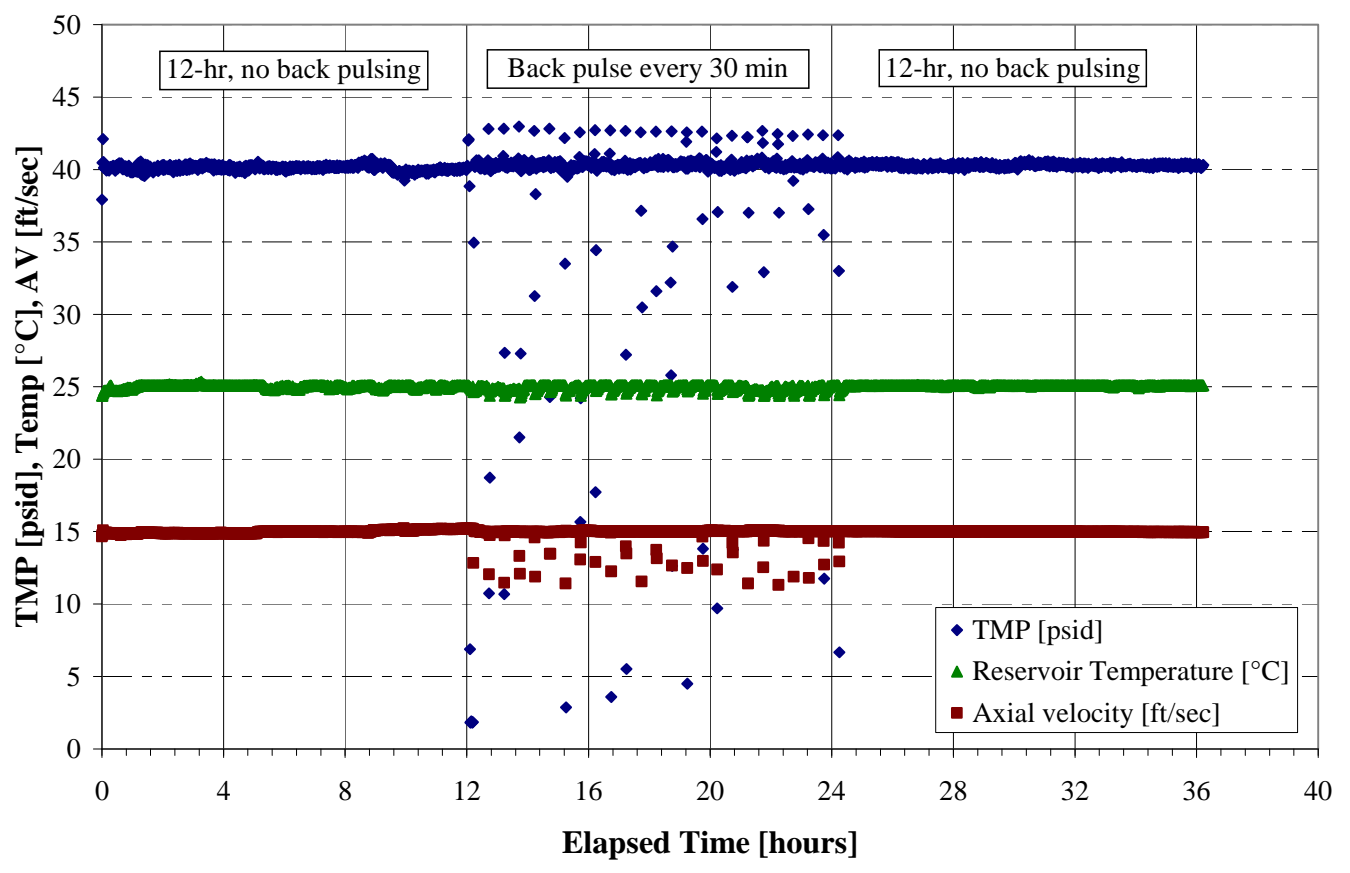

Figure 4.2. Process Performance Relative to Target Conditions for TMP ( $40 \pm 5 \mathrm{psid})$, AV ( $15 \pm 1 \mathrm{ft} / \mathrm{sec}$ ), and Reservoir Temperature $\left(25 \pm 5^{\circ} \mathrm{C}\right)$ for Low-Solids Filter Conditioning Test \#2

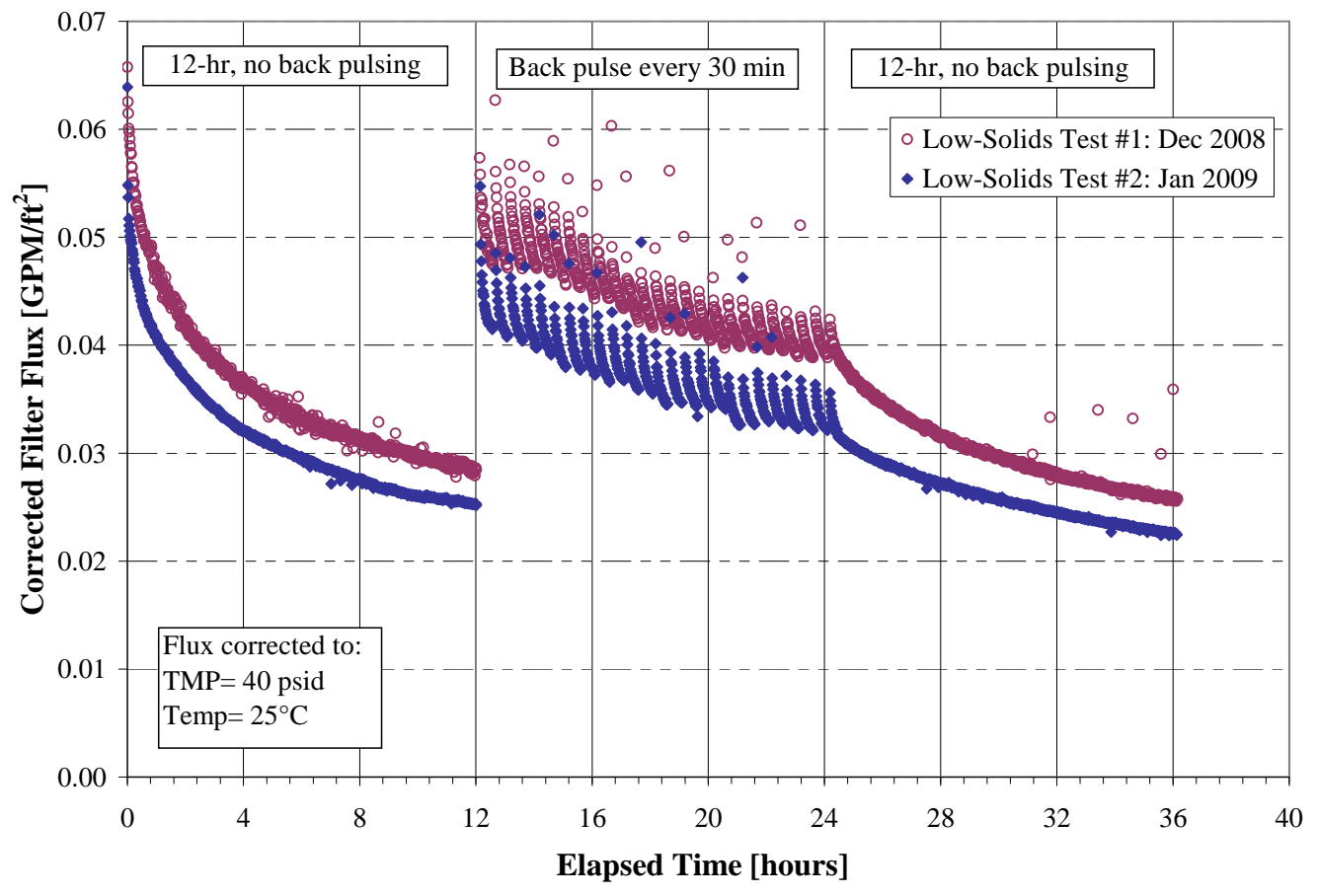

Figure 4.3. Comparison of the Corrected Filter Flux between the First and Second Low-Solids Filter Conditioning Tests 


\subsubsection{Discussion for Low-Solids Filter Conditioning Tests}

In Test \#1, the filter flux decreased during the filter conditioning test from initial values near $0.066 \mathrm{GPM} / \mathrm{ft}^{2}$ down to $0.026 \mathrm{GPM} / \mathrm{ft}^{2}$ by the end of the test. In Test \#2, the filter flux decreased from initial values near $0.055 \mathrm{GPM} / \mathrm{ft}^{2}$ down to $0.022 \mathrm{GPM} / \mathrm{ft}^{2}$. As shown in Figure 4.3, the filtration behavior between the two tests is consistent, with the filter flux in Test \#2 mirroring the flux of Test \#1, offset approximately $15 \%$ to $20 \%$ lower throughout the test. The difference is either attributable to differences between the two batches of pre-leached simulant employed or from differences in initial membrane resistance due to filter history. Further description and discussion concerning filter cleaning and potential impacts to testing can be found in Section 4.5.

Upon investigation of differences in physical properties between the two simulants (Table 4.2), it becomes clear that the permeate for Test \#2 is higher in density, dissolved solids, and viscosity than the permeate for Test \#1. The UDS are the same and the particle-size distributions are in agreement. At low solids concentrations, flux is inversely proportional to permeate viscosity as shown by Equation 3.7 (Section 3.3).

For the purpose of comparison, one may assume the TMP $\left(\Delta \mathrm{P}_{\mathrm{m}}\right)$ and membrane resistance to be constant between Test \#1 and Test \#2 and determine the ratio of expected flux as a ratio of permeate viscosity, represented as

$$
\frac{J_{1}}{J_{2}}=\frac{\mu_{\text {permeate }, 2}}{\mu_{\text {permeate }, 1}}=\frac{2.88 \mathrm{mPa} \mathrm{s}}{2.51 \mathrm{mPa} \mathrm{s}}=1.15
$$

where $J_{1}$ is the flux for Test \#1, and $J_{2}$ is the flux for Test \#2. The ratio of flux between Test \#1 and Test \#2 has been computed for each segment of the conditioning test, presented in Table 4.3 for comparison to the value of 1.15 predicted by the ratio of permeate viscosity. It appears that the difference in permeate flux between the two tests may be satisfactorily explained by the difference in permeate viscosity of the simulants used.

Table 4.3. Ratio of Permeate Flux Between Low-Solids Conditioning Tests

\begin{tabular}{lcc}
\hline Test Segment & Elapsed Time [hours] & Ratio of $\mathrm{J}_{1} / \mathrm{J}_{2}[\mathrm{Avg} \pm \mathrm{StDev}]$ \\
\hline 1. First 12-hour Continuous Test & 0.00 to 12.02 & $1.14 \pm 0.02$ \\
2. Backpulse Every 30 Minutes & 12.15 to 24.10 & $1.19 \pm 0.03$ \\
3. Second 12-hour Continuous Test & 24.18 to 36.13 & $1.16 \pm 0.03$ \\
Full 36-hour Test & 0.00 to 36.13 & $1.16 \pm 0.03$ \\
\hline
\end{tabular}

The rate of flux decrease during each segment of the test may be evaluated by considering both surface and depth-fouling components. During the first steady-state segment, the steep initial decrease may be defined by the rapid surface fouling of a clean membrane surface. Approximately 1 hour into the test, the continued decrease in flux is determined by further development of cake resistance and timedependent depth fouling.

During the backpulsing segment, up to $90 \%$ of the starting flux is restored by removal of surface fouling, but gains are rapidly lost due to particle re-deposition. The flux decline in any 30-minute 
backpulse step is almost exclusively the result of surface fouling, and the overall downward trend between successive backpulse steps is indicative of depth fouling, accelerated as the membrane surface is exposed to fine fouling particles after a backpulse that were excluded by the previous cake layer. Each refreshing of the membrane surface exposes the pores to particles capable of causing depth fouling while not substantially removing accumulated depth fouling. The final steady-state segment starts at the conditioning level of the back-pulsing segment and continues along the time-dependent, depth-fouling, filter-flux decay until the end of the test.

From this test sequence of limited duration, it appears that the flux continues to decrease with time and is asymptotically approaching a minimum filter flux for a given set of process conditions. To determine this value, future testing is recommended where the testing time is up to a factor of 10 longer. Extended testing was performed at PEP during the dewatering of post-caustic-leach batches from Integrated Test A, and tests up to 60 hours in length were performed using the cold-CUF during the bench-scale caustic-leach dewatering tests described in Section 4.4. In neither case was a minimum filter flux achieved at a given set of process conditions.

\subsection{Low-Solids Dewatering Tests \#1 and \#2}

Following each of the two low-solids conditioning tests, additional low-solids slurry was added to the reservoir, and the slurry was dewatered from a starting concentration of 6.9-wt\% UDS to a final concentration of greater than 30-wt\% UDS. No backpulsing, rinsing, or cleaning of the cold-CUF was performed before dewatering (see Table 4.14). The filter conditioning at the conclusion of the 36-hour conditioning test was the starting point for dewatering. The testing proceeded according to these general steps:

1. Add additional low-solids PEP simulant to the CUF slurry reservoir.

2. Operate the CUF system in dewatering mode at target conditions of TMP $=40 \pm 5$ psid and $\mathrm{AV}=15 \pm 1 \mathrm{ft} / \mathrm{sec}$, and dewater the slurry to approximately 20 -wt\% UDS or until the minimum system operating volume is reached.

3. Sample concentrated slurry.

4. Flush the CUF system with $0.01 \mathrm{M} \mathrm{NaOH}$ to clear solids from the system and lay the system up with a fresh charge of $0.01 \mathrm{M} \mathrm{NaOH}$.

\subsubsection{Results for Low-Solids Dewatering Tests}

Additional low-solids simulant from the PEP Shakedown/Functional Testing was added to the cold-CUF slurry reservoir to increase the volume for low-solids dewatering, and the dewatering proceeded according to the steps above. For Test \#1, the additional simulant was withdrawn from the filter loop at PEP between the 12-hour backpulsing segment and the final 12-hour steady-state segment of the low-solids conditioning test. For Test \#2, the additional simulant was withdrawn from UFP-VSL-T02A after the final 12-hour steady-state segment of the conditioning test using the Coriolis densitometer middle-low port. Table 4.4 contains a summary of various test conditions and Table 4.5 contains physical property data for the concentrated simulants following each dewatering test. The physical property data of the starting material may be found in Table 4.2 in the previous section. 
Table 4.4. Test Conditions and Operational Parameters for Low-Solids Dewatering Tests

\begin{tabular}{lcc}
\hline Parameter & Test \#1 & Test \#2 \\
\hline Sample ID of addition & S 000FL 009 XX 0328 CUF 4 & S 02AML 010 XX 0891 CUF 4 \\
PEP Test ID & Shakedown/Functional & Shakedown/Functional \\
Mass and volume of slurry added to & $17.905 \mathrm{~kg}$ & $19.064 \mathrm{~kg}$ \\
reservoir & $14.1 \mathrm{~L}$ & $14.9 \mathrm{~L}$ \\
Total CUF inventory & $23.710 \mathrm{~kg}$ & $24.342 \mathrm{~kg}$ \\
Mass and volume of permeate removed & $18.7 \mathrm{~L}$ & $19.0 \mathrm{~L}$ \\
during dewatering & $18.685 \mathrm{~kg}$ & $18.780 \mathrm{~kg}$ \\
Starting wt\% UDS & $15.7 \mathrm{~L}$ & $15.1 \mathrm{~L}$ \\
Wt\% UDS at Knee, calculated & $6.9 \pm 0.1 \%$ & $6.9 \pm 0.1 \%$ \\
Ending wt\% UDS, calculated & $23.1 \%$ & $22.7 \%$ \\
Ending wt\% UDS, measured & $34.8 \%$ & $31.1 \%$ \\
Process start time & $36.6 \pm 0.7 \%$ & $33.2 \pm 0.6 \%$ \\
Process end time & $12 / 03 / 200819: 26 \mathrm{PST}$ & $01 / 06 / 200920: 46 \mathrm{PST}$ \\
Time elapsed for dewatering step & $12 / 04 / 200803: 30$ PST & $01 / 07 / 200905: 28 \mathrm{PST}$ \\
Time elapsed at dewatering knee & 8.07 hours & 8.70 hours \\
Time elapsed to achieve 20 wt\% UDS & 6.52 hours & $7.33 \mathrm{hours}$ \\
\hline
\end{tabular}

The combined slurry was circulated in the slurry loop at target AV and pressure for 10 minutes to allow for complete mixing, and the slurry dewatering step began by opening the permeate flow valve, oriented into a clean, tared container for permeate collection. A permeate sample was collected directly from the permeate line during dewatering.

Few changes to the process controls were required during the initial several hours of the dewatering step, consisting of minor adjustments to the pump VFD, throttle valve, and chiller set point. As the slurry became increasingly concentrated, the chiller set point was incrementally lowered while the pump VFD was slightly decreased. While seeming to defy conventional fluid pumping models, less pumping power is required as the slurry concentration increases because of the improved pumping efficiency of the rotary lobe pump with higher-consistency, better-lubricating fluids.

The dewatering step proceeded until the process conditions could no longer be satisfactorily maintained. While the Test Plan specified dewatering to a target concentration of 20 -wt\% UDS, the dewatering proceeded past this target to the operating limit of the cold-CUF. The dewatering data past 20 -wt\% helped further define the dewatering curve. As shown in Figure 4.4 and Figure 4.5, using the concentrations and times in Table 4.4, the target conditions were maintained with no upsets to greater than 30-wt\% UDS, representing the upper limit of CUF operations with the given pre-leach simulant. Application of this information to PEP and PTF operations must take into account differences in pumps, heat exchangers, filter bundle configuration, vessel sizes, slurry and permeate loop volumes, and other variables (see Daniel et al. 2009b, Table 6.1, for a summary of differences between CUF and PEP). The operating limit the CUF system is often determined by circulating simulant volume, as concentrating by a factor of 3 or 4 in the given vessel leads to low tank levels and air entrainment.

At the conclusion of the dewatering step, with slurry loop pressure and flow greatly reduced, several samples of the concentrated slurry were withdrawn from a sample valve connected directly to the slurry flow loop. The sample line was purged with several sample leg volumes before collecting any samples. 
Table 4.5. Physical Properties of Concentrated Simulant Following Low-Solids Dewatering Tests

\begin{tabular}{|c|c|c|c|}
\hline \multirow[b]{2}{*}{ Property } & \multicolumn{2}{|c|}{ Measured Value } & \multirow[b]{2}{*}{ Units } \\
\hline & Test \#1 & Test \#2 & \\
\hline \multicolumn{4}{|l|}{ Rheology } \\
\hline Bingham Yield Stress & $15.3 \pm 0.3$ & $12.4 \pm 0.2$ & $\mathrm{~Pa}$ \\
\hline Bingham Consistency & $17.0 \pm 0.4$ & $16.6 \pm 0.5$ & $\mathrm{mPa} \cdot \mathrm{s}$ \\
\hline Permeate Viscosity ${ }^{(\mathrm{a})}$ & $2.51 \pm 0.05$ & $2.88 \pm 0.06$ & $\mathrm{mPa} \cdot \mathrm{s}$ \\
\hline \multicolumn{4}{|l|}{ Density } \\
\hline Slurry Bulk Density & $1.54 \pm 0.03$ & $1.51 \pm 0.06$ & $\mathrm{~kg} / \mathrm{L}$ \\
\hline Permeate Density & $1.19 \pm 0.02$ & $1.24 \pm 0.02$ & $\mathrm{~kg} / \mathrm{L}$ \\
\hline Coriolis Permeate Density & $1.22 \pm 0.00$ & $1.23 \pm 0.00$ & $\mathrm{~kg} / \mathrm{L}$ \\
\hline \multicolumn{4}{|l|}{ Solids Concentrations } \\
\hline Total Solids & $52.4 \pm 1.0$ & $51.1 \pm 1.0$ & wt $\%$ \\
\hline Undissolved Solids & $36.6 \pm 0.7$ & $33.2 \pm 0.6$ & wt $\%$ \\
\hline Dissolved Solids In Permeate & $25.1 \pm 0.5$ & $26.9 \pm 0.5$ & wt $\%$ \\
\hline \multicolumn{4}{|l|}{ Particle Size Distribution } \\
\hline $\mathrm{d}_{10}$ & $0.9 \pm 0.1$ & $0.9 \pm 0.1$ & $\mu \mathrm{m}$ \\
\hline$d_{50}$ & $4.4 \pm 0.1$ & $4.1 \pm 0.1$ & $\mu \mathrm{m}$ \\
\hline $\mathrm{d}_{90}$ & $15.2 \pm 0.1$ & $14.4 \pm 0.1$ & $\mu \mathrm{m}$ \\
\hline
\end{tabular}

The concentrated slurry was drained from the system after the sample was collected, and all components of the slurry loop and permeate piping were flushed with four sequential 4-L rinses of $0.01 \mathrm{M}$ $\mathrm{NaOH}$. The rinse solution was repetitively backpulsed to remove solid particles from the system. Physical cleaning of the tank with a brush and scour pad was performed, and the system was laid up with 4-L of $0.01 \mathrm{M} \mathrm{NaOH}$.

Results from the two dewatering tests are presented in the following five figures. Figure 4.4 and Figure 4.5 display the process performance of the CUF system during Low-Solids Dewatering Tests \#1 and \#2, respectively. The TMP, AV, and reservoir temperature were successfully maintained at the target operating conditions and within the tolerances specified for these tests (TMP $=40 \pm 5$ psid, $\mathrm{AV}=15 \pm 1 \mathrm{ft} / \mathrm{sec}$, and Temp $=25 \pm 5^{\circ} \mathrm{C}$ ). The individual dewatering curves are shown in Figure 4.6 and Figure 4.7, and a comparison between the tests is given in Figure 4.8. A discussion of the results follows the charts. 


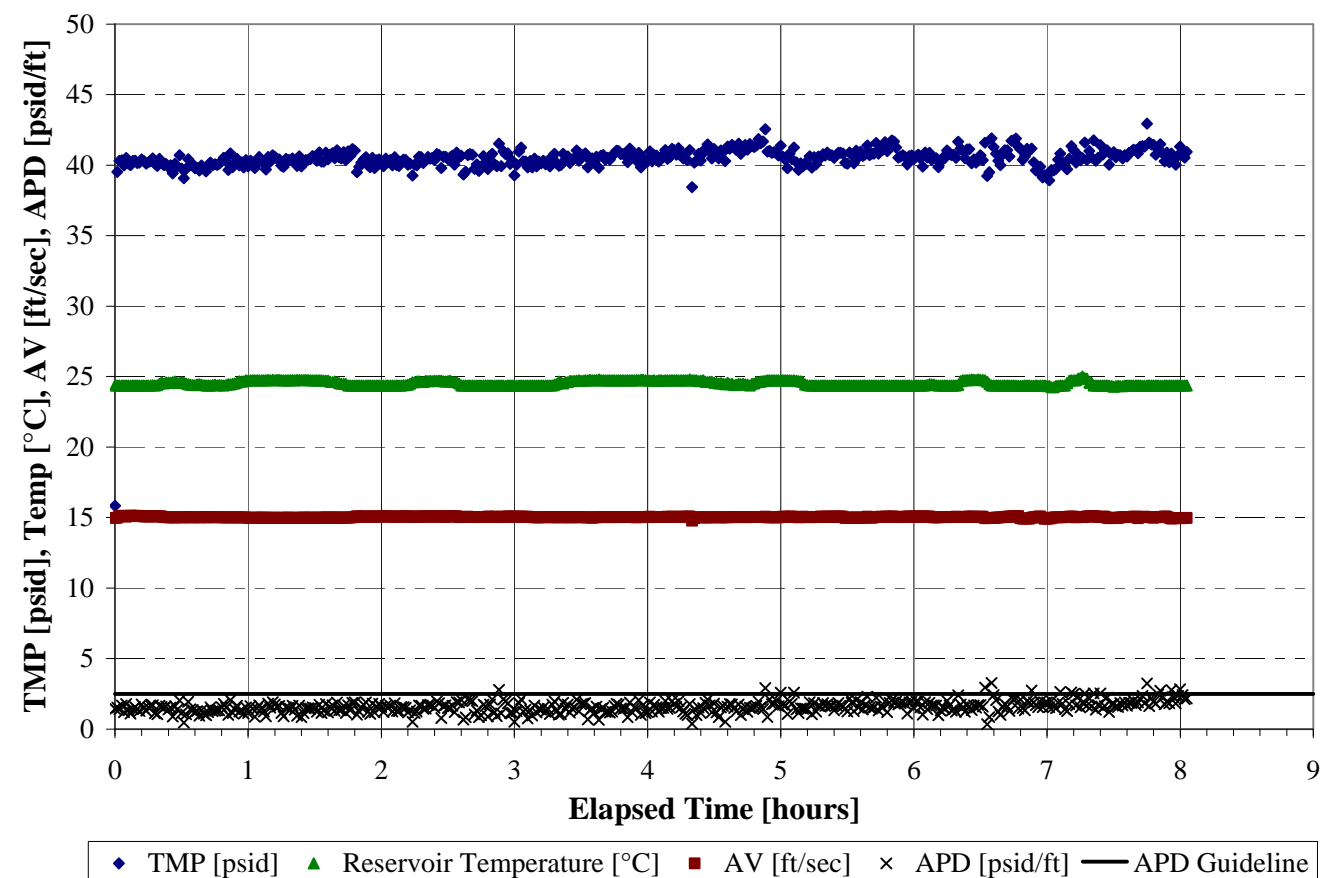

Figure 4.4. Process Performance Relative to Target Conditions for TMP ( $40 \pm 5$ psid), AV ( $15 \pm 1 \mathrm{ft} / \mathrm{sec}$ ), Reservoir Temperature $\left(25 \pm 5^{\circ} \mathrm{C}\right)$, and APD $(<2.5 \mathrm{psid} / \mathrm{ft})$ for the Low-Solids Dewatering Test \#1

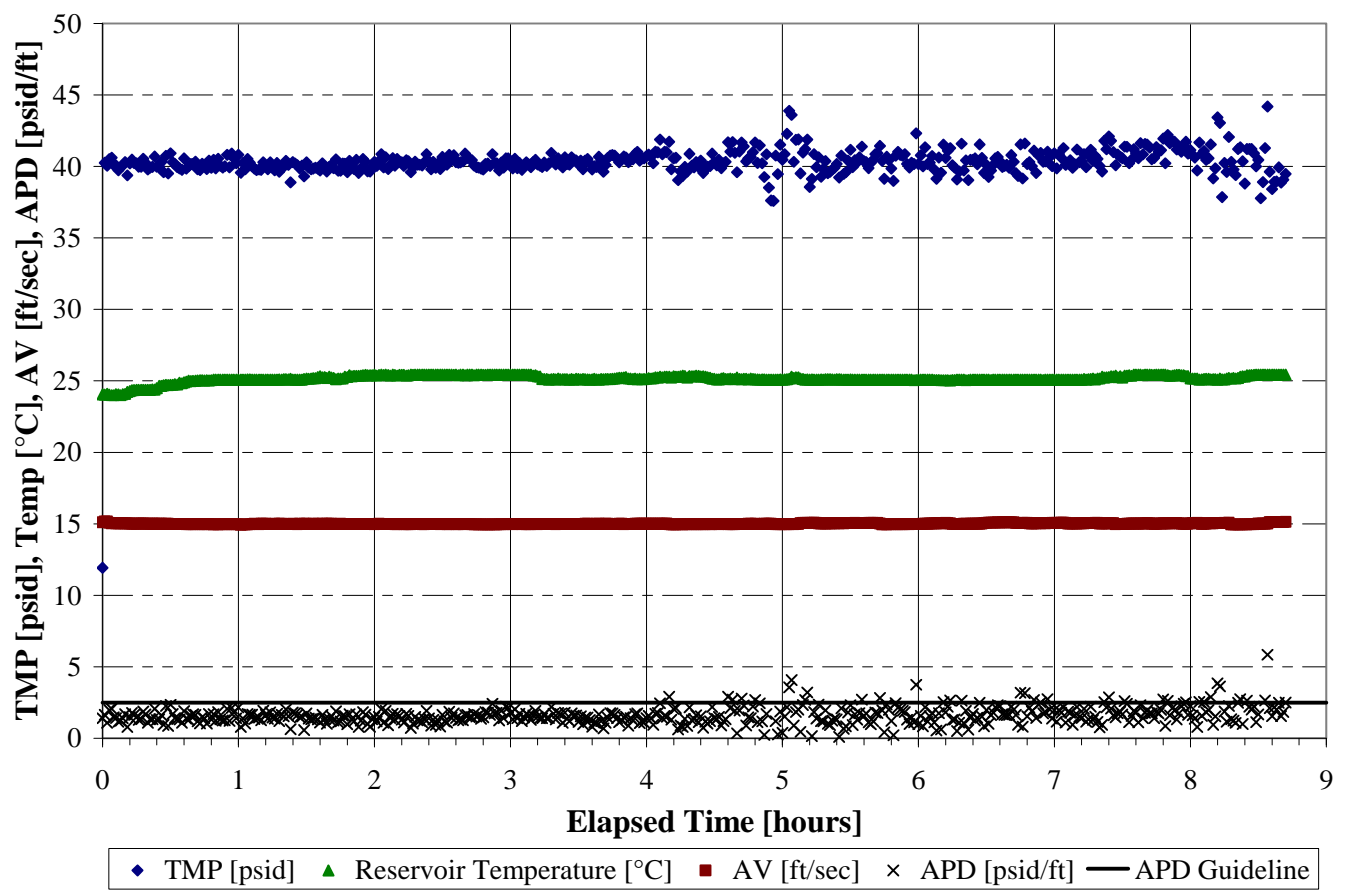

Figure 4.5. Process Performance Relative to Target Conditions for TMP ( $40 \pm 5 \mathrm{psid})$, AV ( $15 \pm 1 \mathrm{ft} / \mathrm{sec}$ ), Reservoir Temperature $\left(25 \pm 5^{\circ} \mathrm{C}\right)$, and APD $(<2.5 \mathrm{psid} / \mathrm{ft})$ for the Low-Solids Dewatering Test \#2 


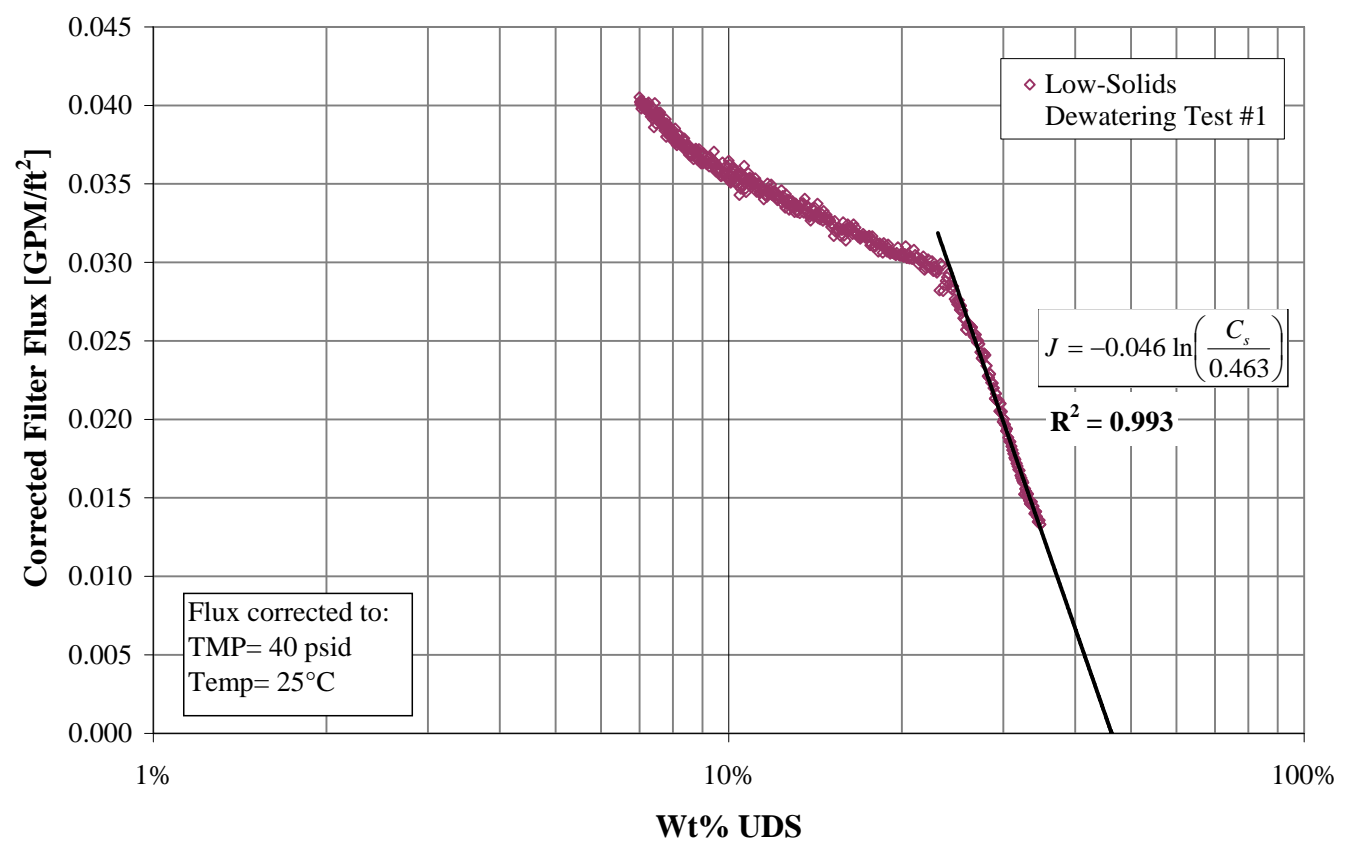

Figure 4.6. Filter Flux as a Function of UDS Concentration on a Semi-Log Plot for Low-Solids Dewatering Test \#1. Extrapolation of curve predicts a gel concentration of 46.3-wt\% UDS

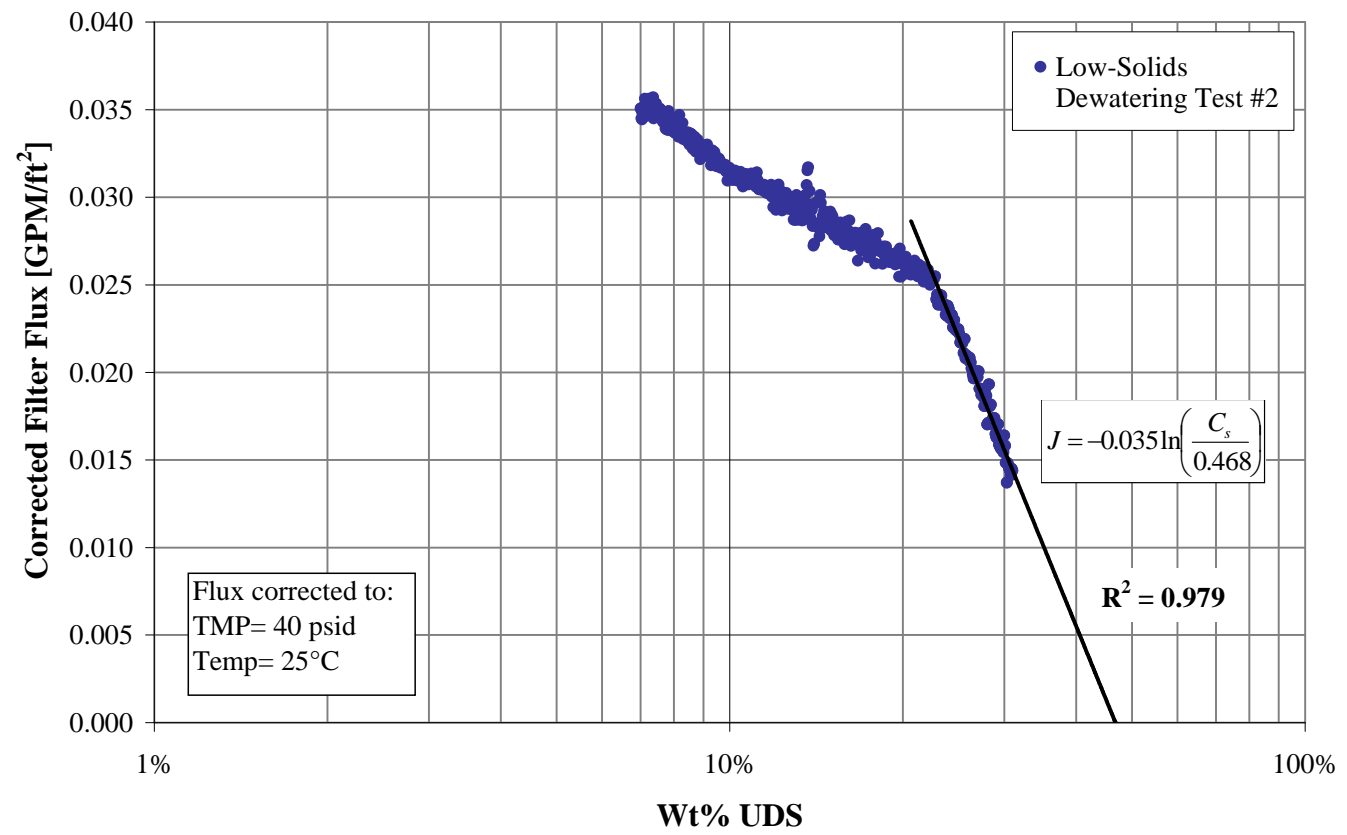

Figure 4.7. Filter Flux as a Function of UDS Concentration on a Semi-Log Plot for Low-Solids Dewatering Test \#2. Extrapolation of curve predicts a gel concentration of 46.8-wt\% UDS 


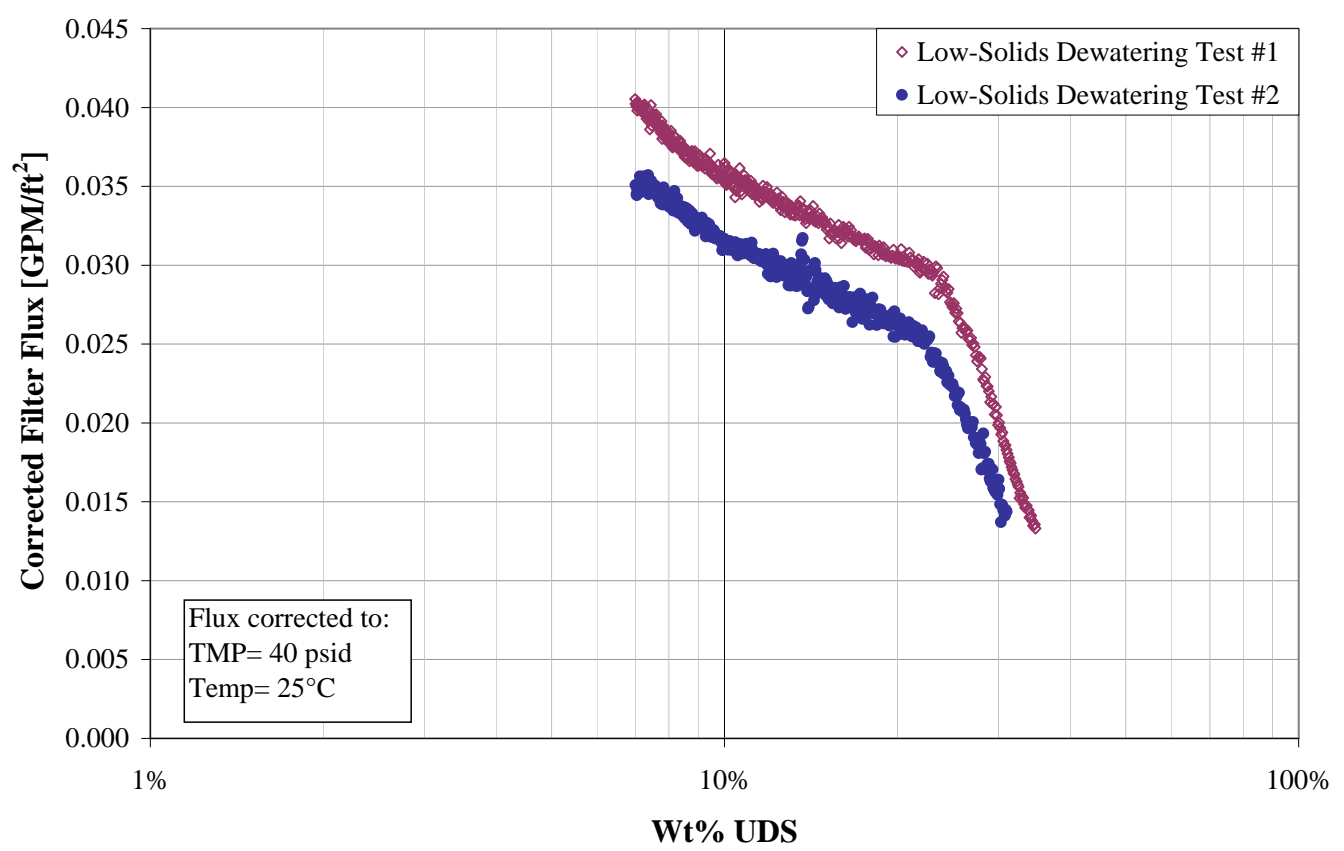

Figure 4.8. Comparison of Low-Solids Dewatering Test \#2 to Test \#1. Both tests employed pre-leached simulant with a starting UDS concentration of approximately 7-wt \%

\subsubsection{Discussion for Low-Solids Dewatering}

From Figure 4.6 and Figure 4.7, it can be seen that the transition from membrane-resistance controlled filtration to cake-resistance controlled filtration, or knee, occurs near 23-wt\% UDS for both dewatering tests (see Table 4.4). The decline in flux in the concentration range of 6.9 to 23 -wt $\%$ UDS can be characterized primarily as a function of increasing concentration and continued depth fouling. The effect of surface fouling is not significant as the surface fouling generated during the previous conditioning test was not backpulsed from the element before dewatering.

From 23-wt\% UDS to the end of dewatering, the decline in flux proceeds according to a concentration polarization model, exhibiting a logarithmic decay to a limiting gel concentration (see Section 3.3.4). Regression of the slope confirms the expected logarithmic decay relationship with high correlation factors $\left(\mathrm{R}^{2}=0.993\right.$ and 0.979$)$. Extrapolated to the point where the curve would intersect the $\mathrm{X}$-axis $(\mathrm{J}=0)$, the limiting gel concentration is calculated to be 46.3 -wt $\%$ UDS for Test \#1 and 46.8-wt\% UDS for Test \#2.

In earlier simulant studies, the limiting gel concentration at a given TMP was independently calculated using the compaction pressure exerted on samples during centrifugation under established conditions; however, due to variation in sample handling and centrifugation at SWRI, calculations of this type did not consistently produce reasonable estimates of the limiting gel concentration for these tests. The results of such calculations are not included. What is noteworthy is that the two low-solids simulant samples tested over a month apart were observed to predict a knee in the dewatering curve and a limiting gel concentration in close agreement, despite small differences in the suspending phase. 
Comparing the dewatering curves of the two tests (Figure 4.8), the flux for Test \#2 is consistently lower than Test \#1. Over the first 3 hours of dewatering, the average ratio of $J_{1}$ to $J_{2}$ is $1.12 \pm 0.02$, as compared to the flux ratio of 1.15 based on the inverse ratio of permeate viscosity (Equation 4.2). Based on the discussion in the previous section, the difference in permeate flux may be explained by the difference in the permeate viscosity of the simulants.

\subsection{High-Solids Dewatering Tests \#1 and \#2}

Two high-solids filtration tests were performed with the cold-CUF, the first in January 2009, and the second in March 2009. High-Solids Dewatering Test \#2 was the basis of comparison for PEP to CUF scaling. For both tests, a simulant slurry of leached, washed solids delivered from PEP was dewatered from the starting concentration to the maximum concentration achievable within the specified operating conditions. After the initial dewatering, several additional tests were performed by adding the permeate back to the system and dewatering at different AVs according to the following general steps:

1. Load leached, washed solids slurry from PEP into the CUF slurry reservoir. Sample initial slurry in triplicate.

2. Operate the cold-CUF in dewatering mode at TMP $=40 \pm 5$ psid and AV $=15 \pm 1 \mathrm{ft} / \mathrm{sec}$ and dewater the slurry to $>20$-wt $\%$ UDS or until operating conditions are not sustainable, either due to high APD and/or inability to maintain reservoir temperature.

3. Sample concentrated slurry in triplicate.

4. Return all permeate to the slurry reservoir, mix, and operate the cold-CUF system in dewatering mode at TMP $=40 \pm 5$ psid and AV $=13 \pm 1 \mathrm{ft} / \mathrm{sec}$, and dewater the slurry to $>20$-wt\% UDS or until operating conditions are not sustainable.

5. Return all permeate to the slurry reservoir, mix, and operate the cold-CUF system in dewatering mode at TMP $=40 \pm 5$ psid and AV $=17 \pm 1 \mathrm{ft} / \mathrm{sec}$, and dewater the slurry to $>20$-wt $\%$ UDS or until operating conditions are not sustainable.

6. Return all permeate to the slurry reservoir, mix, and operate the cold-CUF system in dewatering mode at TMP $=40 \pm 5$ psid and AV $=15 \pm 1 \mathrm{ft} / \mathrm{sec}$ and dewater the slurry to $>20$-wt\% UDS or until operating conditions are not sustainable. This is a repeat of the first dewatering test.

7. Sample concentrated slurry and permeate.

In High-Solids Dewatering Test \#1, the repeat dewatering at AV = $15 \mathrm{ft} / \mathrm{sec}$ (Step 6) was not performed. The cold-CUF was drained and rinsed of the previous simulant with $0.01 \mathrm{M} \mathrm{NaOH}$ before the high-solids dewatering tests (see Table 4.14), but no oxalic acid cleaning was performed. All tests were performed at a target reservoir temperature of $25 \pm 5^{\circ} \mathrm{C}$. Permeate flow values were corrected for temperatures to $25^{\circ} \mathrm{C}$, converted to flux values, and corrected to TMP $=40$ psid. Testing at various AVs was not required by the test plan, but was later added as a first-order investigation into the effect of AV over the range of slurry concentrations available in the dewatering step. This information augments data gained from previous TMP/AV matrix testing of High Level Wastes and waste simulants using a CUF system (e.g., Daniel et al. 2009a, Russell et al. 2009b, Shimskey et al. 2009).

\subsubsection{Results for High-Solids Dewatering Tests}

Each of the individual dewatering steps listed above was performed as described by the general steps above. Before starting to dewater the slurry, the slurry was recirculated at the target test conditions with 
the permeate valve closed for a period of 10 minutes to confirm proper mixing. The beginning of the test was marked by the opening of the permeate valve. The permeate was collected in a clean, tared container. At the end of the first dewatering step, slurry samples were collected, and the collected permeate was returned to the slurry reservoir to reconstitute the slurry for the next dewatering step. For the middle dewatering step(s) in a sequence, no concentrated slurry sample was collected. A complete description of the masses of simulant added and permeate collected as well as related process parameters for the high-solids dewatering tests can be found in Table 4.6 and Table 4.7.

Table 4.6. Operational Parameters for High-Solids Dewatering Test \#1

\begin{tabular}{lccc}
\hline Parameter & AV = 15 ft/sec & AV = 13 ft/sec & AV = 17 ft/sec \\
\hline Sample ID & \multicolumn{2}{c}{ S 02AML 029 XX 1000 CUF 4 } \\
PEP Test ID & \multicolumn{3}{c}{ Shakedown/Functional } \\
Total mass and volume of slurry in CUF system & $24.266 \mathrm{~kg}$ & $24.061 \mathrm{~kg}$ & $23.927 \mathrm{~kg}$ \\
& $23.1 \mathrm{~L}$ & $22.9 \mathrm{~L}$ & $22.8 \mathrm{~L}$ \\
& $18.005 \mathrm{~kg}$ & $17.360 \mathrm{~kg}$ & $18.498 \mathrm{~kg}$ \\
Mass and volume of permeate removed during & $17.8 \mathrm{~L}$ & $17.2 \mathrm{~L}$ & $18.3 \mathrm{~L}$ \\
dewatering & $6.9 \pm 0.1 \%$ & No sample & No sample \\
Starting wt\% UDS, measured & $\mathrm{N} / \mathrm{A}$ & $6.8 \%$ & $6.7 \%$ \\
Starting wt\% UDS, calculated & $20.1 \%$ & $19.3 \%$ & $22.1 \%$ \\
Wt\% UDS at knee, calculated & $27.1 \%$ & $24.6 \%$ & $29.8 \%$ \\
Ending wt\% UDS, calculated & $33.0 \pm 0.5 \%$ & No sample & $35.2 \%$ \\
Ending wt\% UDS, measured & $1 / 14 / 200911: 45$ & $1 / 15 / 200910: 14$ & $1 / 16 / 200909: 30$ \\
Start of dewatering (PST) & $1 / 14 / 200917: 08$ & $1 / 15 / 200915: 53$ & $1 / 16 / 200914: 36$ \\
End of dewatering (PST) & 5.38 hours & 5.65 hours & 5.10 hours \\
Time elapsed for dewatering step & 4.12 hours & 4.65 hours & 4.15 hours \\
Time elapsed at dewatering knee & 4.12 hours & 4.78 hours & 3.92 hours \\
Time elapsed to achieve 20 wt\% UDS & \multicolumn{3}{c}{} \\
\hline
\end{tabular}

Table 4.7. Operational Parameters for High-Solids Dewatering Test \#2

\begin{tabular}{|c|c|c|c|c|}
\hline Parameter & $\mathrm{AV}=15 \mathrm{ft} / \mathrm{sec}$ & $\begin{array}{c}\mathrm{AV}=13 \\
\mathrm{ft} / \mathrm{sec}\end{array}$ & $\begin{array}{c}\mathrm{AV}=17 \\
\mathrm{ft} / \mathrm{sec}\end{array}$ & $\begin{array}{c}\mathrm{AV}=15 \mathrm{ft} / \mathrm{sec} \\
\text { repeat }\end{array}$ \\
\hline Sample ID & \multicolumn{4}{|c|}{ A 02AML 022 XX 2467 CUF 4} \\
\hline PEP Test ID & \multicolumn{4}{|c|}{ Integrated Tests A \& B } \\
\hline Total mass and volume of slurry in CUF & $\begin{array}{l}25.005 \mathrm{~kg} \\
22.3 \mathrm{~L}\end{array}$ & $\begin{array}{l}24.704 \mathrm{~kg} \\
22.1 \mathrm{~L}\end{array}$ & $\begin{array}{l}24.704 \mathrm{~kg} \\
22.1 \mathrm{~L}\end{array}$ & $\begin{array}{l}24.709 \mathrm{~kg} \\
22.1 \mathrm{~L}\end{array}$ \\
\hline $\begin{array}{l}\text { Mass and volume of permeate removed } \\
\text { during dewatering }\end{array}$ & $\begin{array}{l}11.880 \mathrm{~kg} \\
11.9 \mathrm{~L}\end{array}$ & $\begin{array}{l}12.240 \mathrm{~kg} \\
12.2 \mathrm{~L}\end{array}$ & $\begin{array}{l}12.010 \mathrm{~kg} \\
12.0 \mathrm{~L}\end{array}$ & $\begin{array}{l}13.155 \mathrm{~kg} \\
13.1 \mathrm{~L}\end{array}$ \\
\hline Starting wt\% UDS, measured & $15.3 \pm 0.2 \%$ & No sample & No sample & No sample \\
\hline Starting wt\% UDS, calculated & N/A & $15.3 \%$ & $15.3 \%$ & $15.2 \%$ \\
\hline Wt\% UDS at knee, calculated & $21.2 \%$ & $19.6 \%$ & $23.3 \%$ & $21.2 \%$ \\
\hline Ending wt\% UDS, calculated & $29.5 \%$ & $30.2 \%$ & $29.4 \%$ & $32.4 \%$ \\
\hline Ending wt\% UDS, measured & $32.5 \pm 0.5 \%$ & No sample & No sample & $38.8 \%$ \\
\hline Start of dewatering (PST) & 3/25/2009 13:20 & $\begin{array}{c}\text { 3/26/2009 } \\
08: 07\end{array}$ & $\begin{array}{c}3 / 26 / 2009 \\
13: 53\end{array}$ & $\begin{array}{l}\text { 3/27/2009 } \\
\text { 09:12 }\end{array}$ \\
\hline End of dewatering (PST) & 3/25/2009 17:03 & $\begin{array}{c}3 / 26 / 2009 \\
12: 43\end{array}$ & $\begin{array}{c}3 / 26 / 2009 \\
17: 27\end{array}$ & $\begin{array}{l}3 / 27 / 2009 \\
14: 35\end{array}$ \\
\hline Time elapsed for dewatering step & 3.72 hours & 4.60 hours & 3.57 hours & 5.38 hours \\
\hline Time elapsed at dewatering knee & 1.57 hours & 1.32 hours & 2.15 hours & 1.78 hours \\
\hline Time elapsed to achieve $20 \mathrm{wt} \%$ UDS & 1.28 hours & 1.43 hours & 1.40 hours & 1.48 hours \\
\hline
\end{tabular}


Simulant slurries used for dewatering consisted of caustic-leached, washed solids. The simulant for Test \#1 was taken directly from the leached, washed simulant slurry from the Shakedown/Functional Test. The simulant for Test \#2 includes a mixture of leached, washed simulant slurries from Integrated Tests A and B (for a more complete description, please see Section 4.3.1 of WTP-RPT-185 [Daniel et al. 2009b]). Test \#1 simulant started at a concentration of 6.9-wt\% UDS, and Test \#2 started at 15.3-wt\% UDS. Particle size distributions for the two simulants are in agreement, with smaller particles than the pre-leach simulants, and differences in slurry rheology and bulk slurry density are attributable to the higher solids concentration of the Test \#2 simulant. Physical property data for both simulants are given in Table 4.8.

Table 4.8. Physical Properties of High-Solids Simulant Before Initial Dewatering

\begin{tabular}{|c|c|c|c|}
\hline \multirow[b]{2}{*}{ Property } & \multicolumn{2}{|c|}{ Measured Value } & \multirow[b]{2}{*}{ Units } \\
\hline & Test \#1 & Test \#2 & \\
\hline \multicolumn{4}{|l|}{ Rheology } \\
\hline Bingham Yield Stress & $0.098 \pm 0.004$ & $2.1 \pm 0.03$ & $\mathrm{~Pa}$ \\
\hline Bingham Consistency & $2.59 \pm 0.03$ & $4.74 \pm 0.07$ & $\mathrm{mPa} \cdot \mathrm{s}$ \\
\hline Permeate Viscosity ${ }^{(a)}$ & $\mathrm{n} / \mathrm{m}$ & $\mathrm{n} / \mathrm{m}$ & $\mathrm{mPa} \cdot \mathrm{s}$ \\
\hline \multicolumn{4}{|l|}{ Density } \\
\hline Slurry Bulk Density & $1.05 \pm 0.02$ & $1.12 \pm 0.02$ & $\mathrm{~kg} / \mathrm{L}$ \\
\hline Permeate Density & $0.99 \pm 0.02$ & $1.01 \pm 0.02$ & $\mathrm{~kg} / \mathrm{L}$ \\
\hline Coriolis Permeate Density & $1.01 \pm 0.00$ & $1.00 \pm 0.00$ & $\mathrm{~kg} / \mathrm{L}$ \\
\hline \multicolumn{4}{|l|}{ Solids Concentrations } \\
\hline Total Solids & $8.5 \pm 0.2$ & $16.0 \pm 0.3$ & wt\% \\
\hline Undissolved Solids & $6.9 \pm 0.1$ & $15.3 \pm 0.2$ & wt $\%$ \\
\hline Dissolved Solids In Permeate & $1.7 \pm 0.2$ & $0.8 \pm 0.2$ & wt\% \\
\hline \multicolumn{4}{|l|}{ Particle Size Distribution } \\
\hline $\mathrm{d}_{10}$ & $0.6 \pm 0.1$ & $0.6 \pm 0.1$ & $\mu \mathrm{m}$ \\
\hline$d_{50}$ & $1.3 \pm 0.1$ & $1.2 \pm 0.1$ & $\mu \mathrm{m}$ \\
\hline $\mathrm{d}_{90}$ & $2.9 \pm 0.1$ & $2.6 \pm 0.1$ & $\mu \mathrm{m}$ \\
\hline
\end{tabular}

As with the low-solids dewatering tests, the cold-CUF operation was maintained at the target conditions with minimal adjustment at the outset of dewatering. As dewatering progressed, more frequent adjustment was required up to the point where the process conditions could no longer be satisfactorily maintained. While TP-WTP-PEP-044 specified dewatering to a target concentration of $20-\mathrm{wt} \%$ UDS, the dewatering proceeded past this target to the operating limit of the cold-CUF. The flux data past 20 -wt\% helped define the logarithmic decay in the dewatering curve.

Process performance with respect to the target conditions for TMP, AV, slurry reservoir temperature, and APD is shown in the following sets of figures: Figure 4.9 to Figure 4.12 for Test \#1 and Figure 4.15 to Figure 4.18 for Test \#2. The filter TMP was maintained at $40 \pm 5$ psid throughout, except for brief periods in Test \#2 where the TMP increased above 45 psid and was subsequently adjusted. No impact to the determination of corrected filter flux is expected. The AV for each dewatering step was successfully maintained at the target conditions within the specified tolerances ( $\pm 1 \mathrm{ft} / \mathrm{sec}$ for AV). The slurry reservoir temperature was also maintained within tolerance with the exception that in Test \#2 the temperature of the slurry reservoir narrowly exceeded $30^{\circ} \mathrm{C}$ in two dewatering steps. This is outside of the target condition of $25 \pm 5^{\circ} \mathrm{C}$, but based on findings in WTP-RPT-168 (Daniel et al. 2009a), the temperature correction in 
Equation 3.3 may be applied over the range of $25^{\circ} \mathrm{C}$ to $45^{\circ} \mathrm{C}$. The minor variations above $30^{\circ} \mathrm{C}$ encountered in these tests are within the applicable range of the correction. The APD is compared against an operating guideline of 2.5 psid per foot of filter element. This value is derived by taking the PEP APD limit of 25 psid per bundle as specified in the run sheets of each test instruction and dividing by the length of the longer bundles (10 ft). For slurries up to 20-wt\% UDS, the CUF generally operates below this value. Beyond 20-wt\% UDS, the value can be observed to increase dramatically (Figure 4.12 and Figure 4.18).

Filter flux as a function of UDS concentration is given in Figure 4.13 and Figure 4.14 for Test \#1 and Figure 4.19 and Figure 4.20 for Test \#2. The flux data were plotted with respect to the natural log of the concentration of solids (Figure 4.14 and Figure 4.20) to permit greater distinction between results. Each of the dewatering curves exhibit the typical transition to cake-resistance-dominated filtration. A discussion of the results is given in Section 4.3.2.

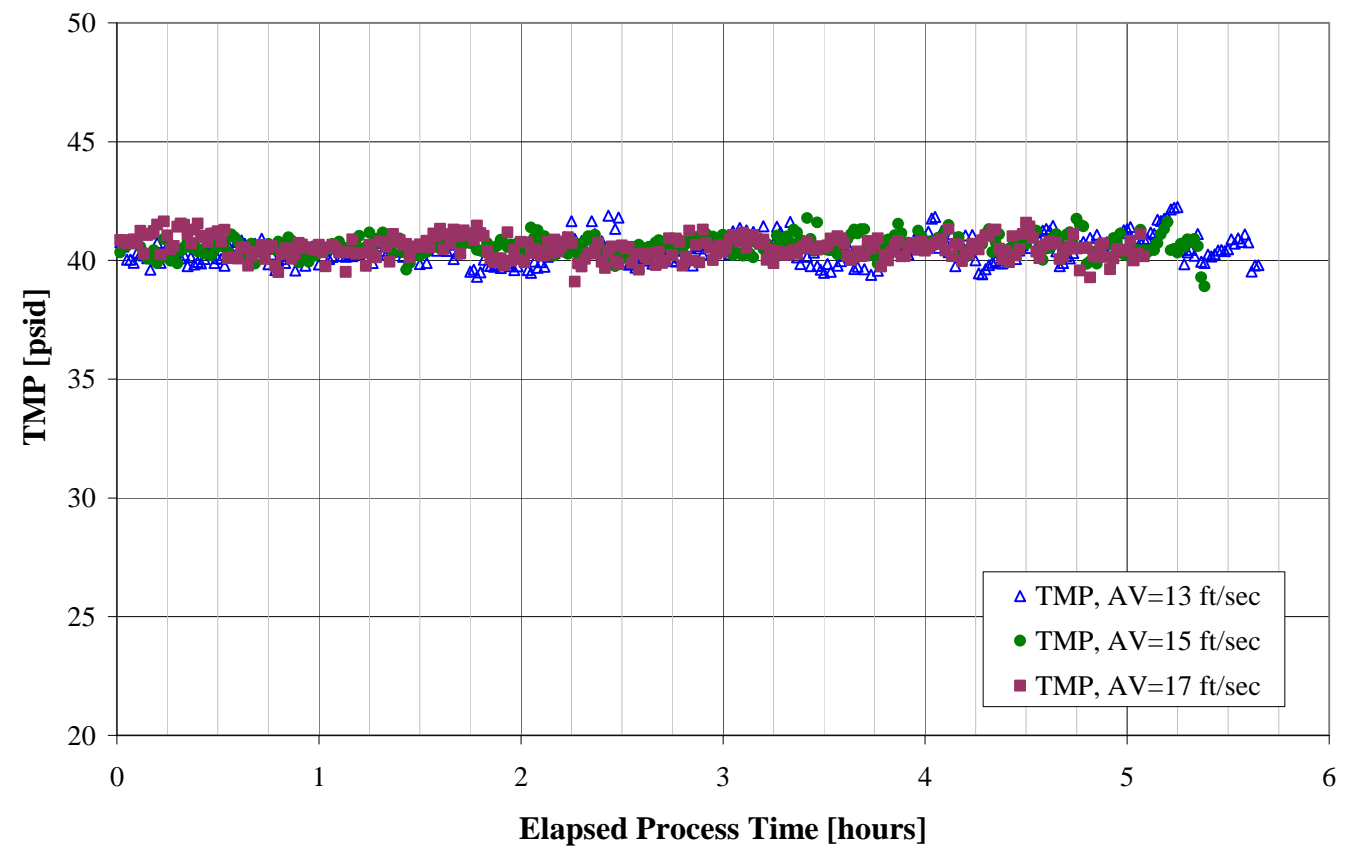

Figure 4.9. TMP During Each of the Dewatering Steps of High-Solids Dewatering Test \#1. The target TMP was $40 \pm 5$ psid. 


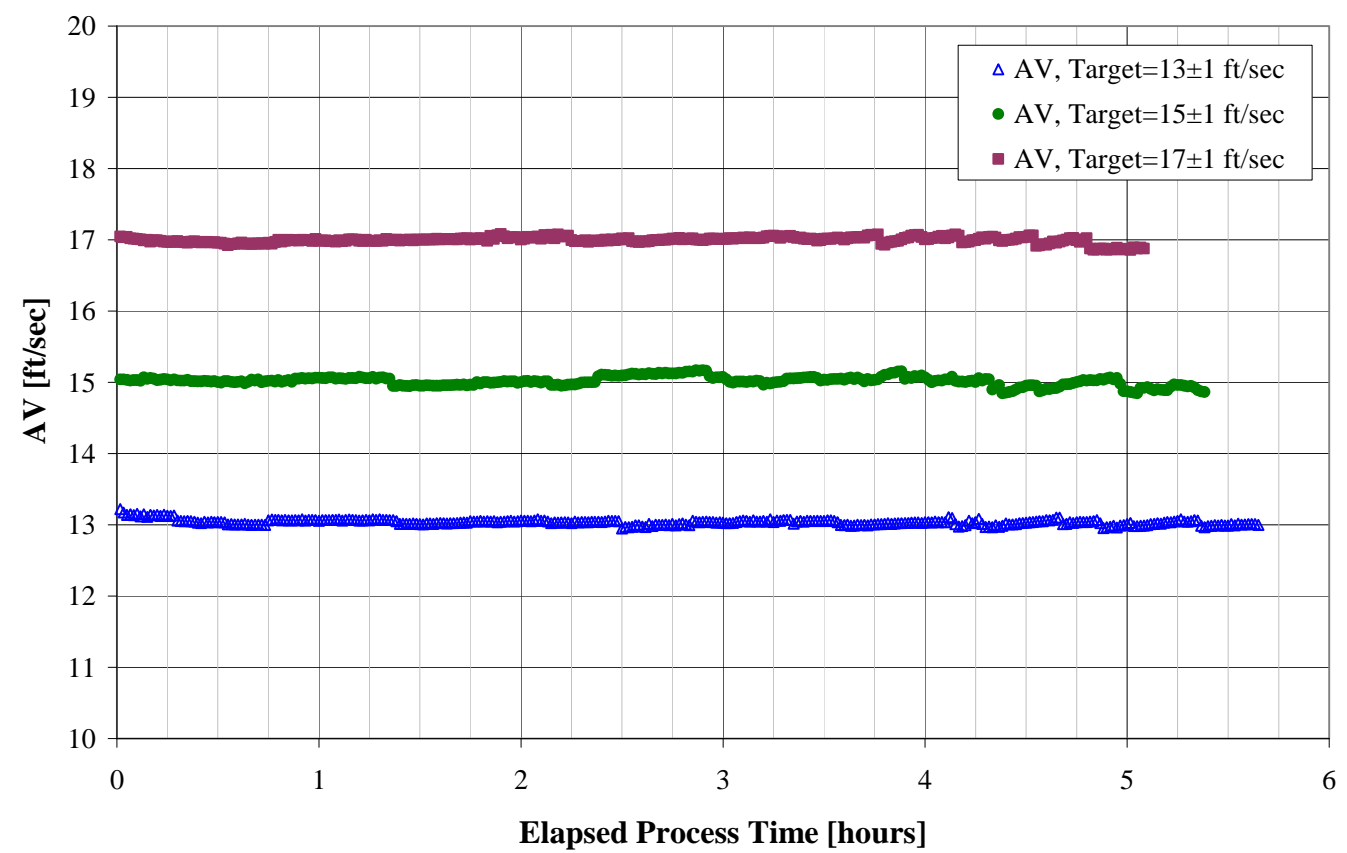

Figure 4.10. AV During Each of the Dewatering Steps of High-Solids Dewatering Test \#1. Target velocities are listed in the legend, with process limits of $\pm 1 \mathrm{ft} / \mathrm{sec}$.

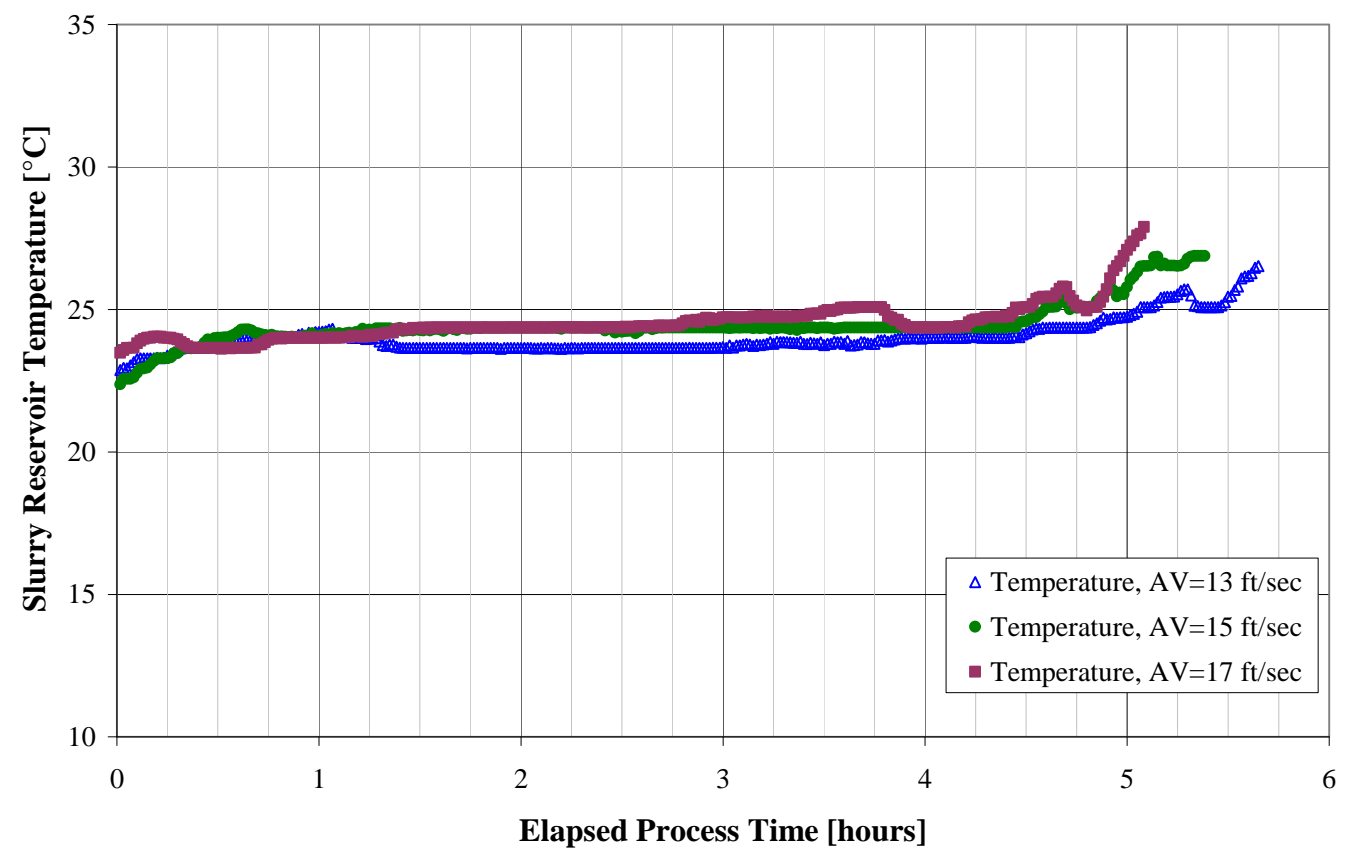

Figure 4.11. Slurry Reservoir Temperature During Each of the Dewatering Steps in High Solids Dewatering Test $\# 1$. The target temperature was $25 \pm 5^{\circ} \mathrm{C}$. 


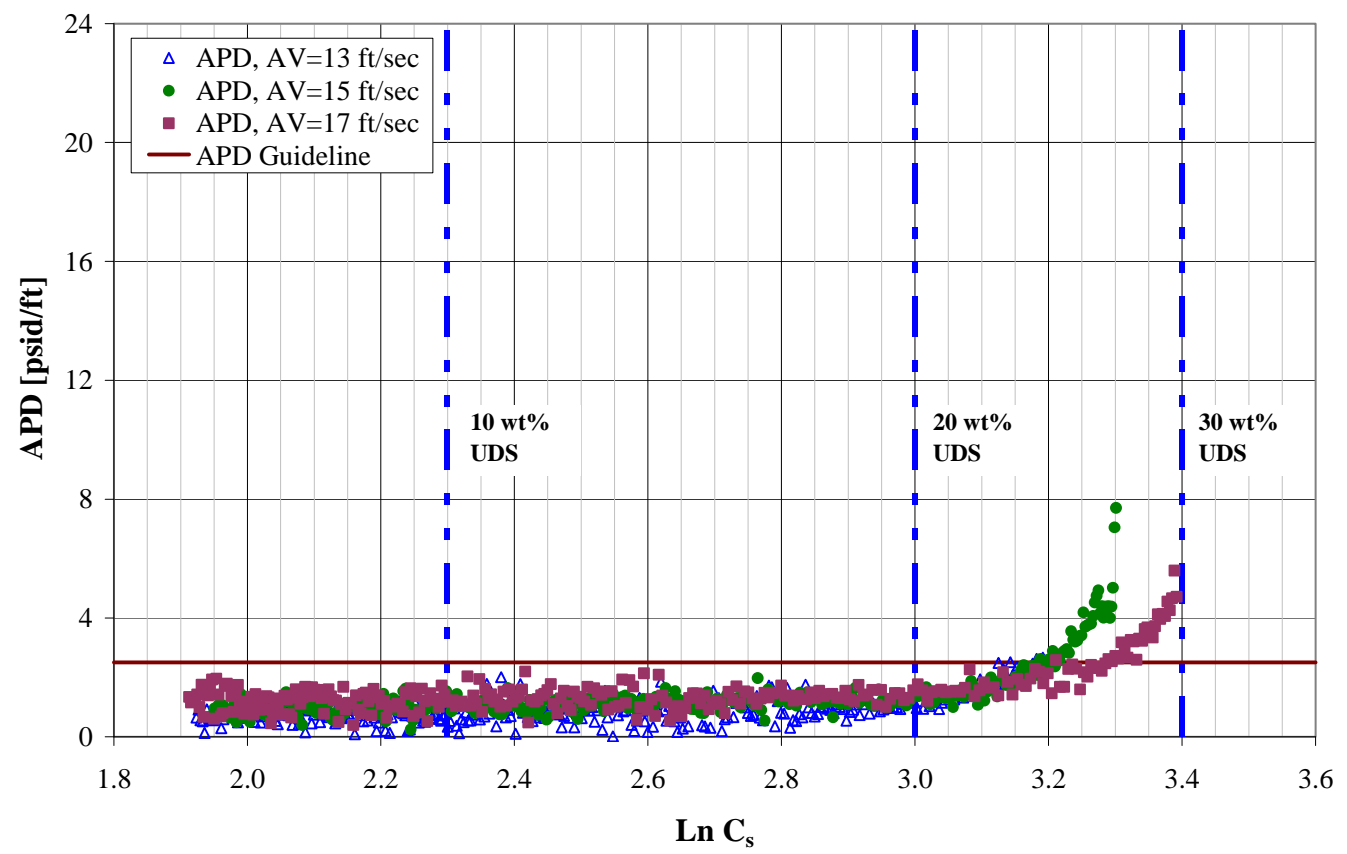

Figure 4.12. APD Plotted Against the Natural Log of the Slurry UDS Concentration for High-Solids Dewatering Test \#1 at Various AVs (13, 15, and $17 \mathrm{ft} / \mathrm{sec})$. The PEP guideline for APD translates to $2.5 \mathrm{psid} / \mathrm{ft}$ for cold-CUF operations.

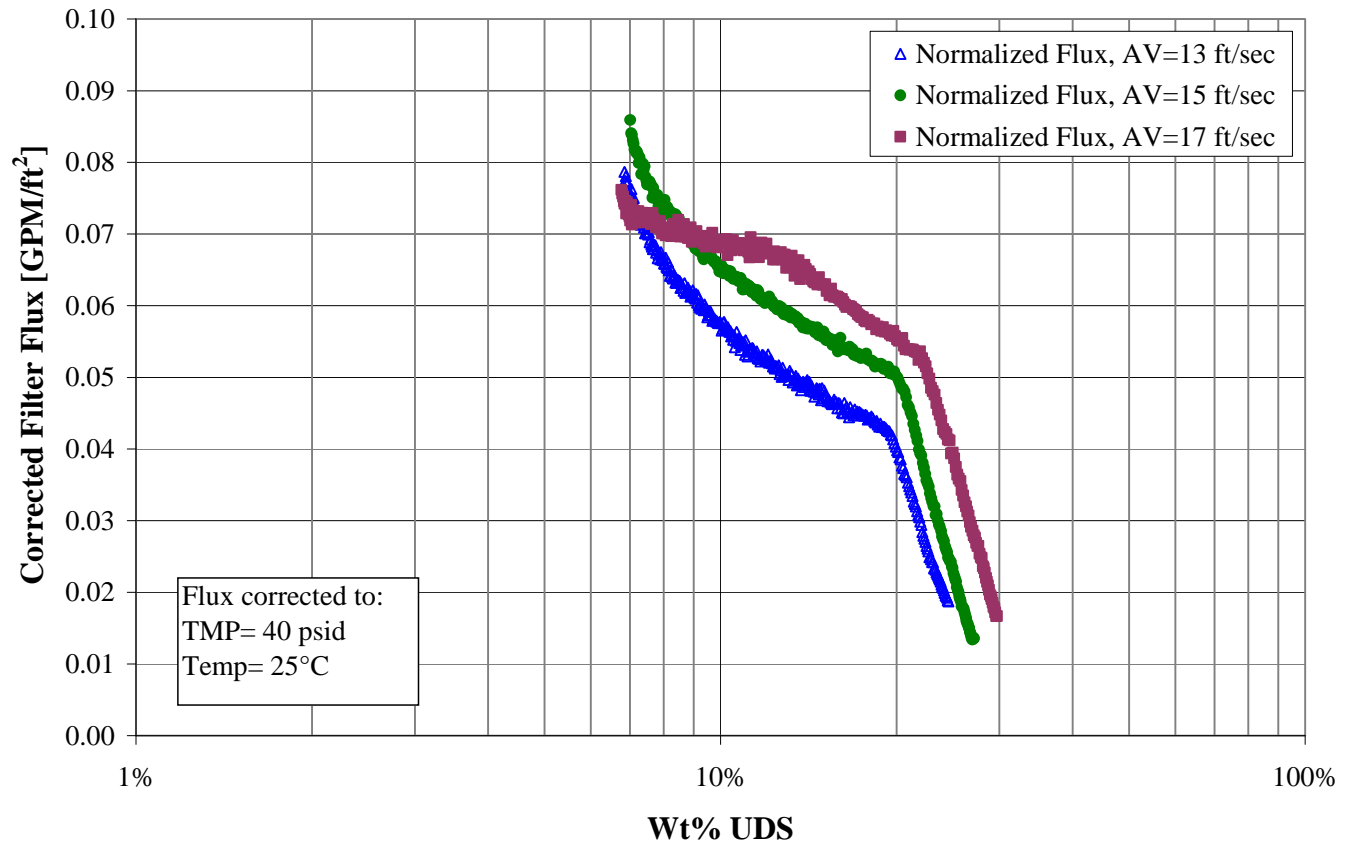

Figure 4.13. Corrected Permeate Flux Plotted Against wt\% UDS for High-Solids Dewatering Test \#1 at Three AVs (13, 15, and $17 \mathrm{ft} / \mathrm{sec})$ 


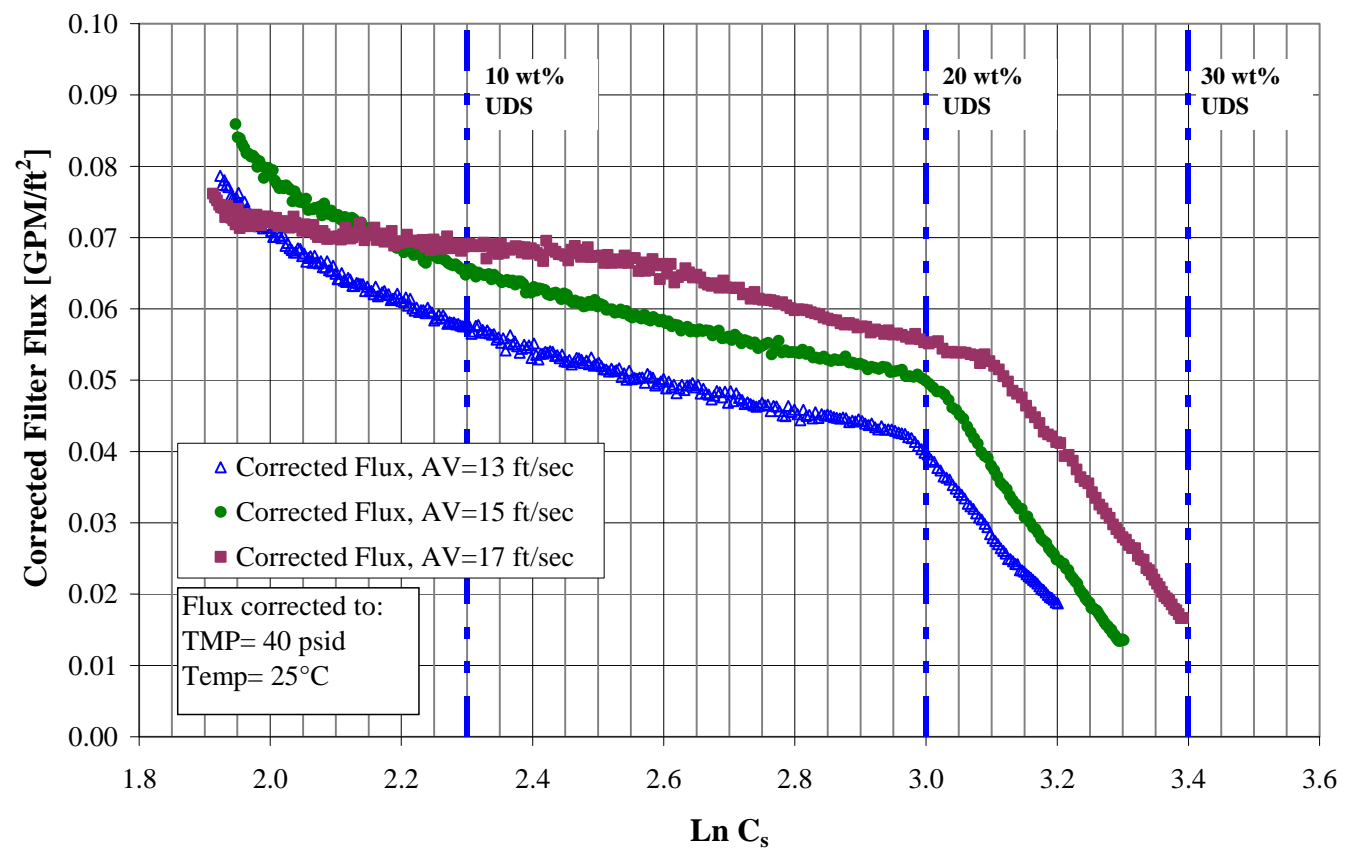

Figure 4.14. Corrected Permeate Flux Plotted Against the Natural Log of the Slurry UDS Concentration for High-Solids Dewatering Test \#1 at Three AVs (13, 15, and $17 \mathrm{ft} / \mathrm{sec}$ )

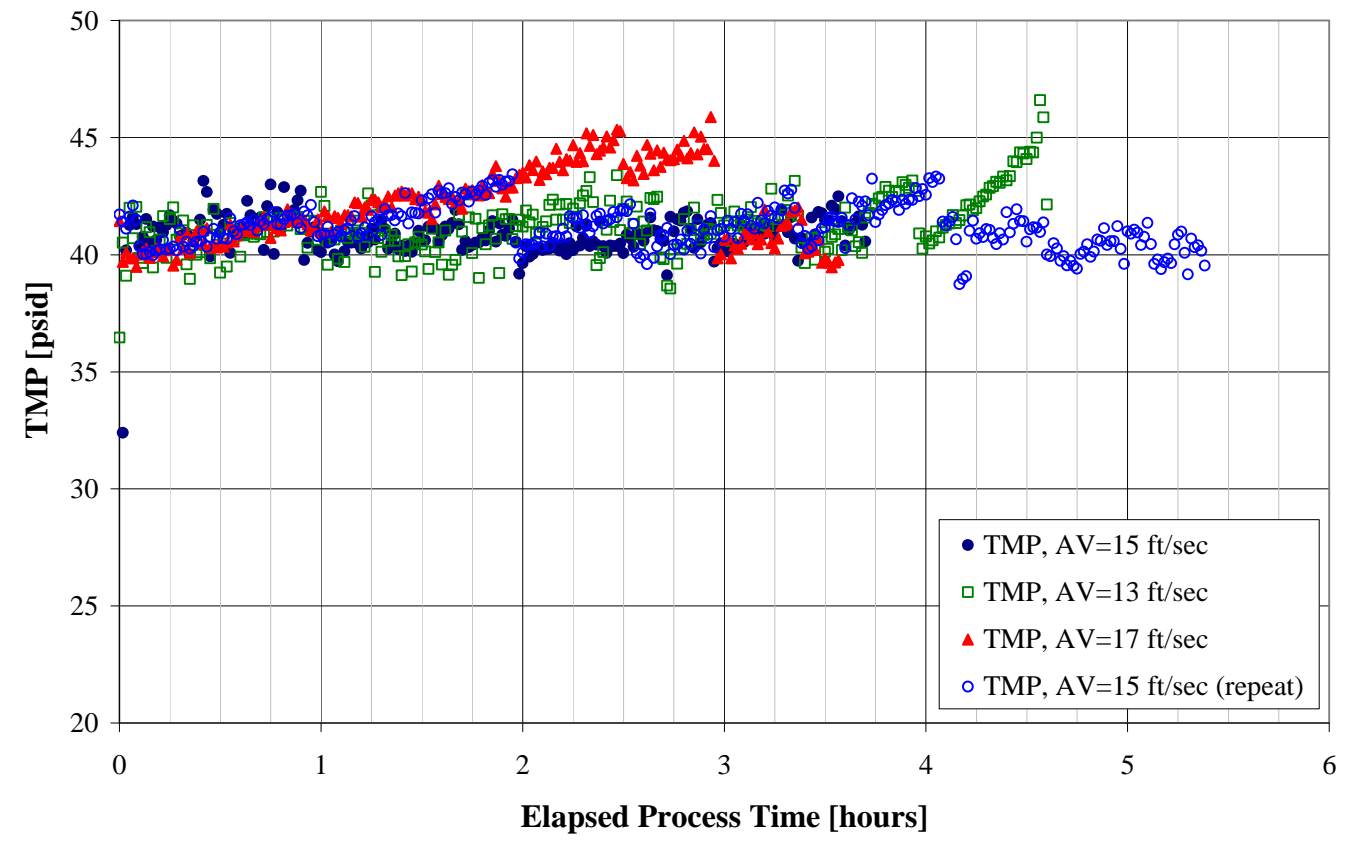

Figure 4.15. TMP During Each of the Dewatering Steps of High-Solids Dewatering Test \#2. The target TMP was $40 \pm 5$ psid. 


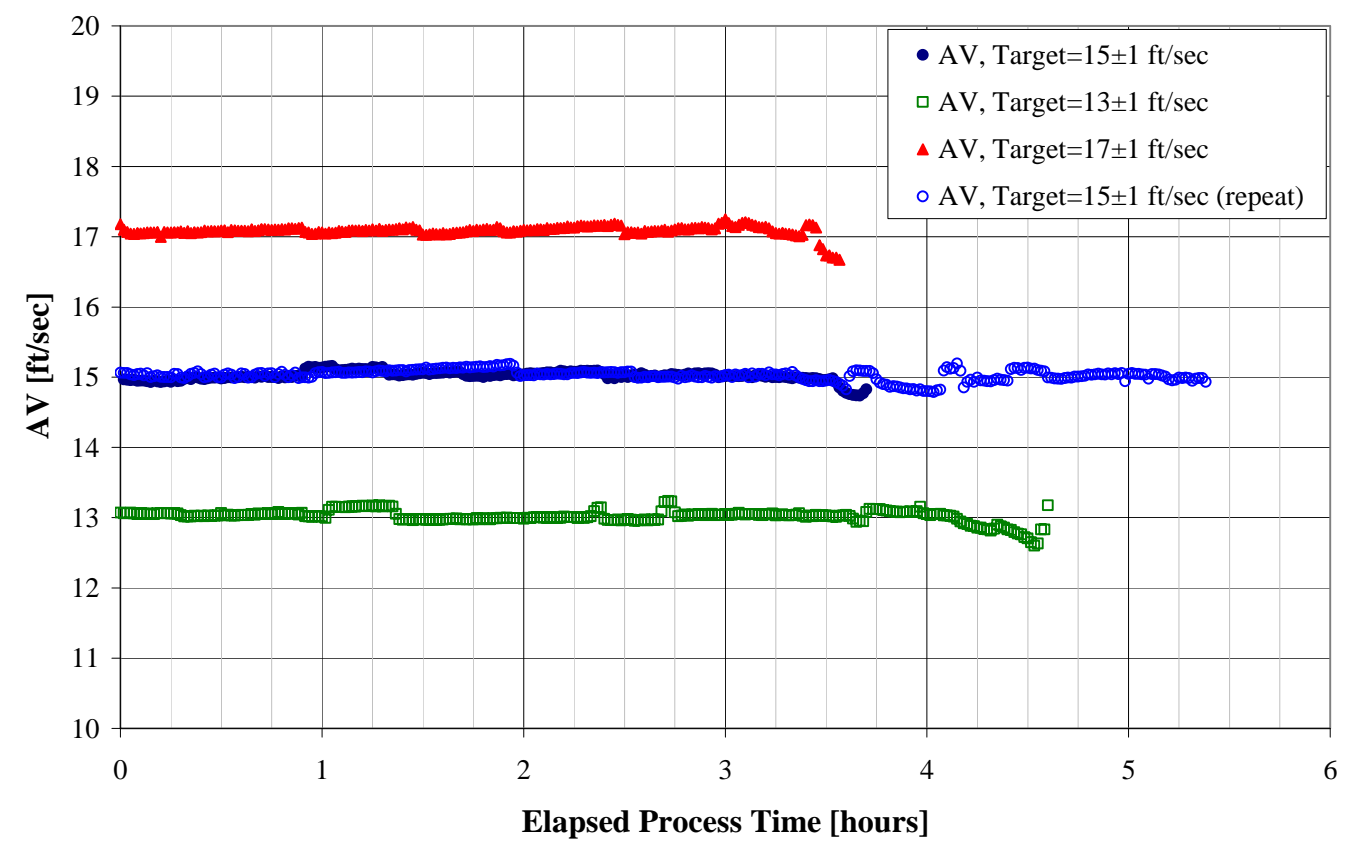

Figure 4.16. AV During Each of the Dewatering Steps of High-Solids Dewatering Test \#2. Target velocities are listed in the legend, with process limits of $\pm 1 \mathrm{ft} / \mathrm{sec}$.

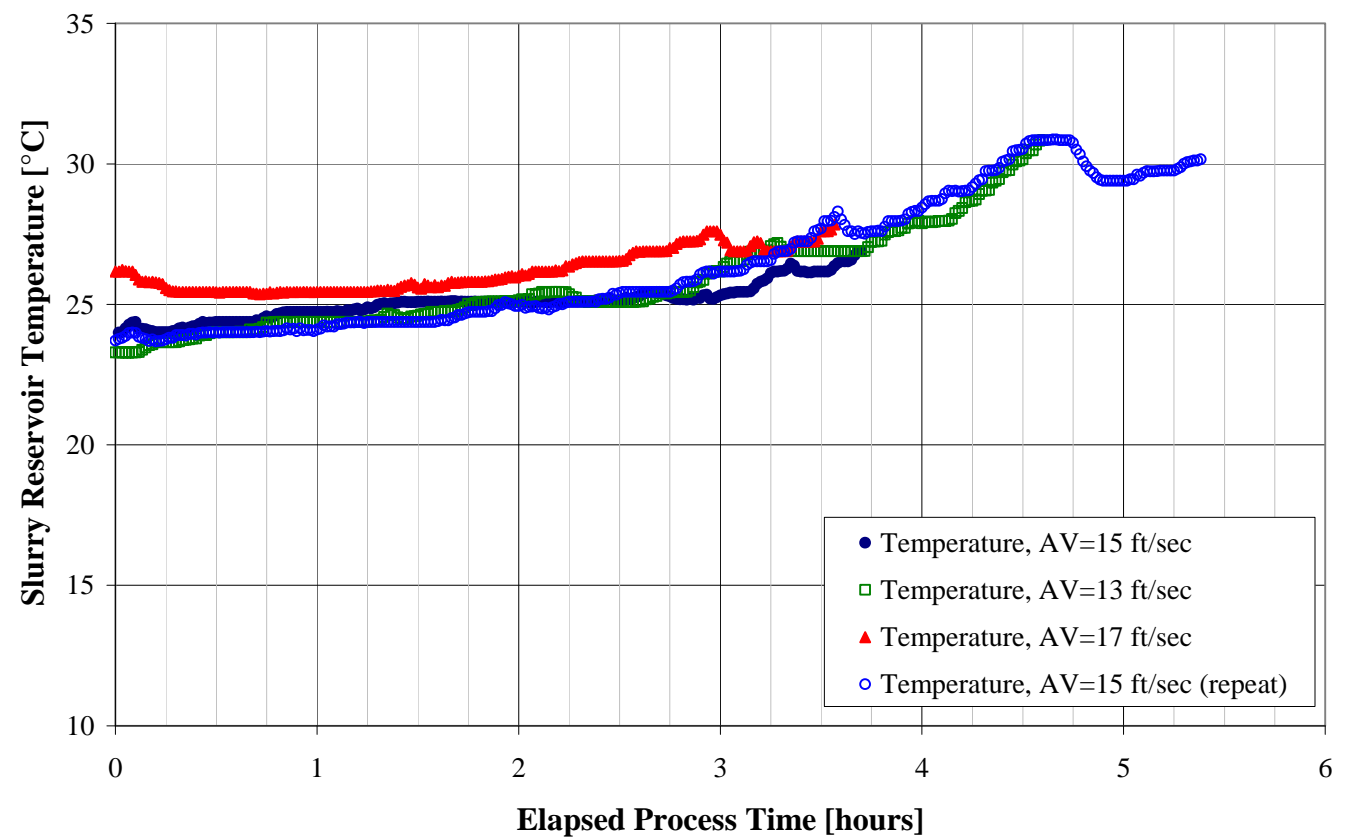

Figure 4.17. Slurry Reservoir Temperature During Each of the Dewatering Steps in High-Solids Dewatering Test $\# 2$. The target temperature was $25 \pm 5^{\circ} \mathrm{C}$. 


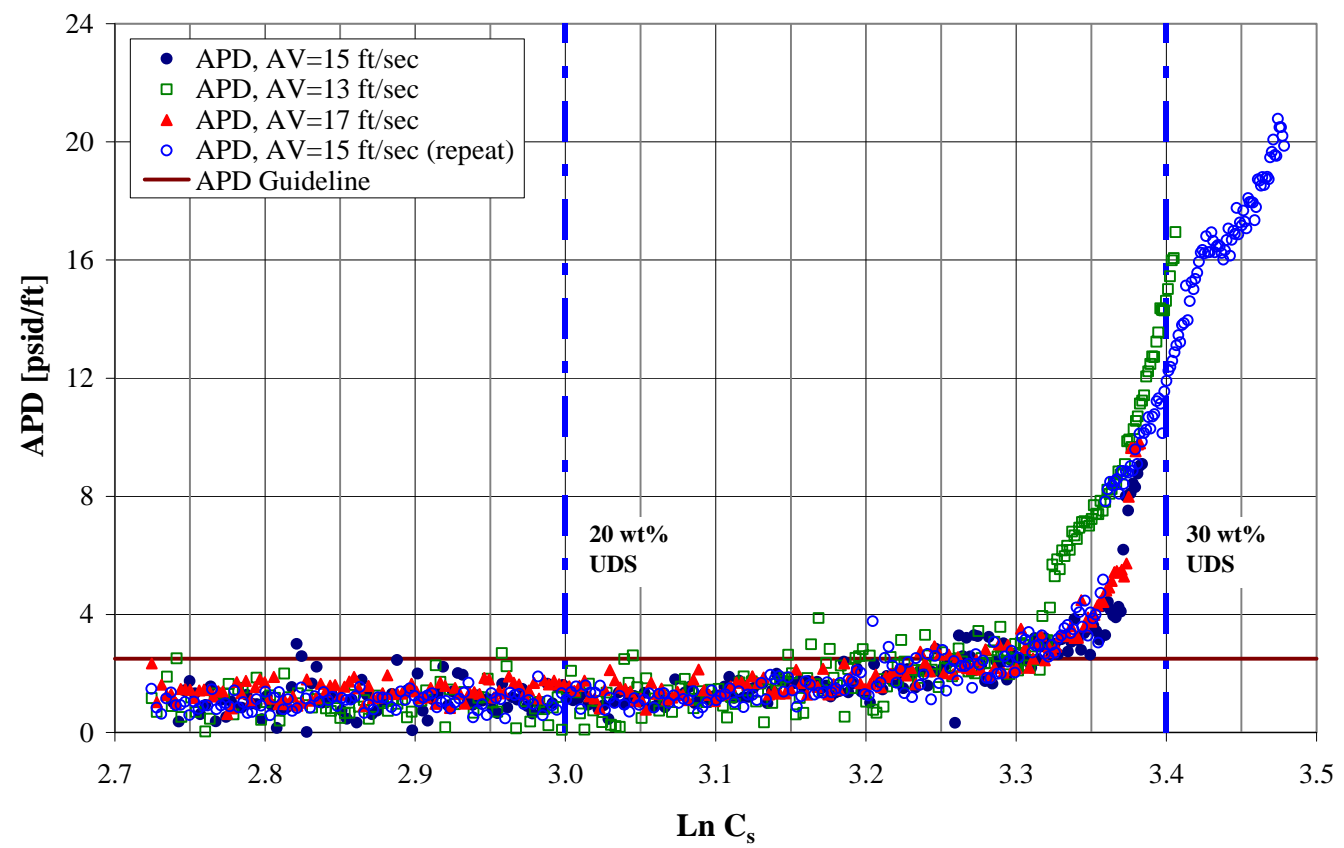

Figure 4.18. APD Plotted Against the Natural Log of the Slurry UDS Concentration for High-Solids Dewatering Test \#2 at Various AVs (13, 15, and $17 \mathrm{ft} / \mathrm{sec})$. The PEP guideline for APD translates to $2.5 \mathrm{psid} / \mathrm{ft}$ for cold-CUF operations.

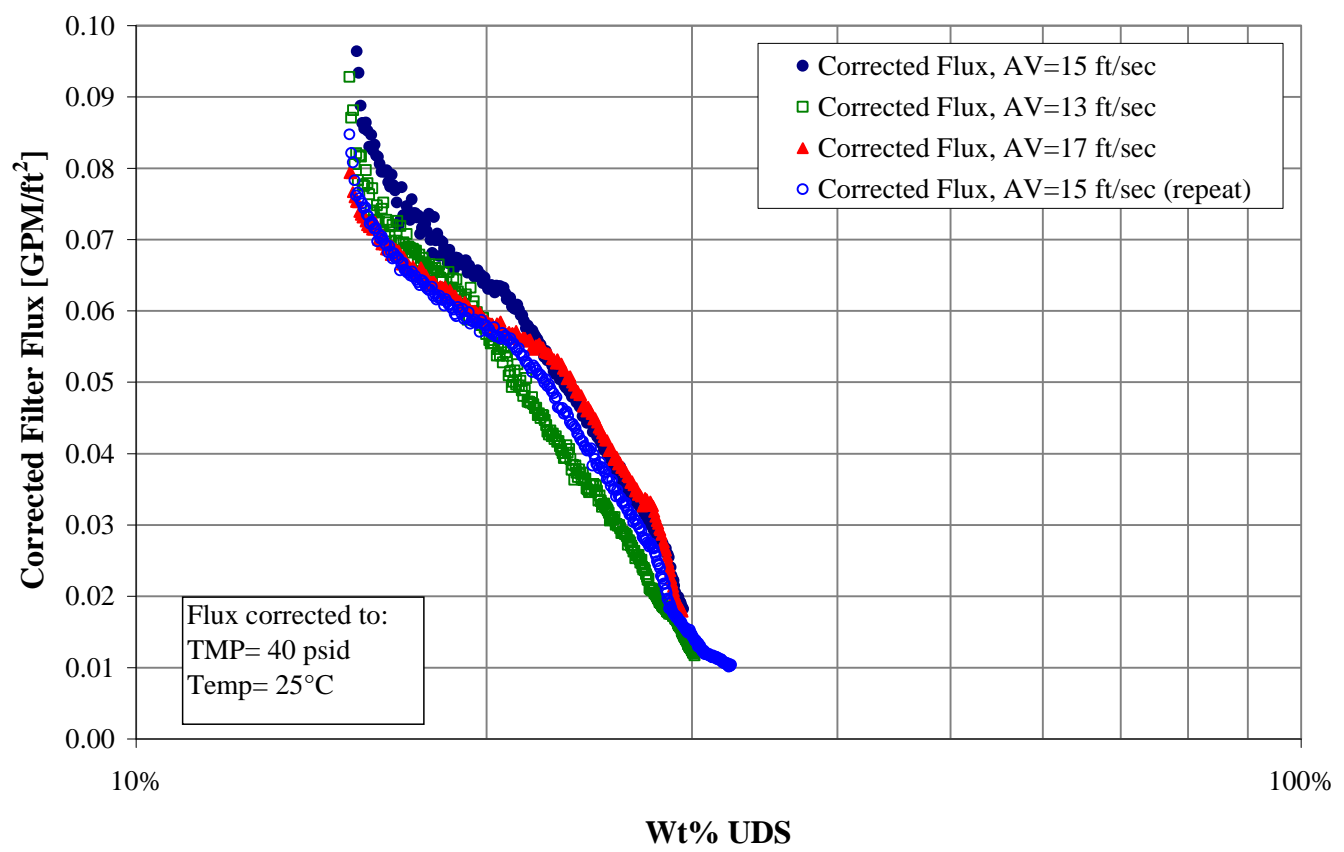

Figure 4.19. Corrected Permeate Flux Plotted Against wt\% UDS for High-Solids Dewatering Test \#2 at Three AVs (13, 15, and $17 \mathrm{ft} / \mathrm{sec})$ 


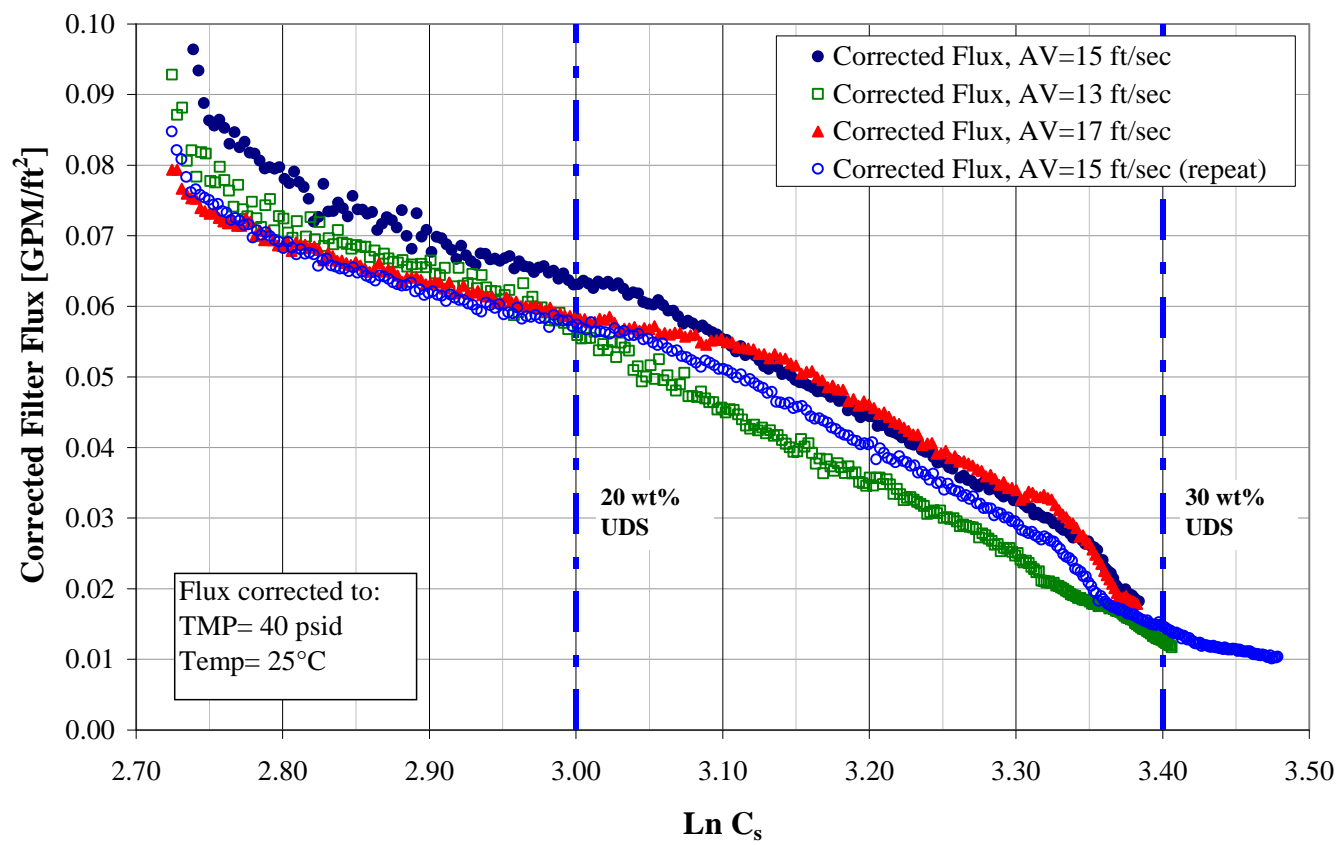

Figure 4.20. Corrected Permeate Flux Plotted Against the Natural Log of the Slurry UDS Concentration for High-Solids Dewatering Test \#2 at Various AVs (13, 15, and $17 \mathrm{ft} / \mathrm{sec}$ )

After the initial dewatering step (AV = $15 \mathrm{ft} / \mathrm{sec}$ ) for Test \#1 and Test \#2, samples of the concentrated slurry were collected and analyzed for rheology, UDS concentration, and PSD. Measured properties of these samples are presented in Table 4.9. The physical properties are comparable between the two tests, and although no rheology sample was collected after the first dewatering step of Test \#1, rheology samples from subsequent dewatering steps exhibit the high yield stress and consistency values reported for Test \#2.

Table 4.9. Physical Properties of Concentrated High-Solids Simulant Following First Dewatering

\begin{tabular}{|c|c|c|c|}
\hline \multirow[b]{2}{*}{ Property } & \multicolumn{2}{|c|}{ Measured Value } & \multirow[b]{2}{*}{ Units } \\
\hline & Test \#1 & Test \#2 & \\
\hline \multicolumn{4}{|l|}{ Rheology } \\
\hline Bingham Yield Stress & $\mathrm{n} / \mathrm{m}$ & $88.8 \pm 3.1$ & $\mathrm{~Pa}$ \\
\hline Bingham Consistency & $\mathrm{n} / \mathrm{m}$ & $14.8 \pm 0.9$ & $\mathrm{mPa} \cdot \mathrm{s}$ \\
\hline \multicolumn{4}{|l|}{ Density } \\
\hline Slurry Bulk Density & $1.32 \pm 0.03$ & $1.32 \pm 0.05$ & $\mathrm{~kg} / \mathrm{L}$ \\
\hline Permeate Density & $1.03 \pm 0.02$ & $1.02 \pm 0.02$ & $\mathrm{~kg} / \mathrm{L}$ \\
\hline Coriolis Permeate Density & $1.01 \pm 0.00$ & $1.00 \pm 0.00$ & $\mathrm{~kg} / \mathrm{L}$ \\
\hline \multicolumn{4}{|l|}{ Solids Concentrations } \\
\hline Total Solids & $34.3 \pm 0.6$ & $33.1 \pm 0.5$ & wt $\%$ \\
\hline Undissolved Solids & $33.0 \pm 0.5$ & $32.5 \pm 0.5$ & wt $\%$ \\
\hline Dissolved Solids In Permeate & $2.0 \pm 0.4$ & $0.9 \pm 0.3$ & wt $\%$ \\
\hline \multicolumn{4}{|l|}{ Particle Size Distribution } \\
\hline $\mathrm{d}_{10}$ & $0.5 \pm 0.1$ & $0.4 \pm 0.1$ & $\mu \mathrm{m}$ \\
\hline$d_{50}$ & $1.1 \pm 0.1$ & $1.0 \pm 0.1$ & $\mu \mathrm{m}$ \\
\hline $\mathrm{d}_{90}$ & $3.2 \pm 0.1$ & $2.9 \pm 0.1$ & $\mu \mathrm{m}$ \\
\hline
\end{tabular}




\subsubsection{Discussion of High-Solids Dewatering Tests}

The high-solids dewatering tests encompass seven total dewatering tests, three for High-Solids Dewatering Test \#1 and four for High-Solids Dewatering Test \#2. To help maintain order and presentation, the discussion has been broken into a subsection for each test.

\subsubsection{High-Solids Dewatering Test \#1}

In High-Solids Test \#1, the slurry was dewatered from 6.9-wt\% UDS to final concentrations near 30-wt\% UDS. This wide range of UDS concentration provided an excellent window for studying filtration behavior at different AVs. In both Figure 4.13 and Figure 4.14, two trends with respect to AV are noted:

1. Increasing AV leads to a higher UDS concentration at the knee. ${ }^{(a)}$

2. Increasing AV leads to higher filter flux over the course of the dewatering, leading to a shorter time from the beginning of the dewatering step to the target concentration of 20 -wt\% UDS.

Using values from Table 4.6, a comparison of these two parameters is given in Table 4.10 for each of the three dewatering steps in High-Solids Dewatering Test \#1. The mass-transfer coefficient and slurry gel concentration are also given. The dewatering at $\mathrm{AV}=17 \mathrm{ft} / \mathrm{sec}$ requires nearly $20 \%$ less time than the dewatering at $A V=13 \mathrm{ft} / \mathrm{sec}$, and the knee shifts 2.8-wt\% UDS. It appears that the dewatering behavior for the tests at $A V=13 \mathrm{ft} / \mathrm{sec}$ and $15 \mathrm{ft} / \mathrm{sec}$ proceeds along the same general trend at different magnitudes, leading to the same gel concentration with differing mass-transfer coefficients. The dewatering at $\mathrm{AV}=17 \mathrm{ft} / \mathrm{sec}$ appears to cause sufficient cake shearing through turbulent flow to lessen the impact of cake resistance farther into the dewatering step, leading to a higher gel point and later onset of the exponential increase in APD with UDS concentration (Figure 4.12).

Table 4.10. Comparison of Trends for Increasing AV, High-Solids Dewatering Test \#1

\begin{tabular}{lccc}
\hline Parameter & $\mathrm{AV}=13 \mathrm{ft} / \mathrm{sec}$ & $\mathrm{AV}=15 \mathrm{ft} / \mathrm{sec}$ & $\mathrm{AV}=17 \mathrm{ft} / \mathrm{sec}$ \\
\hline $\mathrm{Wt} \%$ UDS at knee, calculated & $19.3 \%$ & $20.1 \%$ & $22.1 \%$ \\
Time elapsed to achieve 20-wt\% UDS & 4.78 hours & 4.12 hours & 3.92 hours \\
$\mathrm{k}\left[\mathrm{GPM} / \mathrm{ft}^{2}\right]$ & -0.106 & -0.128 & -0.125 \\
$\mathrm{C}_{\mathrm{g}}[\mathrm{wt} \%]$ & $29.1 \%$ & $29.9 \%$ & $34.0 \%$ \\
\hline
\end{tabular}

\subsubsection{High-Solids Dewatering Test \#2}

In comparison to High-Solids Dewatering Test \#1, the effect of dewatering at different AVs is not as readily apparent (see Figure 4.19). Differentiation of the results can be accomplished by viewing the plots on different scales (Figure 4.20), but the main factor is that in High-Solids Dewatering Test \#1, the starting concentration was 6.9-wt\% UDS whereas in High-Solids Dewatering Test \#2, the starting concentration was 15.3-wt\% UDS to permit the concentration of the slurry at PEP to a UDS concentration sufficient for comparison to cold-CUF results. The consequence of directly performing a dewatering test of concentrated slurry is that the initial rapid flux decay occurs over a shorter concentration range and

(a) The knee is a characteristic transition point between membrane-dominated flux resistance to cake-dominated flux resistance. See Section 3.3.4, and especially Figure 3.7, for a description of the knee in the dewatering curve. 
may not be fully complete at the time where the knee occurs. In Test \#1, the extra time to dewater from 6.9-wt\% to $15.3-w t \%$ allowed for greater stabilization of the flux before the knee making it more apparent. A comparison of the dewatering trends is given in Table 4.11.

Table 4.11. Comparison of Trends for Increasing AV, High-Solids Dewatering Test \#2

\begin{tabular}{lcccc}
\hline \multicolumn{1}{c}{ Parameter } & $\mathrm{AV}=13 \mathrm{ft} / \mathrm{sec}$ & $\mathrm{AV}=15 \mathrm{ft} / \mathrm{sec}$ & $\mathrm{AV}=15 \mathrm{ft} / \mathrm{sec}$ repeat & $\mathrm{AV}=17 \mathrm{ft} / \mathrm{sec}$ \\
\hline $\mathrm{Wt} \%$ UDS at knee, calculated & $19.6 \%$ & $21.2 \%$ & $21.2 \%$ & $23.3 \%$ \\
Time elapsed to achieve 20-wt\% UDS & 1.43 hours & 1.28 hours & 1.48 hours & 1.40 hours \\
$\mathrm{k}\left[\mathrm{GPM} / \mathrm{ft}^{2}\right.$ ] & -0.109 & -0.115 & -0.109 & -0.118 \\
$\mathrm{C}_{\mathrm{g}}[\mathrm{wt} \%]$ & $33.8 \%$ & $35.9 \%$ & $35.4 \%$ & $36.1 \%$ \\
\hline
\end{tabular}

For Test \#2, there may be two competing mechanisms at the transition point: the transient flux decay attributable to surface fouling and the transition from membrane-resistance-dominated filtration to cake-resistance-dominated filtration. A single backpulse was performed immediately before each test to clear the cake from the previous test and allow the cake to develop directly from the TMP and AV target conditions in the filter. This necessary step was the source of the transient flux decay, and it could be minimized by allowing for a period of filter conditioning in recycle mode before slurry dewatering, resulting in a flatter curve up to the knee. This was not explicit in the Test Plan, except in the case of the low-solids tests, but it is a consideration for future testing.

Taking into consideration the above qualifications, it is still possible to designate a knee in each dewatering curve and to see quantitatively that the knee in the curves shifts from 19.6-wt\% UDS to 23.3-wt\% UDS over the range of AV tested. If the first test at AV $=15 \mathrm{ft} / \mathrm{sec}$ can be considered a conditioning test for this simulant, such that only the following three tests are considered in Figure 4.20, the trends for Test \#2 are similar to those observed for Test \#1. The repeat test at AV $=15 \mathrm{ft} / \mathrm{sec}$ confirms the transition point of the initial test and also gives an indication of the relative magnitude of timedependent filter fouling apart from the transient decay after a backpulse. This value is approximately $0.005 \mathrm{GPM} / \mathrm{ft}^{2}$, or approximately $5 \%$ of the initial flux $\left(0.090 \mathrm{GPM} / \mathrm{ft}^{2}\right)$. The primary flux decay anticipated is the observed transient decay after backpulsing and the logarithmic decay associated with the transition to cake-resistance-dominated filtration.

\subsection{Post-Caustic-Leach Dewatering and Oxalate Washing Test}

During the dewatering of six post-caustic-leach batches during PEP Integrated Test A, questions arose concerning the low and declining flux observed during the extended dewatering process (14 days). A series of tests was initiated using the cold-CUF to determine whether the low and declining flux observed at PEP would also be observed in the cold-CUF and also to attempt to isolate whether the observed flux was connected to the super-saturation of sodium oxalate in the permeate. In regards to the first question, it was confirmed in the cold-CUF that the flux was extremely low $\left(0.014 \mathrm{GPM} / \mathrm{ft}^{2}\right)$ for post-caustic-leach simulant compared to pre-leach simulant (0.03 to $0.05 \mathrm{GPM} / \mathrm{ft}^{2}$; see Sections 4.1 and 4.2) and continued to decline over timeframes of up to 60 hours. Concerning the effect of oxalate super-saturation, the design of the test, results, and conclusions is given in the following section. 


\subsubsection{Test Sequence and Results}

Before beginning this test sequence, the cold-CUF was flushed thoroughly with $0.01 \mathrm{M} \mathrm{NaOH}$, but was not cleaned with oxalic acid (see Table 4.14). A baseline filter flux with $0.01 \mathrm{M} \mathrm{NaOH}$ was measured before adding the post-caustic-leach slurry from PEP (Figure 4.21). When the initial slurry was added and filtration began, the flux declined to the level observed in the PEP post-caustic-leach dewatering (Figure 4.22). This answered the first objective of the test by demonstrating that the low flux observed at PEP was characteristic of the slurry for both PEP and cold-CUF systems.

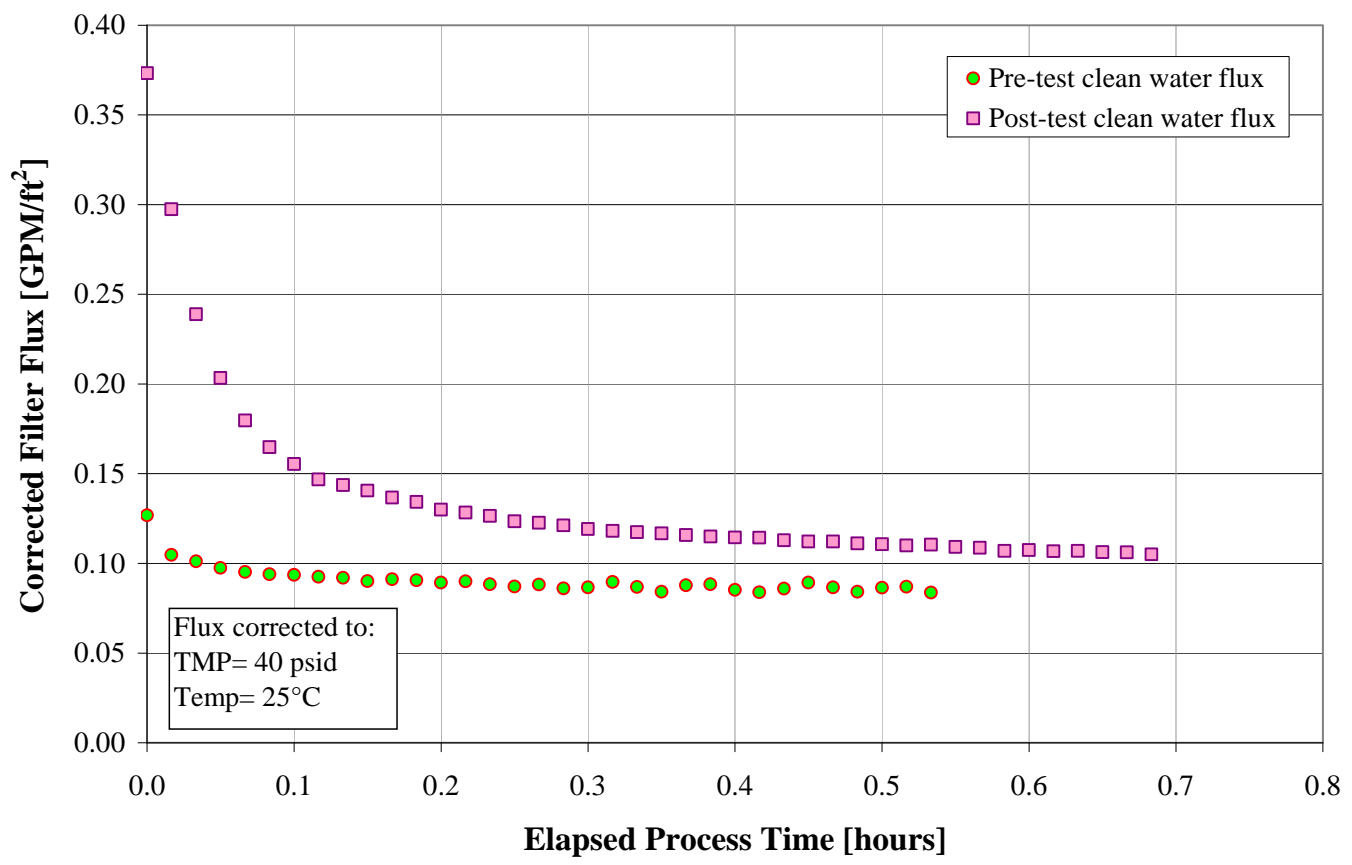

Figure 4.21. Clean Water Flux Before and After Post-Caustic-Leach Dewatering and Oxalate Washing Tests, Showing Minimal Change in Filter Conditioning as a Result of Testing

Solids washing was performed to remove the solid oxalate from the slurry. Then, the slurry was reconstituted with permeate from PEP matching the permeate composition of the initial sample. In this way, it was possible to see whether the filtration behavior was different after washing and whether the super-saturation of oxalate in the leach permeate (and potential for small precipitates) was a significant cause of the observed low flux. The cold-CUF system was operated within the target conditions for all tests in this sequence (TMP $=40 \pm 5 \mathrm{psid}, \mathrm{AV}=15 \pm 1 \mathrm{ft} / \mathrm{sec}$, and Temp $=25 \pm 5^{\circ} \mathrm{C}$ ). Further details are described in the following steps.

1. Initially, $25.250 \mathrm{~kg}$ of post-caustic-leach batch \#5 from PEP Integrated Test A was added to the CUF slurry reservoir. The simulant was filtered in recycle mode for 30 hours before proceeding to dewater the slurry.

2. The dewatering operation lasted an additional 27 hours during which $22.553 \mathrm{~kg}$ of permeate was collected. The initial sample was processed for 57 hours total before proceeding to the washing steps. 
3. The concentrated initial sample was washed using two 20-L volumes of $0.01 \mathrm{M} \mathrm{NaOH}$. The first wash solution was added to the slurry reservoir, allowed to mix, and dewatered to the minimum volume of the system. The second wash was performed in the same manner.

4. The concentrated washed solids slurry was contacted with a 20-L volume of leach permeate collected from the PEP during post-caustic-leach batch dewatering. The intent of this step was to displace the $0.01 \mathrm{M} \mathrm{NaOH}$ wash liquor from the washed solids with a permeate that would be comparable to the original permeate.

5. The slurry was dewatered, and a second 20-L volume of PEP leach permeate was added to the reservoir, thereby approximately reconstituting the initial slurry minus the oxalate solids removed by washing.

6. The washed, reconstituted slurry was filtered in recycle mode for 24 hours, concluding the testing.

A simplified mass balance of the cold-CUF inventory during these process steps is given in Table 4.12. Sample masses withdrawn during testing are excluded from this mass balance to aid clarity. Most samples were taken from permeate collected during dewatering operations that was not returned to the system and are therefore of no consequence to the cold-CUF inventory. The limited number of slurry samples can be considered negligible to quantities of simulant involved in each step.

Table 4.12. Process Steps and Simplified Mass Balance of Post-Caustic-Leach Dewatering and Washing Tests

\begin{tabular}{|c|c|c|c|c|c|c|}
\hline Process Step & $\begin{array}{c}\text { Net mass } \\
\text { change }[\mathrm{kg}]\end{array}$ & $\begin{array}{c}\text { Cold-CUF } \\
\text { inventory }[\mathrm{kg}]\end{array}$ & $\begin{array}{c}\rho_{\text {permeate }} \\
{[\mathrm{kg} / \mathrm{L}]}\end{array}$ & $\begin{array}{c}\text { TS } \\
{[\mathrm{wt} \%]}\end{array}$ & $\begin{array}{c}\text { DS } \\
{[\mathrm{wt} \%]}\end{array}$ & $\begin{array}{l}\text { UDS } \\
{[\mathrm{wt} \%]}\end{array}$ \\
\hline $\begin{array}{l}\text { Add initial sample (A 01AIM 13C } \\
\text { XX } 2760 \text { CUF 4) }\end{array}$ & 25.250 & 25.250 & N/A & 32.6 & 31.4 & 1.7 \\
\hline Dewater initial sample & -22.553 & 2.697 & 1.29 & 44.5 & 30.7 & 19.9 \\
\hline Add Wash 1 & 19.180 & 21.877 & N/A & 5.8 & 4.6 & 1.2 \\
\hline Dewater Wash 1 & -19.740 & 2.137 & 1.03 & 4.6 & 4.6 & N/A \\
\hline Add Wash 2 & 19.435 & 21.572 & N/A & 2.5 & 0.4 & 2.1 \\
\hline Dewater Wash 2 & -18.805 & 2.767 & 1.00 & 0.4 & 0.4 & N/A \\
\hline $\begin{array}{l}\text { Add Permeate Sample } 1 \text { (A 00PF1 } \\
007 \text { XX } 2758 \text { CUF 4) }\end{array}$ & 25.530 & 28.297 & N/A & $\mathrm{n} / \mathrm{m}$ & $\mathrm{n} / \mathrm{m}$ & $\mathrm{n} / \mathrm{m}$ \\
\hline Dewater permeate sample & -25.035 & 3.262 & 1.28 & 29.5 & 29.5 & N/A \\
\hline $\begin{array}{l}\text { Add Permeate Sample } 2 \text { (A 00PF1 } \\
007 \text { XX } 2759 \text { CUF 4) }\end{array}$ & 26.420 & 29.682 & 1.30 & 32.4 & 31.8 & 0.9 \\
\hline
\end{tabular}

A negligible change in filter flux was noted for the initial phase of dewatering compared to operations in recycle mode, and the flux continued to decline over the course of the first 12 hours of slurry dewatering as it had in the previous 30 hours of conditioning (see Figure 4.22). At an elapsed time of 42 hours, the flux began to decline at an increasing rate, leading up to the exponential decline observed over an elapsed time of 52 to 55 hours. At this point in the testing, dewatering was halted because of the inability to maintain process conditions, and $250-\mathrm{mL}$ of permeate was returned to the reservoir to aid pumping. From 55 to 57 hours, a short additional amount of filtration in recycle mode was performed, corresponding to the small section of stable flux at the end of the curve in Figure 4.22. 


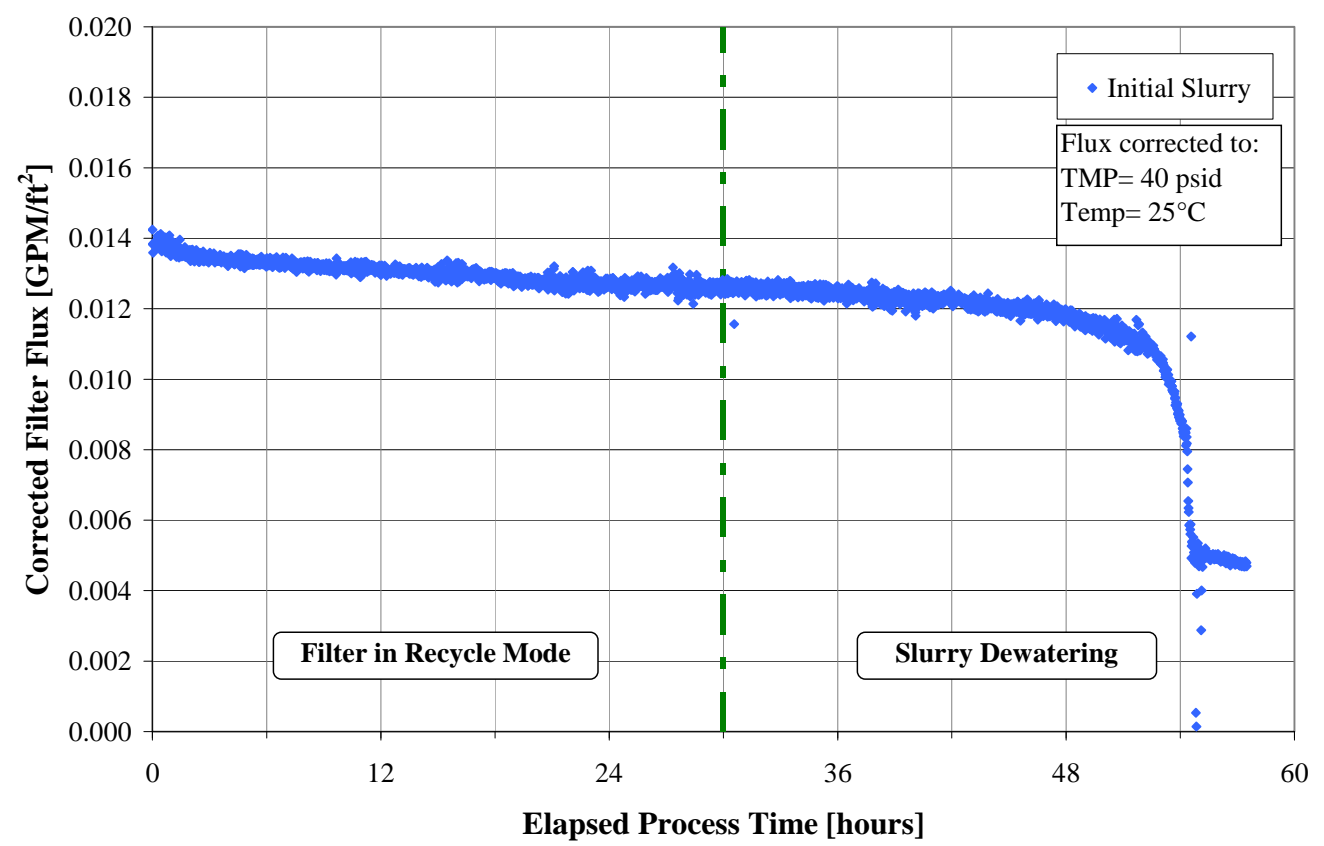

Figure 4.22. Corrected Filter Flux for the Filtration of the Initial Post-Caustic-Leach Slurry in Recycle Mode Followed by Dewatering of the Slurry

After adding the 0.01-M NaOH washes, the flux increased dramatically to an initial value of over $0.09 \mathrm{GPM} / \mathrm{ft}^{2}$, with final values between 0.04 and $0.05 \mathrm{GPM} / \mathrm{ft}^{2}$ (Figure 4.23). During the first wash, all of the solid sodium oxalate and a portion of the sodium phosphate were dissolved and removed from the system. A significant spike of sodium oxalate can be seen in the permeate of the first wash, but no additional oxalate was dissolved in the second wash, as the dilution factor between the first and second wash permeates $(\sim 10)$ was the same for sodium oxalate as it was for the inert components sodium and sulfur (see Table 4.13$)$. The starting flux for the first wash $\left(0.09 \mathrm{GPM} / \mathrm{ft}^{2}\right)$ was higher than the starting flux for the second wash $\left(0.07 \mathrm{GPM} / \mathrm{ft}^{2}\right)$, but after 3 hours of elapsed dewatering time, the trend in flux for the two wash steps approached parity. It is not obvious why the second wash dewatering step would start at a lower flux than the first because the permeate density and wt\% dissolved solids (DS), two indicators of permeate viscosity, were both lower (see Table 4.12). The difference in starting flux is indicative of time-dependent filter conditioning so that the starting point of the second test is impacted by the state of the membrane after the first wash dewatering.

Table 4.13. Concentration of Representative Analytes in Process Permeates During the Post-CausticLeach Dewatering and Oxalate Washing Tests

\begin{tabular}{lccccc}
\hline & $\begin{array}{c}\text { Aluminum } \\
\mathrm{mg} / \mathrm{mL}\end{array}$ & $\begin{array}{c}\text { Sodium } \\
\mathrm{mg} / \mathrm{mL}\end{array}$ & $\begin{array}{c}\text { Sulfur } \\
\mathrm{mg} / \mathrm{mL}\end{array}$ & $\begin{array}{c}\text { Oxalate } \\
\mathrm{mg} / \mathrm{mL}\end{array}$ & $\begin{array}{c}\text { Phosphate } \\
\mathrm{mg} / \mathrm{mL}\end{array}$ \\
\hline Initial Slurry Permeate & 10.46 & 163.8 & 3.96 & 0.195 & 0.681 \\
Wash 1 Permeate & 0.745 & 14.00 & 0.259 & 2.940 & 0.422 \\
Wash 2 Permeate & 0.058 & 1.380 & 0.021 & 0.228 & 0.041 \\
First Permeate Addition & 5.620 & 89.54 & 2.11 & 0.171 & 0.732 \\
Reconstituted Slurry Permeate & 10.88 & 169.0 & 4.04 & 0.168 & 0.790 \\
\hline Note: Aluminum, sodium, and sulfur by ICP-OES; oxalate and phosphate by IC anion analysis & \\
\hline
\end{tabular}




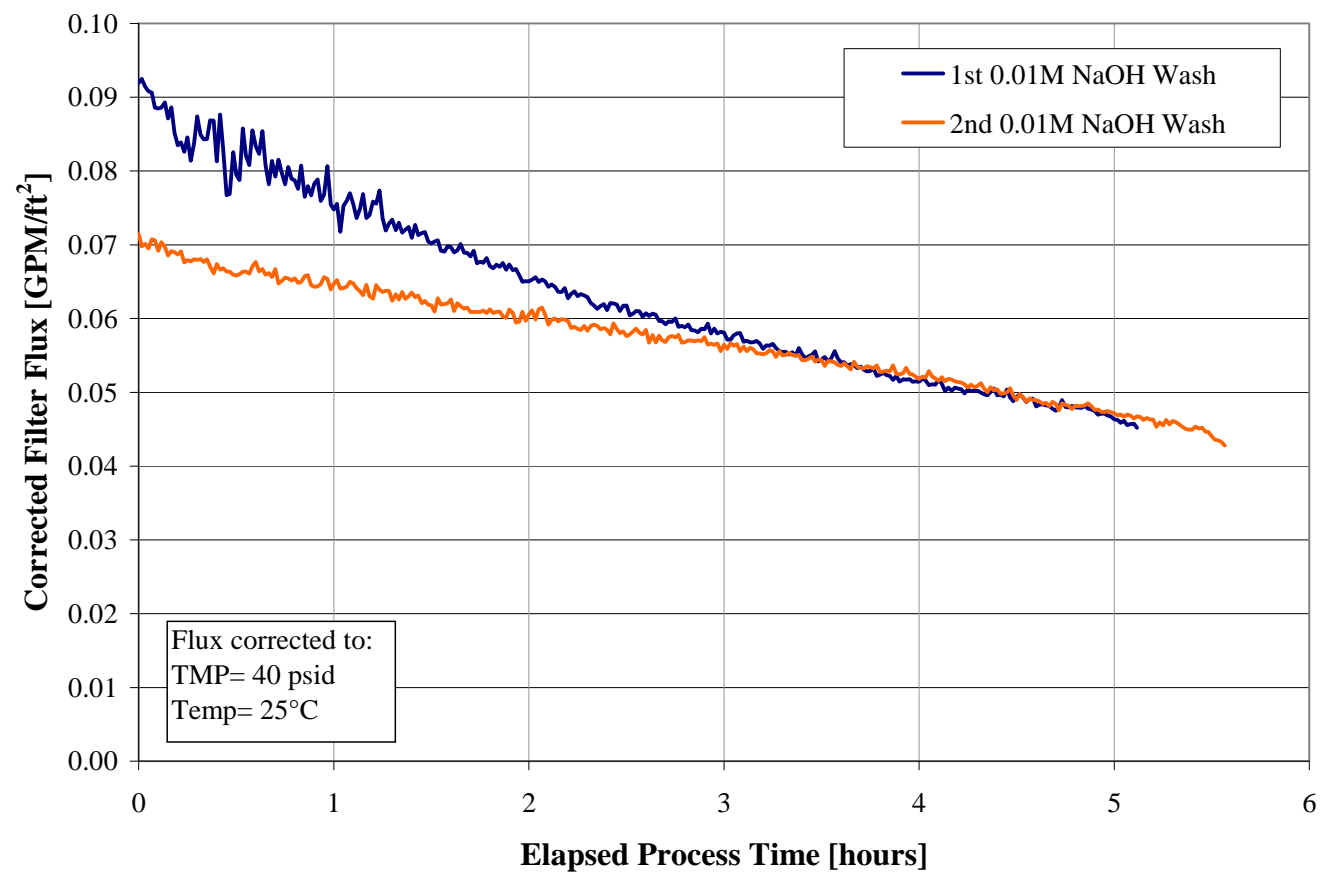

Figure 4.23. Corrected Filter Flux for the Two 0.01-M NaOH Wash Dewatering Steps

After adding the first volume of leach permeate and dewatering, the second volume was added, and the cold-CUF was run in recycle mode for 24 hours. The flux is similar compared to the initial 30-hour test in recycle mode as shown in Figure 4.24. Solid sodium oxalate was washed from the post-caustic--leach slurry and upon reconstitution of the washed solids with leach permeate, the flux was found to be equivalent. This demonstrates that the super-saturation and precipitation of sodium oxalate fines during cooling of caustic-leach batches does not strongly influence permeate flux as initially hypothesized. The high concentration of dissolved solids, corresponding to a high permeate viscosity (measured at $4.144 \mathrm{mPa} \cdot \mathrm{s}$ for post-caustic-leach slurry at $\mathrm{PEP}^{(\mathrm{a})}$ ), may be a more significant contributor to the observed low permeate flux.

Before and after the test sequence, a brief clean water flux test with $0.01 \mathrm{M} \mathrm{NaOH}$ was performed to provide benchmarks of the condition of the filter. To maintain similarity to conditions at PEP, oxalic acid cleaning was not performed, either before or after the test. The results of the before-and-after flux tests are given in Figure 4.21. The results show that the clean water flux was nominally higher after the test sequence, but the flux was similar enough to demonstrate that the test sequence did not significantly alter the condition of the filter element and cause a known deviation from the objective of maintaining similar conditioning between cold-CUF and PEP filter elements.

(a) Sample A 02A OL 015 XX 2294 RHE 4, presented in Table 5.20, Section 5.2.3 of WTP-RPT-191: Guzman-Leong CE et al. 2009. PEP Run Report for Integrated Test A; Caustic Leaching in UFP-VSL-T01A, Oxidative Leaching in UFP-VSL-T02A. WTP-RPT-191 (Draft), Pacific Northwest National Laboratory, Richland, Washington. 


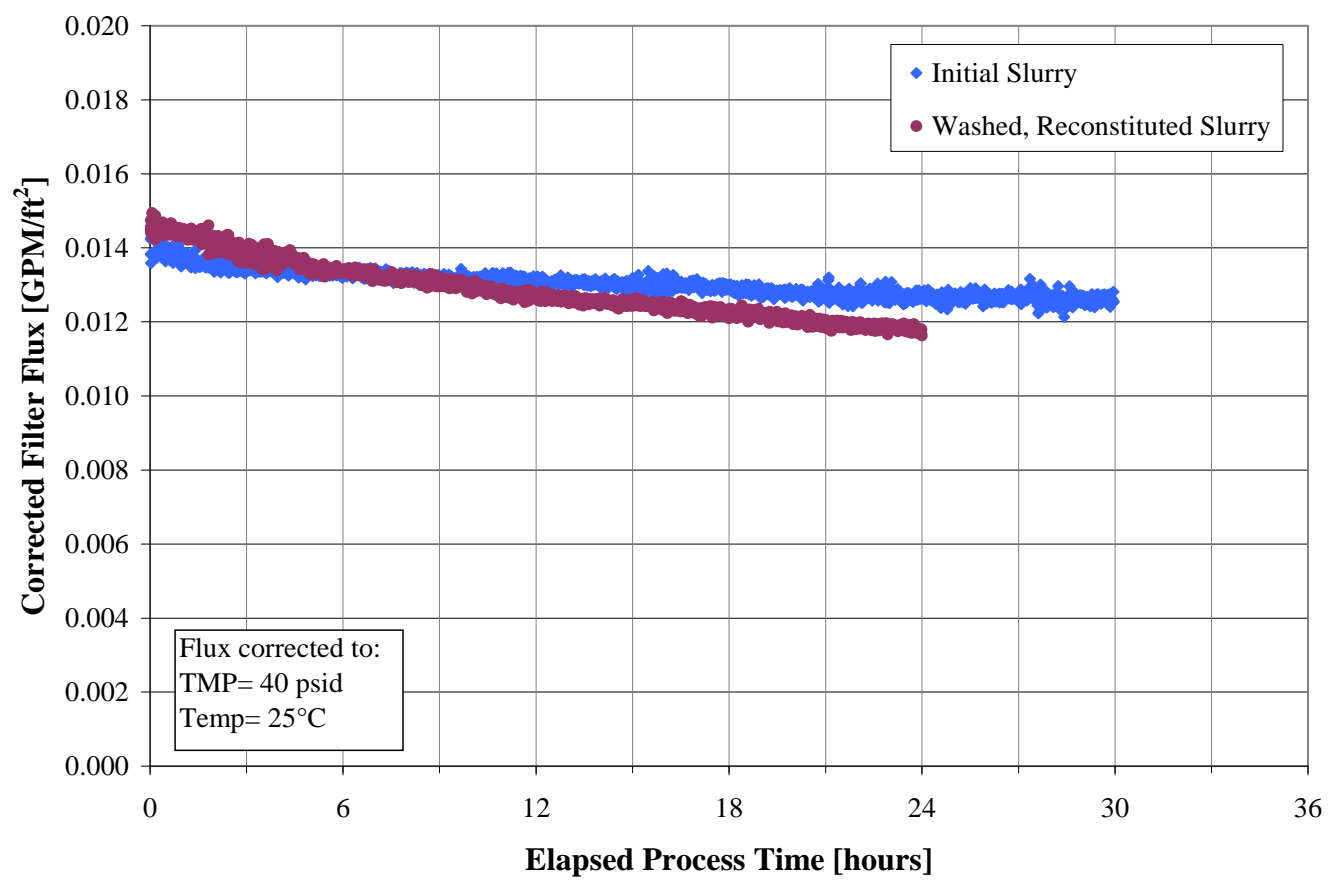

Figure 4.24. Comparison of the Corrected Filter Flux Between the Initial Post-Caustic-Leach Slurry and the Slurry Reconstituted After Washing with 0.01 M NaOH, Showing Close Agreement in Timeframe Tested

\subsection{Filter Fouling and Cleaning}

Before beginning the bench-scale scaling tests using the cold-CUF, several tests were conducted to support water and simulant shakedown testing at the PEP, including a study of the PEP process water that was found to be fouling the ultrafilter bundles in the PEP. Section 4.5.1 covers this fouling and cleaning test sequence. Section 4.5.2 describes the steps and results of an oxalic acid filter cleaning step conducted between the first and second low-solids conditioning tests. The 2-ft filter element used for these tests had been used extensively for simulant testing over the previous 18 months (see Russell et al. 2009b). A history of the condition of the filter element during bench-scale testing and cleaning steps performed is given in Table 4.14.

Degradation of the ultrafiltration loop pumps was discovered midway through the PEP testing sequence, and iron corrosion particles from the degraded pump housings may have contributed to the low clean water flux observed in PEP filter cleaning sequences. Further information about acid cleaning at PEP, pump degradation, and observed corrosion products is discussed in Section 4.3.2 of WTP-RPT-190 ${ }^{(\mathrm{a})}$ and Section 4.1 of WTP-RPT-192. ${ }^{\text {(b) }}$

(a) GB Josephson et al. 2009. PEP Run Report for Simulant Shakedown/Functional Testing. WTP-RPT-190 (Draft), Pacific Northwest National Laboratory, Richland, Washington.

(b) JGH Geeting et al. 2009. Pretreatment Engineering Platform (PEP) Integrated Test B Run Report- Caustic Leaching and Oxidative Leaching in UFP-VSL-TO2A. WTP-RPT-192 (Draft), Pacific Northwest National Laboratory, Richland, Washington. 
Table 4.14. Cold-CUF Filter Element Conditioning History and Cleaning Performed

\begin{tabular}{|c|c|c|}
\hline $\begin{array}{l}\text { Tests Performed in Chronological } \\
\text { Order }\end{array}$ & Prior Cleaning & $\begin{array}{c}\text { Clean Water Flux }{ }^{(\mathrm{a})} \\
\left(\mathrm{GPM} / \mathrm{ft}^{2}\right)\end{array}$ \\
\hline Low-Solids Conditioning Test \#1 & $0.5 \mathrm{M}$ oxalic acid & $>1.5$ \\
\hline Low-Solids Dewatering Test \#1 & $\begin{array}{l}\text { No cleaning; proceeded directly from } \\
\text { conditioning test }\end{array}$ & $\mathrm{n} / \mathrm{m}$ \\
\hline Low-Solids Conditioning Test \#2 & $0.5 \mathrm{M}$ oxalic acid & $>1.5$ \\
\hline Low-Solids Dewatering Test \#2 & $\begin{array}{l}\text { No cleaning; proceeded directly from } \\
\text { conditioning test }\end{array}$ & $\mathrm{n} / \mathrm{m}$ \\
\hline High-Solids Dewatering Test \#1 & $\begin{array}{l}\text { Low-solids simulant flushed from the } \\
\text { system with } 0.01 \mathrm{M} \mathrm{NaOH} \text {; no acid } \\
\text { cleaning performed }\end{array}$ & 0.12 \\
\hline $\begin{array}{l}\text { Post-Caustic-Leach Dewatering and } \\
\text { Oxalate Washing }\end{array}$ & $\begin{array}{l}\text { High-solids simulant flushed from the } \\
\text { system with } 0.01 \mathrm{M} \mathrm{NaOH} \text {; no acid } \\
\text { cleaning performed }\end{array}$ & 0.09 \\
\hline High-Solids Dewatering Test \#2 & $\begin{array}{l}\text { Caustic-leached simulant flushed from the } \\
\text { system with } 0.01 \mathrm{M} \mathrm{NaOH} \text {; no acid cleaning } \\
\text { performed }\end{array}$ & 0.10 \\
\hline
\end{tabular}

\subsubsection{PEP Process Water Fouling and Cleaning Tests}

During the course of water shakedown testing at PEP in September 2008, an unanticipated low filter flux was observed for the filter bundles. Since the filter elements were all new and had not previously been used with simulant, it was expected that the clean water flux should be $\sim 1.5 \mathrm{GPM} / \mathrm{ft}^{2}$ at $\mathrm{TMP}=40$ psid, but the performance of the filter bundles was less than $0.030 \mathrm{GPM} / \mathrm{ft}^{2}$ at those conditions. To help determine if it was the PEP process water that was fouling the elements and to efficiently determine recommended cleaning steps to restore filter flux, 35-L of PEP process water was delivered to the cold-CUF ${ }^{(\mathrm{a})}$ for testing. The water consisted of $0.01 \mathrm{M} \mathrm{NaOH}$ with added McCormick ${ }^{\mathrm{TM}}$ brand blue food dye to enable the functioning of the laser tank-level detection system.

The food dye selected contained water, propylene glycol, FD\&C Blue 1, FD\&C Red 40, and propylparaben. FD\&C Blue 1 is also known as Brilliant Blue $\left(\mathrm{C}_{37} \mathrm{H}_{34} \mathrm{~N}_{2} \mathrm{Na}_{2} \mathrm{O}_{9} \mathrm{~S}_{3}\right.$, CAS 3844-45-9), a large organic molecule derived from coal tar. As a known variable, the effect of the food dye and its various components on flux was of an initial and obvious interest to the testing. Other factors that may have impacted the filter performance included biofouling caused by microbes in the PEP vessels and pipes, residues (grease, oils, dust) introduced during the equipment fabrication process, or corrosion products from pump degradation that was later discovered. Regardless of the cause, it was most important to determine whether the process water was the cause of the low flux and to establish practicable cleaning methods to restore filter flux.

(a) When these tests were performed, the cold-CUF was configured with an 8-ft filter element used in previous filtration scaling tests (Daniel et al. 2009a). It was subsequently reconfigured to a 2 -ft element for all other bench-scale testing. 
Testing of the PEP process water performed in the cold-CUF is outlined in the following steps:

1. The cold-CUF was thoroughly cleaned using oxalic acid to establish a baseline clean water flux $>1.25 \mathrm{GPM} / \mathrm{ft}^{2}$. The cold-CUF was drained. At the point that these tests were performed, the cold-CUF was configured with an 8-ft filter element used in previous filtration scaling tests.

2. Process water from the PEP was introduced into the system and filtered in recycle mode at various TMP and AV settings. It was observed that the initial permeate from the blue water was substantially clear, indicating exclusion of the pigment by the membrane. Throughout the testing, even after some pigment began to enter the permeate, the permeate was a visibly lighter blue than the bulk fluid. After approximately 4 hours in recycle mode, the process water was concentrated by dewatering at TMP $=40$ psid. During this time interval, the corrected flux dropped from starting values of $0.21 \mathrm{GPM} / \mathrm{ft}^{2}$ to $0.023 \mathrm{GPM} / \mathrm{ft}^{2}$, a factor of 10 , and it was comparable to the flux observed at PEP. It was established that components in the PEP process water fouled the filter.

3. To recover the clean water flux, various cleaning steps were performed:

a. Flushing with deionized (DI) water resulted in minimal improvement.

b. Adding $25 \mathrm{ppm}$ Alconox detergent resulted in dissolution and visible removal of dye from the filter with an accompanying increase in flux.

c. 1-M NaOH cleaning resulted in no further improvement, and actually led to a decline in flux as compared to the previous step.

d. Adding $1000 \mathrm{ppm}$ Alconox detergent and heating to $60^{\circ} \mathrm{C}$ caused the flux to return to the level observed in the previous Alconox cleaning step.

e. 2-M $\mathrm{HNO}_{3}$ cleaning resulted in no improvement.

f. 0.5-M oxalic acid cleaning resulted in the restoration of flux to the filter baseline.

4. Based on these observations, the fouling and cleaning sequence was repeated so a recommendation could be made to PEP as to how to proceed with filter cleaning. Steps from the first cleaning that had no obvious benefit were omitted. The steps are given in sequence below and the results are shown in the accompanying figures.

a. Repeat fouling with PEP process water (Figure 4.25).

b. Perform a clean water flux test with $0.01 \mathrm{M} \mathrm{NaOH}$ (Figure 4.26).

c. Clean the system with $0.5 \mathrm{M}$ oxalic acid (Figure 4.26).

d. Perform a clean water flux test with $0.01 \mathrm{M} \mathrm{NaOH}$ (Figure 4.26).

e. Clean system with 25-ppm Alconox detergent.

f. Perform a clean water flux test with $0.01 \mathrm{M} \mathrm{NaOH}$ (Figure 4.27).

From the observations during the cleaning test and the results in the following figures, it appears that both Alconox detergent and $0.5 \mathrm{M}$ oxalic acid are effective in restoring clean water flux to a filter element fouled by the PEP process water. In the first set of cleaning steps, the Alconox detergent preceded the oxalic acid, but in the repeat cleaning, the order was reversed. The order of cleaning may or may not be significant. The cleaning in Steps $4 \mathrm{~b}$ to $4 \mathrm{f}$ was presented as the recommended cleaning sequence at PEP for this application. 


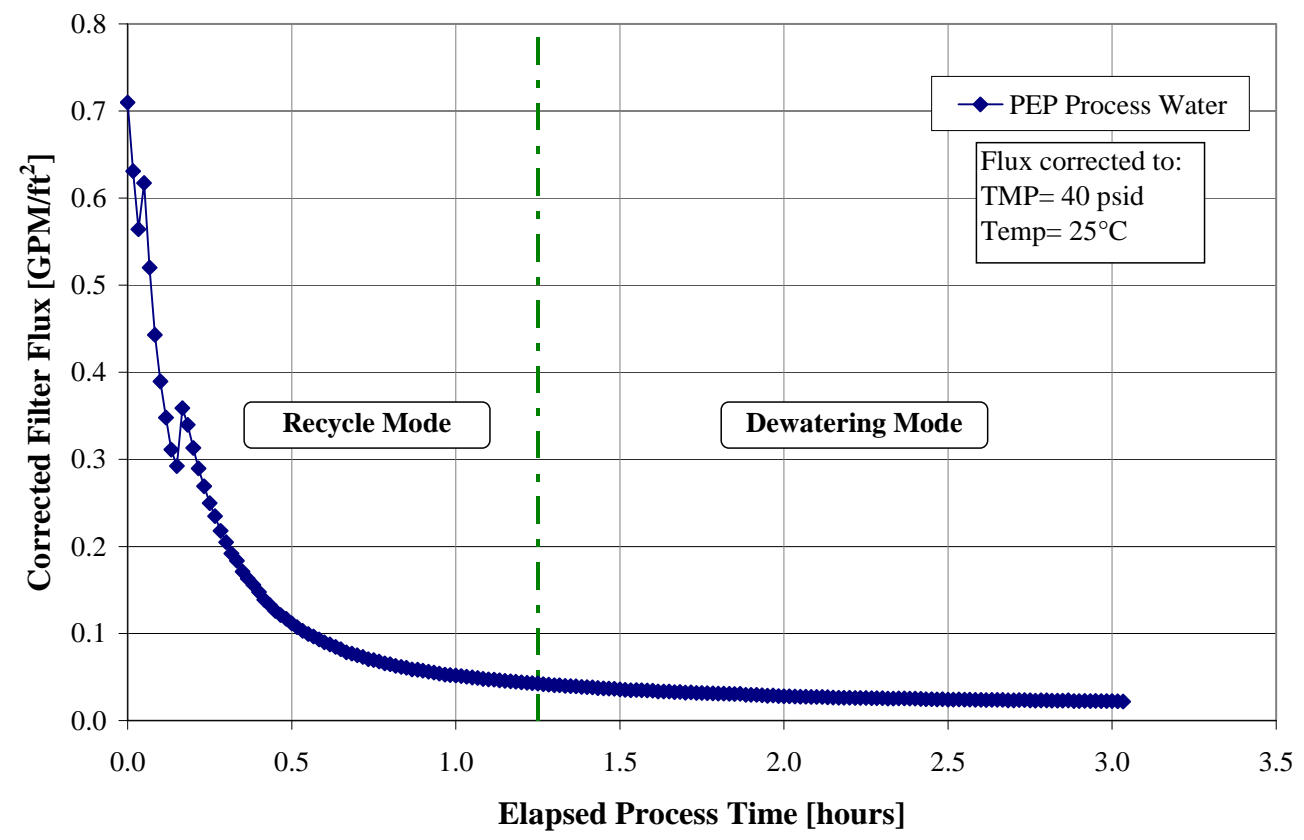

Figure 4.25. Fouling of Cold-CUF During Filtration of PEP Process Water

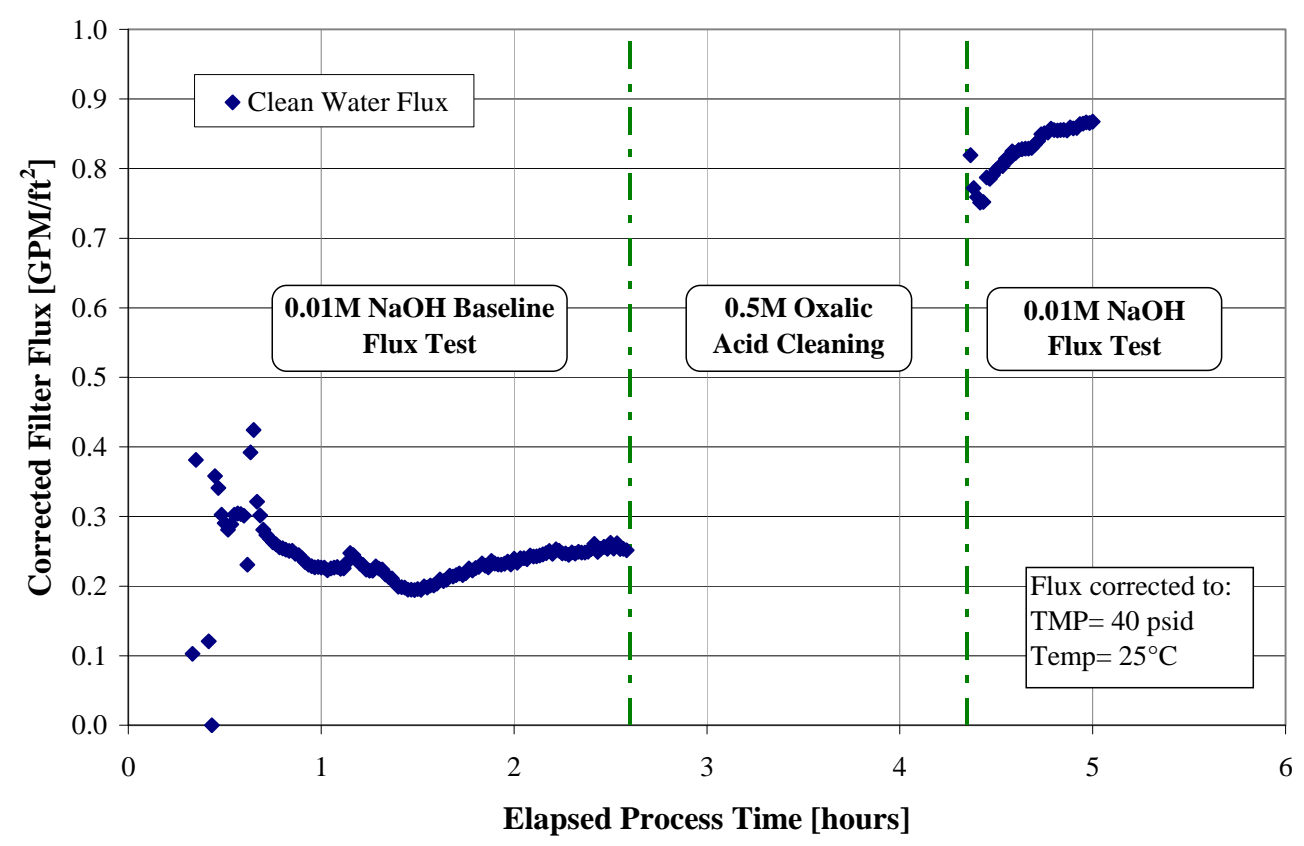

Figure 4.26. Clean Water Flux Testing of Cold-CUF System Before and After Oxalic Acid Cleaning 


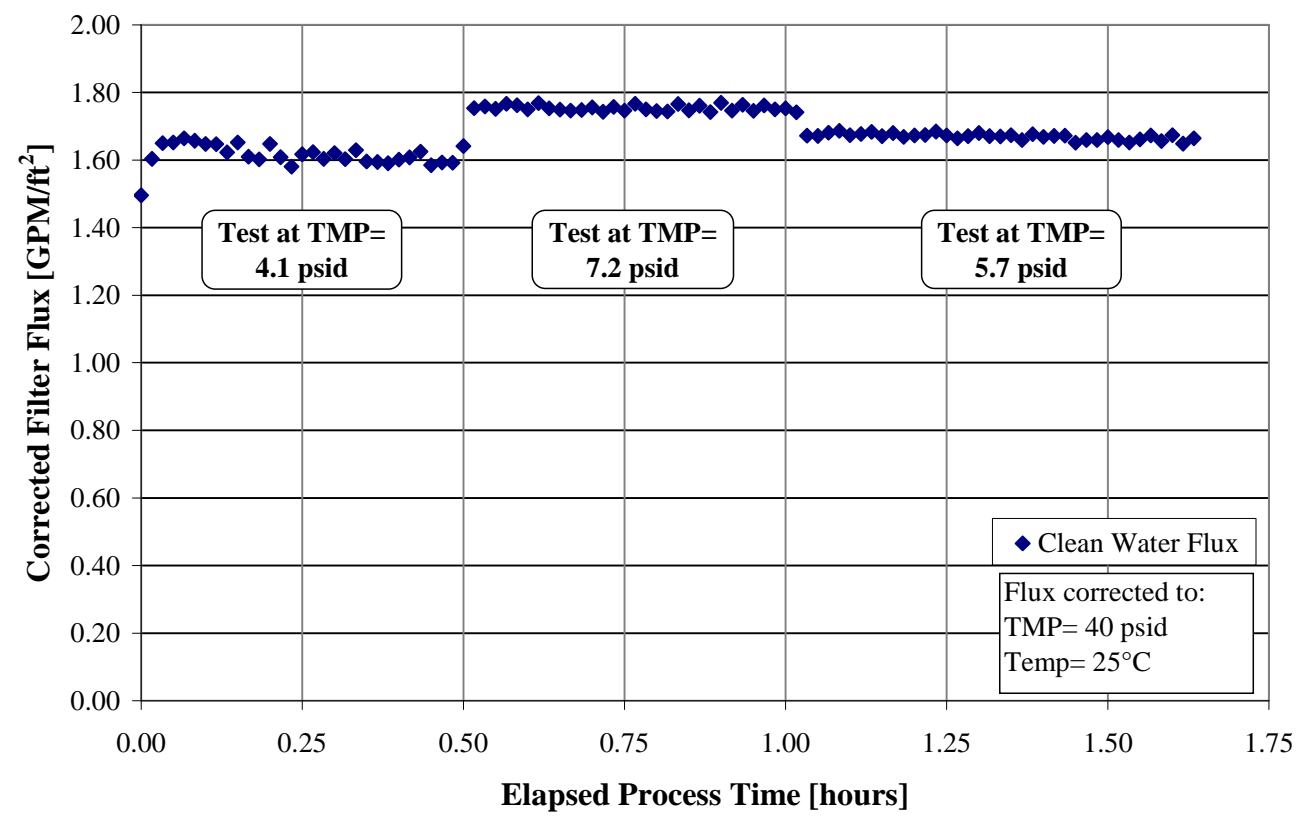

Figure 4.27. Clean Water Flux After Cleaning with 25 ppm Alconox Detergent

\subsubsection{Oxalic Acid Cleaning After Simulant Use}

Throughout the course of cold-CUF simulant testing, cleaning the filter element and system between tests has been required to remove deeply fouled particles and restore a clean water flux equal to or nearly equal to the previous clean water flux. Originally, it was specified ${ }^{(a)}$ that the baseline filter cleaning technology for WTP operations would use 2.0 M nitric acid as the chemical cleaning agent. During the course of early simulant testing at PNNL in July and August of 2007, it was discovered that the nitric acid cleaning was insufficient to restore a clean water flux. Since it was hypothesized that iron hydroxide particles caused a substantial proportion of the fouling, a mixture of $0.5 \mathrm{M}$ oxalic acid was introduced to the fouled filter element. The idea to use a dilute solution of oxalic acid was derived from a report describing Mott filter element cleaning for various wastes and simulants (Poirier 2002).

After applying 0.5 M oxalic acid, an order of magnitude improvement in flux was observed. Subsequent flushing and cleaning served to restore the clean water flux to greater than $1.5 \mathrm{GPM} / \mathrm{ft}^{2}$. Since that time, the cold-CUF has consistently been cleaned with $0.5 \mathrm{M}$ oxalic acid between runs to baseline the condition of the filter element, although cleaning with oxalic acid is not prototypic of planned WTP operations. In this series of bench-scale tests, it was decided that the cold-CUF should be cleaned in like manner to the PEP between the first and second low-solids conditioning tests. Such a cleaning would permit better comparison between the tests because the filter conditioning would proceed from a common starting place. The cleaning plan for PEP operations did not specify a chemical cleaning agent, but left

(a) PS Townson. 2001. “241-AW-101 LAW Entrained Solids Ultrafiltration Test Specification.” TSP-24590-01-00001, Rev. 0, Bechtel National, Inc., Richland, Washington. 
the determination of the agent and cleaning sequence to WTP staff (TP-RPP-WTP-506, Appendix $\mathrm{C}^{(\mathrm{a})}$ ). All chemical cleaning performed on the cold-CUF system during the period of the bench-scale testing described in this report was performed to match cleaning at PEP as specified by WTP staff and communicated during meetings or by email.

The cold-CUF was cleaned with oxalic acid on December 30, 2008. After thoroughly flushing the cold-CUF with four volumes of $0.01 \mathrm{M} \mathrm{NaOH}$ as specified in the test instruction, the system was completely drained, including the shell side of the filter element, the backpulse chamber, and all associated permeate piping. Approximately 4-L of $0.5 \mathrm{M}$ oxalic acid was then introduced to the slurry reservoir and allowed to circulate through the slurry recirculation loop and back and forth across the filter element by means of filling and discharging the backpulse chamber. During this time, the permeate flow valve remained closed to isolate the flow meters from unnecessary exposure to the acid and to minimize the number of acid-wetted surfaces that must later be rinsed. The oxalic acid was allowed to circulate for 30 minutes and was then drained from the system. All acid-wetted surfaces were rinsed with DI water using the chemical feed funnel on the backpulse chamber. The slurry reservoir was rinsed with a plastic squeeze bottle filled with DI water. By using the chemical feed port on the backpulse chamber, one may rinse the wetted surfaces with a minimum volume of DI water per rinse since it is not necessary to operate the cold-CUF pump, for which several liters of rinse water are required.

Once the residual oxalic acid had been rinsed from the system, 3-L of $0.01 \mathrm{M} \mathrm{NaOH}$ was added to the slurry reservoir and allowed to recirculate through the system. The backpulse chamber was filled and discharged several times. To evaluate the clean water flux at this point in the cleaning, the system was run in recycle mode at TMP $=18,12$, and 28 psid for approximately 20 minutes at each pressure with no backpulses in between. Immediately following the backpulse at the beginning of the test, the clean water flux was $1.51 \mathrm{GPM} / \mathrm{ft}^{2}$ (corrected to TMP $=40 \mathrm{psid}$ ), but declined over the course of the test to $0.70 \mathrm{GPM} / \mathrm{ft}^{2}$. Backpulsing the system would again restore the flux to $>1.5 \mathrm{GPM} / \mathrm{ft}^{2}$, but rapid decay in flux was observed, suggesting the presence of suspended fines re-depositing on the membrane surface.

To restore a stable clean water flux, the system was completely drained, and the filter element was again flushed with $0.01 \mathrm{M} \mathrm{NaOH}$ via the chemical feed funnel. Each 200-mL rinse volume was drained from the slurry sampling valve and from the shell side of the filter element before the next rinse volume was delivered as an attempt to avoid infinite dilution of suspended particles through back-mixing of rinse volumes. As each rinse volume was removed from the system, the suspended particles associated with that rinse volume were removed.

After approximately 10 rinses were delivered in this fashion, the slurry reservoir was filled with 4-L of $0.01 \mathrm{M} \mathrm{NaOH}$, and the clean water flux test was repeated. The cold-CUF was run in recycle mode at TMP $=12$, 20, and 16 psid in sequence, with 15 minutes of test time at each pressure. A rapid decay in flux after backpulsing was no longer observed, and the clean water flux, corrected to TMP $=40$ psid, ranged from 1.5 to $1.6 \mathrm{GPM} / \mathrm{ft}^{2}$ at the various TMPs tested over the duration of the test. This compares favorably to the clean water flux achieved at the conclusion of filter cleaning during the PEP process water testing in the previous section (1.6 to $\left.1.7 \mathrm{GPM} / \mathrm{ft}^{2}\right)$ and meets the criteria for simulant testing. At this point, filter cleaning was deemed sufficient and Low-Solids Conditioning Test \#2 followed, starting January 5, 2009.

(a) GB Josephson, OP Bredt, JK Young, and DE Kurath. 2008. Pretreatment Engineering Platform (PEP) Testing (Phase I). TP-RPP-WTP-506, Rev. 0.4, Pacific Northwest National Laboratory, Richland, Washington. 



\subsection{Conclusions}

Bench-scale filtration tests were performed in support of PEP Phase I testing. For each test, the cold-CUF system was operated at the target conditions using simulant slurries received from PEP. Results from these tests were used to support a scaling factor for filtration. Other key findings and observations from this testing include the following:

1. Low-solids conditioning and dewatering: differences in flux between Test \#1 and Test \#2 can be explained by the difference in permeate viscosity.

2. Each of the high-solids dewatering tests was repeated at different AVs as a preliminary investigation of the effect of AV on filtration over the range of solids concentrations provided by dewatering. Observations from these tests are:

a. Increasing AV leads to a higher UDS concentration at the characteristic transition point in the dewatering curve between membrane-dominated flux resistance to cake-dominated flux resistance.

b. With other factors held constant, increasing the AV leads to higher average filter flux over the course of slurry dewatering, leading to a shorter time from the beginning of the dewatering step to the target concentration of $20-\mathrm{wt} \%$ UDS.

3. The presence of oxalate fines precipitated from saturated post-caustic-leach solution was determined not to significantly influence filter flux during post-caustic-leach dewatering.

4. Oxalic acid cleaning has been shown to be an effective means of restoring clean water filter flux after simulant use and may be applied to general cleaning of the filter element. Alconox detergent cleaning before or after oxalic acid cleaning may enhance the effectiveness of oxalic acid cleaning. 



\subsection{References}

Daniel RC, JM Billing, KJ Cantrell, ML Luna, RA Peterson, ML Bonebrake, RW Shimskey, and LK Jagoda. 2009a. Characterization of Filtration Scale-Up Performance. WTP-RPT-168, Rev. 0, PNNL-18117, Pacific Northwest National Laboratory, Richland, Washington.

Daniel RC, JM Billing, JR Bontha, CF Brown, BD Hanson, NK Karri, ML Kimura, and DE Kurath. 2009b. EFRT Issue Resolution: Comparison of Filter Performance at PEP and CUF Scale.

WTP-RPT-185, Rev. 0, PNNL-18498, Pacific Northwest National Laboratory, Richland, Washington.

Poirier MR and SD Fink. 2002. Investigation of Alternative Approaches for Cleaning Mott Porous Metal Filters. WSRC-TR-2002-00526, Rev. 0, Westinghouse Savannah River Company, Aiken, South Carolina.

Rapko BM, GJ Lumetta, JR Deschane, and RA Peterson. 2007. Process Development for Permanganate Addition During Oxidative Leaching of Hanford Tank Sludge Simulants. WTP-RPT-164, Rev. 0, PNNL-16794, Pacific Northwest National Laboratory, Richland, Washington.

Russell RL, RA Peterson, HD Smith, DE Rinehart, PM Aker, and EC Buck. 2009a. Development and Characterization of Boehmite Component Simulant. WTP-RPT-184, Rev. 1, PNNL-18176, Pacific Northwest National Laboratory, Richland, Washington.

Russell RL, JM Billing, RA Peterson, DE Rinehart, and HD Smith. 2009b. Development and Demonstration of Ultrafiltration Simulants. WTP-RPT-183, Rev. 0, PNNL-18090, Pacific Northwest National Laboratory, Richland, Washington.

Shimskey RW, JM Billing, EC Buck, RC Daniel, KE Draper, MK Edwards, JGH Geeting, RT Hallen, ED Jenson, AE Kozelisky, PJ MacFarlan, RA Peterson, LA Snow, and RG Swoboda. 2009. Filtration and Leach Testing for REDOX Sludge and S-Saltcake Actual Waste Sample Composites. WTP-RPT-172, Rev. 0, PNNL-17965, Pacific Northwest National Laboratory, Richland, Washington. 

PNNL-18673

WTP-RPT-203, Rev 0

\section{Distribution}

No. of

Copies

OFFSITE
No. of

Copies

\section{ONSITE}

1 Pacific Northwest National Laboratory (authors will be notified electronically)

J.M. Billing

P7-25

R.C. Daniel

P7-22

D.E. Kurath

K3-52

R.A. Peterson

P7-22

R.L. Russell

K6-24

Information Release (pdf)

Project File (1)

K3-52

3 Bechtel National, Inc.

WTP R\&T Docs (2)

H4-02

S.M. Barnes

H4-02

Dist. 1 


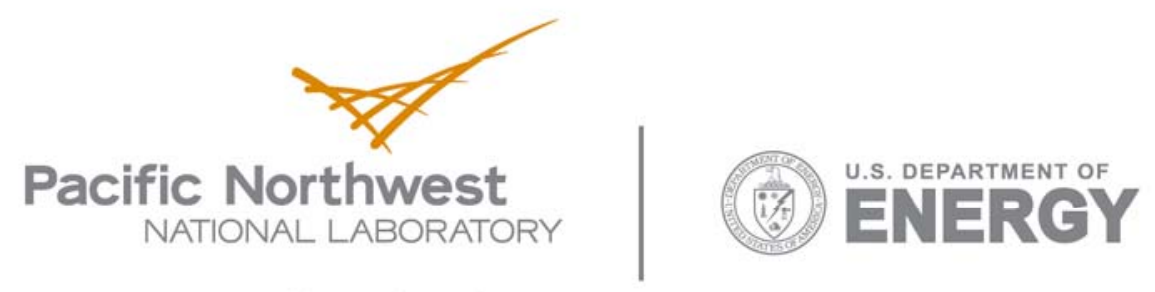

902 Battelle Boulevard

P.O. Box 999

Richland, WA 99352

1-888-375-PNNL (7665)

www.pnl.gov 